\title{
Single cell RNA-Seq reveals distinct stem cell populations that drive sensory hair cell regeneration in response to loss of Fgf and Notch signaling
}

Mark E. Lush¹, Daniel C. Diaz*1, Nina Koenecke ${ }^{1}$, Sungmin Baek ${ }^{1}$, Helena Boldt ${ }^{1}$, Madeleine K. St. Peter ${ }^{1}$, Tatiana Gaitan-Escudero1, Andres Romero-Carvajal ${ }^{1,2}$, Elisabeth M. Busch-Nentwich ${ }^{3,4}$, Anoja Perera ${ }^{1}$, Kate Hall ${ }^{1}$, Allison Peak ${ }^{1}$, Jeffrey S. Haug $^{1}$ and Tatjana Piotrowski ${ }^{1, * *}$

${ }^{1}$ Stowers Institute for Medical Research, Kansas City, MO 64110, USA

${ }^{2}$ Pontificia Universidad Catolica del Ecuador, Ciencias Biologicas, Quito, Ecuador

${ }^{3}$ Wellcome Sanger Institute, Wellcome Genome Campus, Hinxton, CB10 1SA, UK

${ }^{4}$ University of Cambridge, Department of Medicine, Cambridge, CB2 OQQ, UK

${ }^{*}$ co-first authors

${ }^{* *}$ corresponding author

key words: sensory hair cells, hearing, regeneration, single cell RNA-Seq, support cells, fgf3, proliferation, lateral line system, 


\begin{abstract}
Loss of sensory hair cells leads to deafness and balance deficiencies. In contrast to mammalian hair cells, zebrafish ear and lateral line hair cells regenerate from poorly characterized, proliferating support cells. Equally ill-defined is the gene regulatory network underlying the progression of support cells to cycling hair cell progenitors and differentiated hair cells. We used single cell RNA-Sequencing (scRNA-Seq) of lateral line sensory organs and uncovered five different support cell types, including quiescent and activated stem cells. In silico ordering of support cells along a developmental trajectory identified cells that self-renew and new groups of genes required for hair cell differentiation. scRNA-Seq analyses of fgf3 mutants, in which hair cell regeneration is increased, demonstrates that Fgf and Notch signaling inhibit proliferation of support cells in parallel by inhibiting Wnt signaling. Our scRNA-Seq analyses set the foundation for mechanistic studies of sensory organ regeneration and is crucial for identifying factors to trigger hair cell production in mammals. As a resource, we implemented a shiny application that allows the community to interrogate cell type specific expression of genes of interest.
\end{abstract}




\section{Introduction}

Non-mammalian vertebrates readily regenerate sensory hair cells during homeostasis and after injury, whereas in mammals hair cell loss leads to permanent hearing and vestibular loss (Bermingham-McDonogh and Rubel, 2003; Brignull et al., 2009; Corwin and Cotanche, 1988; Cruz et al., 2015; Ryals and Rubel, 1988). The molecular basis for the inability of mammals to trigger proliferation and a regenerative response is still unknown. Understanding hair cell production in regenerating species is essential for elucidating how regeneration is blocked in mammals. We and others showed that the zebrafish lateral line system is a powerful in vivo model to study the cellular and molecular basis of hair cell regeneration (Kniss et al., 2016; Lush and Piotrowski, 2014b; Ma and Raible, 2009; Romero-Carvajal et al., 2015; Viader-Llargues et al., 2018). The lateral line is a sensory system that allows aquatic vertebrates to orient themselves by detecting water motion. The lateral line organs (neuromasts), distributed on the head and along the body contain approximately 60 cells, composed of central sensory hair cells surrounded by support cells and an outer ring of mantle cells (Fig. 1A, B). The lateral line system is one of the few sensory organs where stem cell behaviors can be observed at the single cell level in vivo because the organs are located in the skin of the animal, are experimentally accessible and easy to image. These properties make it an ideal system to study hair cell regeneration. Despite the unusual location of the hair cells on the trunk, lateral line and ear hair cells develop by similar developmental mechanisms. Importantly, the morphology and function of sensory hair cells are evolutionarily conserved from fish to mammals (Duncan and Fritzsch, 2012; Nicolson, 2005; Whitfield, 2002). For example, mutations in genes causing deafness in humans also disrupt hair cells in the zebrafish lateral line (Nicolson, 2005, Fig. S2, Data file 6). We therefore hypothesize that the basic gene regulatory network required for hair cell regeneration could be very similar in zebrafish and mammals. In support of this hypothesis, our findings that Notch signaling needs to be downregulated to activate Wnt-induced proliferation during hair cell regeneration is also true in the mouse cochlea (Li et al., 2015b; Romero-Carvajal et al., 2015).

In zebrafish regeneration occurs via support cell proliferation and differentiation, and in chicken and amphibians hair cells regenerate from proliferating and 
transdifferentiating support cells (Balak et al., 1990; Bermingham-McDonogh and Rubel, 2003; Harris et al., 2003; Jones and Corwin, 1996; Lush and Piotrowski, 2014b; Ma et al., 2008; Wibowo et al., 2011b; Williams and Holder, 2000). Yet, even in regenerating species, support cells are not well characterized due to a dearth of molecular markers and the lack of distinct cytological characteristics.

Using time-lapse analyses and tracking of all dividing cells in regenerating neuromasts, coupled with cell fate analyses, we previously identified two major support cell lineages: 1) support cells that divide symmetrically to form two progenitor cells (amplifying divisions); and 2) support cells that divide to form two hair cells (differentiating divisions) (Romero-Carvajal et al., 2015). A recent publication has confirmed these lineages (Viader-Llargues et al., 2018). The two cell behaviors display a striking spatial compartmentalization. Amplifying divisions occur in the dorsal-ventral (D/V) poles and differentiating divisions occur in the center. Mantle cells surrounding the support cells only divide after severe injury to the neuromasts but rarely divide if only hair cells are killed. In addition, we observed quiescent support cells. Thus, there are at least 4 support cell types in a neuromast that likely play different functions in balancing progenitor maintenance with differentiation to ensure the life-long ability to regenerate.

To identify the gene regulatory network that triggers support cell proliferation and hair cell differentiation, we previously performed bulk RNA-Seq of support cells at different time points during regeneration (Jiang et al., 2014). These studies revealed the dynamic changes in signaling pathway activations over time. However, the unexpected diversity and mosaicism in support cells that we discovered during fate analyses (Romero-Carvajal et al., 2015) was masked in the RNA-Seq analysis of pooled support cells. To determine how many support cell populations exist in a neuromast and to characterize their transcriptomes, we performed scRNA-Seq analysis on 1521 purified, homeostatic neuromast cells from a transgenic line. As the lateral line neuromasts are GFP-positive and only consist of about 60 cells we were able to purify a rich cohort of lateral line cells (25x coverage). Our analysis identified seven major neuromast cell populations, revealing genes that are specifically expressed in these cells and characterized the transcriptional dynamics of the process of differentiation and of progenitor maintenance. These results led to the hypothesis that some support cell populations are involved in signaling to trigger 
regeneration, which we tested by scRNA-Seq analyses of fgf3 mutants that strikingly show increased proliferation and hair cell regeneration. Our scRNA-Seq analysis identified fgf3 targets that we could not identify in bulk RNA-Seq analyses. Importantly, we show that Notch and Fgf signaling act in parallel and that both need to be downregulated together to induce efficient regeneration. Knowing the temporal dynamics and identity of genes required for proliferation and hair cell differentiation are essential for devising strategies to induce hair cell regeneration in mammals.

\section{Results}

\section{Single cell RNA-Seq reveals support cell heterogeneity}

We reasoned that transcriptional profiling of homeostatic neuromast cells would identify known and previously uncharacterized support cell populations. In addition, as hair cells are continuously replaced, we aimed to identify amplifying and differentiating support cells at different stages of differentiation. We isolated neuromast cells by fluorescence activated cell sorting (FACS) from 5 day post-fertilization (dpf) dissociated transgenic zebrafish in which hair cells, as well as support cells are GFP-positive (Et(Gw57a); $T g$ (pou4f3); Fig. 1A) and performed scRNA-Seq analyses using the 10X Chromium System (Data file 1). The lateral line also possesses neuromasts with an epithelial planar cell polarity that is offset by $90^{\circ}$ depending on which primordium they originated from (priml or primll, (López-Schier et al., 2004)) and the scRNA-Seq analysis contains cells from all of these neuromasts. For clarity we only discuss gene expression patterns in priml-derived neuromasts.

Unsupervised clustering partitioned 1,521 neuromast cells into 14 different clusters (Butler et al., 2018). We combined some of the less well-defined clusters and identified 7 major neuromast cell types (Fig. 1C, D). For each population we identified genes specifically expressed or highly enriched (Fig. 1C, E; Data file 2). The t-distributed Stochastic Neighbor Embedding (t-SNE) plots for Table 1E are shown in Data file 3. Based on marker gene expression, groups 1, 2 and 4 encompass the hair cell lineage, with cluster 1 being differentiated hair cells, cluster 2 being young hair cells, and 4 representing proliferating hair cell progenitors (Fig. 1D). The other groups of cycling cells 
belong to clusters 3 and 10, and because they fail to express hair cell lineage genes, they likely represent amplifying support cells. The proposed hair cell and amplifying support cell lineages are described in detail below. Cells in all other clusters represent different support cell populations (all data can be queried at https://piotrowskilab.shinyapps.io/neuromast_homeostasis_scrnaseq_2018/ ； see Materials and Methods)

To determine if the distinct cell groups defined by scRNA-Seq can be detected in neuromasts, we performed in situ hybridization experiments with cluster marker genes (Figs. 1E-Q). Mature, differentiated hair cells are centrally and apically located in a neuromast (tekt3, Fig. 1F, R, S; dark green). Immediately above the mature hair cells are young hair cells that form a ring and express atoh1b (cluster 2, Fig. 1G, R, S). Fig. 1H shows that delta ligands are only expressed in a subset of the young hair cells (light green). Lfing and ebf3a mark the most basal, central support cells (Fig. 1I, J, S, U; blue). Lfng is also expressed in support cells that are situated underneath hair cells in the mouse cochlea (Maass et al., 2016). The central cell population in neuromasts expresses gata2a/b and slc1a3a/glasta, which are markers for hematopoietic and neural stem cells, respectively (Fig.3 I; Data file 6, (Hewitt et al., 2016; Llorens-Bobadilla et al., 2015)). Within the central cell cluster, a subset of cells expresses other stem cell-associated genes, such as is/1 and fabp7a (clusters 7, 9; Fig. 1K; (Kim et al., 2016; Makarev and Gorivodsky, 2014; Morihiro et al., 2013; Shin et al., 2007)). In addition, members of the retinoic acid pathway, such as crabp2a, dhrs3a and rdh10a are restricted to clusters 7 and 9 (Fig. 1E). Even though central cells express genes characteristic for stem cells in other systems, our lineage tracing experiments showed that they only give rise to hair cells and do not self-renew (Romero-Carvajal et al., 2015).

Cells in the D/V poles of neuromasts that express wnt2 are located immediately adjacent to the mantle cells, and proliferate to generate more support cells that do not differentiate into hair cells (see below; (Romero-Carvajal et al., 2015)). As these cells selfrenew and possibly represent a stem cell population, we were particularly interested in characterizing new markers for these cells and tested the expression of sost, fsta, srrt/ars, six $2 b$ and adcyap1b (Fig. 1E, L, T; orange cells). However, all of these polar genes are 
expressed in more cells than just the ones immediately adjacent to mantle cells, precluding us from obtaining a specific marker for the amplifying cells (Fig. 1T; red cells). Moreover, D/V polar cells do not form their own cluster but are distributed throughout several clusters including some mantle cells (clusters 5,6), central cells (cluster 11) and amplifying, non-differentiating cells (cluster 3 ).

The most distinct support cell population are the mantle cells represented in clusters 5 and 6 and marked by ovgp1 and sfrp1a (Fig. 1M, N). Mantle cells are the outermost cells in a neuromast and sit immediately adjacent to amplifying support cells (Fig. 1B, M, N, R-U). Lineage tracing of mantle cells in medaka revealed that mantle cells give rise to support and hair cells and constitute long term stem cells (Seleit et al., 2017). In addition, they give rise to postembryonic neuromasts during development and restore neuromasts on regenerating tail tips (Dufourcq et al., 2006; Ghysen and DamblyChaudière, 2007; Jones and Corwin, 1993; Ledent, 2002; Wada et al., 2010). In addition to representing stem cells, mantle cells may provide the amplifying support cells with niche factors.

We also identified a number of genes that are expressed in a ring-like pattern, such as fndc7rs4, tfap2a, tcf7/2, hopx, cmah and alpl (Fig. 10, data not shown). These genes are not restricted to any cluster but are expressed in mantle cells, anterior-posterior (A/P) cells and polar cells. Expression is relatively low in central cells and absent in the hair cell lineage (Data file 3). Interestingly, hopx, cmah and alpl are stem cell markers in different systems raising the possibility that they also mark stem cells in neuromasts (Fuchs, 2009; Takeda et al., 2011). In summary we identified and validated the presence of previously unknown support cell populations, some of which are signaling to trigger regeneration, as shown below.

\section{Cycling cells characterize the amplifying and differentiating lineages}

As proliferation is the basis for zebrafish hair cell regeneration we were particularly interested in identifying cycling support cells. Cells in clusters 10, 3 and 4 express pcna (proliferating cell nuclear antigen), required for DNA replication and repair, as well as the 
mitotic spindle regulator stmn1a (Fig. 1D, 2A, D; Data file 4; (Rubin and Atweh, 2004). Genes that regulate early versus later phases of the cell cycle are expressed in complementary subsets of the pcna+ cells (Fig. 2B, C, Data file 5). Genes with the associated GO terms DNA replication and DNA repair, such as $m c m 4$ are expressed in cells closer to clusters 11 and 14, whereas genes involved in chromosome segregation and mitosis are expressed in cells closer to the younger hair cells in the t-SNE plot (cdk1; Fig. 2B, C, and D).

Differential gene expression analysis between the proliferating cells in clusters 3 , 4 and 10 revealed that only cluster 4 cells express genes characteristic for the hair cell lineage such as atoh $1 b$ and dld (Fig. 1G and H; (Cai and Groves, 2015)). As cluster 10 and 3 cells are only defined by the presence of cell cycle genes, we wondered which noncycling support cell type they might be most closely related to. To mitigate the effect of cell cycle genes, we regressed out $S$ and G2/M phase genes using Seurat's cell cycle scoring function (Butler et al., 2018). Using the original cluster classification on the newly generated t-SNE plot, we observed that several cluster 3 (red) cells are now intermingled with D/V support cells in clusters 10,11, 12 (Fig. S1). Likewise, some of the cluster 4 hair cell progenitor cells now localize within the central support cells (Fig. S1). Thus, cluster 3 cells likely belong to the group of amplifying support cells adjacent to mantle cells that give rise to two undifferentiated daughter cells (Fig. 2E, F, G; support cells, red), whereas cluster 4 cells are more central support cells that give rise to two daughters that differentiate into hair cells (Fig. 2E, F, G; green cells, (Romero-Carvajal et al., 2015)).

Long term stem cells are often relatively quiescent in the absence of a severe or prolonged injury. We labeled 5dpf homeostatic neuromasts for $24 \mathrm{hr}$ with BrdU and subsequently scored non-proliferating support cells (grey squares), and progeny of the dividing cells that differentiated into GFP+ hair cells (green squares) or remained support cells (red squares, Fig. 2G; reanalyzed data from Romero-Carvajal et al., 2015). To visualize and compute the ratio of quiescent cells, we plotted the location of each progeny and calculated the BrdU index and spatial distribution of the different cell types (RomeroCarvajal et al., 2015; Venero Galanternik et al., 2016). Amplifying divisions are restricted to the D/N poles, whereas differentiating divisions are more centrally located but do not show a bias toward any quadrant. D/N poles possess more cells than the A/P poles (Fig. 
$2 \mathrm{H}$ ), however, $6.5 \%$ of the D/N cells proliferate, whereas only $0-1 \%$ proliferate in the A/P poles (Fig. 2l). Thus, cells in the A/P poles and central cells beneath the hair cells are relatively quiescent during homeostasis (Cruz et al., 2015; Romero-Carvajal et al., 2015). The expression of the zona pellucida-like domain-containing protein 1 gene si:ch73261i21.5 in the A/P poles has a striking complementary expression pattern to the D/V maker wnt2 and is expressed in quiescent cells (Fig. 2J and K). Therefore, A/P genes could play a role in regulating quiescence.

Having established different support and hair cell populations and their proliferation status allows us to interrogate the expression pattern of any gene (see shiny app).

\section{Heatmaps and the ordering of cells along pseudotime reveals how gene networks change in different lineages}

Cell cycle analyses suggested the existence of two lineages of cycling cells. To identify possible lineage progression and relationships between non-cycling, cycling and differentiating cells, we generated a dendrogram of the 14 cell clusters (Fig. 3A, Fig. 1D) with nodes and terminal branches represented by a number. We then produced heatmaps of genes enriched in each of the nodes and branches (Data files 7, 8). Node 15 distinguishes the transcriptome of differentiated hair cells from support cells. In other species, SoxB1 genes characterize the prosensory domain from which hair cells and support cells arise (Dabdoub et al., 2008; Kuzmichev et al., 2012). Node 17 shows that the SoxB1 family member sox2, its target sox21a and sox3 are expressed in support and mantle cells but are downregulated in differentiated hair cells (Fig. 3D; Data file 8, Data file 3). Thus, mantle and all support cells constitute the prosensory domain in a lateral line neuromast.

Genes that span multiple support cell clusters identified two lineages emerging within the prosensory domain (Fig. 3B, C, Data file 8). Clusters 7, 9, 8, 14 and 4 comprise the differentiating hair cell lineage, whereas clusters $5,6,12,11,10$ and 3 encompass the amplifying lineage (Fig. 3B and C). Indeed, lineage tracing experiments determined that central support cells give rise to hair cells (Romero-Carvajal et al., 2015), whereas 
mantle cells give rise to support and hair cells if traced for several months and constitute long term stem cells (Seleit et al., 2017).

Heatmaps of factors involved in ribosome and protein synthesis also provide lineage information. Quiescent neural stem cells show low levels of ribosomal subunits and protein synthesis (Llorens-Bobadilla et al., 2015). Likewise, we observed mantle (clusters 5,6) and A/P cells (cluster 13) expressing low levels of rpl (ribosomal protein-L) and rps (ribosomal protein small subunit) genes but these levels significantly increase in clusters 12 and 11 and the dividing cells in clusters 10 and 3 (Fig. 3B', Fig. S3). Also, the hair cell lineage and the central cells (clusters 7, 8, 9 and 14) show little ribosome synthesis, which drastically increases in dividing hair cell progenitors (Fig. 3C', Fig. S3). The low ribosome synthesis levels suggest that central support and mantle cells resemble quiescent stem or progenitor cells.

Mantle cell genes show fairly specific gene expression, such as tspan1 but also share genes with clusters 12,13, and amplifying support cells in clusters 10, 3, suggesting a lineage relationship (amplifying lineage; Fig. 3B, E; Data file 8, nodes 18, 23). In addition, clusters $6,12,11,10$ and 3 express the D/V polar genes sost, wnt2, adcyap $1 b$ and fsta (Fig. 3B, F; Data set 8, node 24). These genes label the D/V compartments of neuromasts in which amplifying support cells reside next to mantle cells (Fig. 2E and F; (Romero-Carvajal et al., 2015)). However, when sost+ cells are displaced towards the center of the neuromasts, they downregulate sost and differentiate into hair cells (lineage from clusters $11 / 14$ to 4 , green arrow in Fig. 3B, 3G). The amplifying lineage is also supported by genes such as the pluripotency marker hopx, expressed in mantle and A/P cells as well as proliferating, non-differentiating cells in clusters 10 and 3 (Fig. 1E, O, 3B, G; Data file 8, nodes 18, 23, 3, (Li et al., 2015a)). We conclude that the cells adjacent to mantle cells (and possibly mantle cells themselves) constitute the amplifying lineage.

The differentiating lineage is marked by atoh1a which specifies hair cells together with the downstream delta ligands (Fig. 3H, 4A). atoh1a is expressed in non-cycling (clusters $7,8,9$ and 14) and cycling hair cell progenitors (cluster 4), as well as young hair cells (cluster 2). These cells belong to a subset of central support cells that are marked by progenitor markers slc1a3a/glasta, Ifng, ebf3a, gata2b and prox1a (Fig. 1I, J, Fig. 3I- 
K, Data file 8, nodes 26, 22 and 7). Indeed, time lapse analyses of regenerating neuromasts in a prox1a reporter line show that central cells downregulate prox1a as they divide, while turning on the hair cell marker pou4f3:gfp (Fig. S4, Suppl. Movie 1), as described for the mouse cochlea (Bermingham-McDonogh et al., 2006). We conclude that central cells (clusters 7, 9, 8,14 and 4) contain or represent hair cell progenitors.

\section{Dynamics of gene expression during hair cell differentiation}

After establishing that hair cell progenitors reside within central cells and that cluster 1 represents differentiated hair cells we ordered these cells along a path of differentiation (henceforth referred to as pseudotime) to model the expression dynamics of hair cell differentiation. To define this path of differentiation, we built a topology preserving map of our t-SNE plot using partition-based graph abstraction (PAGA, part of the Scanpy program (Wolf et al., 2018) from clusters 14, 4, 2, and 1 (Fig. 3L). Each node represents a cluster and the weight of the lines represents the statistical measure of connectivity. Connectivity between individual cells can been seen in the ForceAtlas2 plot (Fig. 3M). The fact that red cluster 3 amplifying cells are connected with green, differentiating cluster 4 cells again indicates that the amplifying lineage is plastic and that these cells differentiate if displaced to the center of the neuromasts (Fig. 3M, arrow).

Within the hair cell lineage, gene expression changes progressively from the noncycling progenitors (cluster 14) to differentiated hair cells (cluster 1), reflecting developmental time (Fig. 4 A-H, Data file 3). As progenitors are exiting the cell cycle they turn on differentiation genes, many of which are shared between clusters 2 and 1 (Data set 3 and 8, node 16). However, hair cells are subdivided into younger hair cells (cluster 2) and mature hair cells based on differential gene expression (cluster 1; Data file 3, nodes 1 and 2), but the younger hair cells in cluster 2 possess cilia and can be killed with neomycin (Fig. 1R, S; Fig. S5).

To visualize the expression dynamics of all detected hair cell lineage genes we generated a heatmap in which cells are ordered along pseudotime on the x-axis (Fig. 4I). The heatmap reveals groups of genes that possess similar expression dynamics and 
likely form a regulatory network within each cell cluster (Fig. 4I). This map of progressive gene activation serves as a blueprint for hair cell specification and differentiation.

Hair cell specification and differentiation also depends on the downregulation of genes (Matern et al., 2018). Node 17 (Data file 8) shows such genes that are enriched in support cell types and are downregulated in the hair cell lineage (clusters 4,2 and 1; Fig. 4J). For example, in situ hybridization with fndc7a shows that it labels support cells as in the mouse and that the more apically located young and mature hair cells are unlabeled (Fig. 4K, (Maass et al., 2016)). Likewise, a $\operatorname{Tg}\left(N F_{\kappa} B: E G F P\right)$ reporter line shows that the $N F_{\kappa} B$ pathway that regulates proliferation and self-renewal in other systems is expressed in support cells but that hair cells are GFP-negative (Fig. 4L-N; (Kanther et al., 2011; Rinkenbaugh and Baldwin, 2016; Zakaria et al., 2018)). A GO term analysis reveals that genes associated with regulation of transcription, translation, protein folding, cell cycle and Wnt signaling are downregulated in clusters 1 and 2 (Fig. S6). Another group of genes is downregulated as hair cells develop from young to mature hair cells (Fig. 4O, Data set 8, node 2 and 24). These downregulated genes are associated with the GO terms translation, regulation of cell cycle and Notch signaling (dla, $d l b, d l c, d l d)$. Notch signaling plays an essential role in specifying hair cells versus support cells and a detailed expression analysis of Notch receptors, ligands and downstream targets is shown in Fig. S7. In sum, the pseudotime heatmap provides a blueprint for the succession of gene activation and repression that occurs in support cells as they differentiate into hair cells, thus providing a framework for experimentally inducing hair cell differentiation in mammals.

\section{scRNA-seq reveals that loss of fgf3 in central support cells leads to increased proliferation and regeneration}

Our previous bulk RNA-Seq analysis of regenerating neuromasts revealed that Fgf pathway genes are downregulated $1 \mathrm{~h}$ after hair cell death ((Jiang et al., 2014); Fig. 5A$\left.\mathrm{H}^{\prime}\right)$ suggesting that the downregulation of Fgf signaling could be involved in triggering regeneration, as we showed for Notch signaling (Ma et al., 2008; Romero-Carvajal et al., 2015). Indeed, hair cell regeneration is enhanced in fgf3 mutant larvae and even during 
homeostasis the total cell number per neuromast is increased (Fig. 5I-L).

Because fgf3 disappears as hair cells die, we wondered if fgf3 is expressed in hair cells. The scRNA-Seq analysis of homeostatic neuromasts shows that ligand and receptor expression is complex, and that Fgf signaling is not active in young or mature hair cells (Fig. 5M; clusters 2,1). fgf3 is expressed exclusively in central support cells (clusters 7,8,9) and is downregulated in response to death of the overlying hair cells (Fig. $5 A^{\prime}$ ). We generated a fgf3 knock-in line that recapitulates fgf3 expression (Fig. $5 \mathrm{~N}$ and $\mathrm{O}$, Suppl. Movie 2) and a cross with a prox1a reporter line shows that fgf3 and prox1a are co-expressed, as predicted by the scRNA-Seq data (Fig. 5P and Q). To understand the cellular basis of the increased regeneration response, we performed BrdU analyses of homeostatic and regenerating fgf3-deficient neuromasts. During both homeostasis and regeneration, proliferation is significantly increased in $\mathrm{fgf3}^{-/-}$neuromasts (Fig. 6A-F). Downregulation of Fgf signaling by expression of dn:fgfr1a during homeostasis also increases proliferation and neuromasts are significantly bigger in fgfr1a/fgfr2 double mutants, similarly to fgf3-- (Fig. S8, Fig. 6G-L, Fig. 5L). Therefore, fgf3 likely signals via fgfr1a and fgfr2 receptors. The BrdU plots and the rose diagrams show that in $f^{\prime} f^{-/-}$ homeostatic and regenerating neuromasts amplifying divisions are not restricted to the D/V poles (Fig. 6B, B'; D, D'). This pattern of proliferating cells looks almost identical to the ones observed after upregulation of Wnt signaling (Romero-Carvajal et al., 2015).

\section{fgf3 downregulation leads to Wnt-induced proliferation in parallel to Notch signaling}

To identify genes/pathways underlying the increased proliferation in $\mathrm{fgf3}^{-/}$, we first performed bulk RNA-Seq analysis with $5 \mathrm{dpf}$ homeostatic fgf3 ${ }^{-/}$and siblings. However, the differences in gene expression between siblings and mutants was too low. We therefore performed scRNA-Seq analyses on 1,459 fgf3 mutant and 1,932 sibling cells (Data file 13). A t-SNE plot in which we plotted mutant and sibling datasets together demonstrates that the variance between the two datasets is small as the two datasets intermingle (Fig. 7A, sibling blue, mutant red). The plot also shows that mutant cells contribute to each cluster and that therefore no major cell type is missing in fgf $^{-/-}$(Fig. 
$7 A, B, 1 D)$.

However, the scRNA-Seq analysis revealed fgf3 targets that are down- or upregulated in the mutants (Fig. 7C, Fig. S9). We were particularly interested in genes that regulate the Wnt pathway and/or proliferation and identified that some of the $D / V$ polar genes, such as sost and adcyap1b are downregulated in the mutants (Fig. 7C, Fig. $\mathrm{S9C})$. We validated the downregulation of Wnt inhibitor sost by in situ hybridization in fgf31- and dn:fgfr1 larvae (Fig. 7D-E'). Interestingly, sost is also downregulated 1 hour after hair cell death in wildtype larvae, suggesting that the downregulation of Fgf signaling after neomycin could also be responsible for the downregulation of the Wnt inhibitor sost (Fig. $7 \mathrm{~F}$ and $\mathrm{F}^{\prime}$ ). Also, the Wnt target gene wnt10a is upregulated, illustrating that Wnt signaling is increased in fgf3 mutants (Fig. $7 G$ and G').

To interrogate if the increase in proliferation in Fgf pathway mutants is due to the upregulation of Wnt signaling, we abrogated Wnt signaling in fgf3-/ by crossing them with $h s: d k k 1$ fish. $h s: d k k 1$ significantly inhibits proliferation in siblings and it also reduces proliferation and hair cell numbers in fgf3\% (Fig. 8A-F). Therefore, in homeostatic neuromasts $f g f 3$ inhibits proliferation by inhibiting Wnt signaling, possibly via Sost. As Notch signaling also inhibits proliferation via inhibiting Wnt signaling, we wondered if Notch and Fgf act in the same pathway (Romero-Carvajal et al., 2015). Fgf signaling does not act upstream of Notch signaling, as Notch pathway members are not affected by in situ hybridization in fgf3\% (Fig. 8G-K', Fig. S10). fgf3 on the other hand, is slightly downregulated after Notch signaling inhibition with a $\gamma$-secretase inhibitor (Fig. 8M') while fgf10a and fgfr1a are not affected (Fig. 80-P'). Thus, Notch signaling plays a role in inducing/maintaining fgf3 expression. However, Notch signaling does not inhibit Wnt signaling via the upregulation of Fgf3 signaling, as shown by experiments in which we constitutively activated Notch signaling in fgf $^{-}$by expressing the Notch intracellular domain NICD. Activation of NICD during regeneration strongly inhibits proliferation and hair cell production (Fig. 8Q, R, U, V, (Romero-Carvajal et al., 2015; Wibowo et al., 2011a)). Activation of NICD in fgf3\% also strongly inhibits proliferation and hair cell numbers demonstrating that Notch signaling does not require Fgf to inhibit Wnt signaling (Fig. 8S-V). However, NICD in fgf3-- was not quite as efficient in inhibiting proliferation as 
by itself, arguing that Notch to a small degree affects proliferation via Fgf (Fig. 8U).

We conclude from these data that Notch and Fgf signaling largely act in parallel to inhibit Wnt signaling, with a small amount of proliferation being inhibited by Notch via the upregulation of Fgf signaling (Fig. S10). Thus Notch and Fgf need both to be independently and transiently downregulated for efficient hair cell regeneration.

\section{Discussion}

The scRNA-Seq analyses reported here have characterized in unprecedented detail the different support cell populations present in a homeostatic neuromast. As such, our findings have enabled us to detect subtle gene expression changes in fgf $^{-/}$. Importantly, as dying hair cells are continuously replaced during homeostasis, our analyses also characterized support cells as they differentiated into hair cells. Even though lineage relationships cannot be inferred from scRNA-Seq data alone, the results of our pseudotime and Seurat analysis delineate lineages that have been experimentally confirmed by time lapse and lineage tracing analyses (Romero-Carvajal et al., 2015; Seleit et al., 2017; Viader-Llargues et al., 2018); Fig. 2E, F, 3A-C, L,M). The majority of hair cells originate from central support cells without bias to any of the poles (Fig. 3M, clusters 7, 9, 8, 14 and 4), whereas amplifying divisions are strongly biased towards the D/V poles and occur in the periphery adjacent to mantle cells (Fig. 3M, clusters 10 and 3).

\section{Cells can transition from an amplifying to differentiating lineage}

Interestingly, the PAGA graph (Fig. 3M) shows a connection between cluster 3 (the amplifying support cells) and cluster 4 (the proliferating differentiating support cells) suggesting that the amplifying support cells can turn on differentiation genes as they are displaced toward the center of the neuromast and also become hair cells. This hypothesis is supported by time lapse movies of amplifying support cells during homeostasis and regeneration (Romero-Carvajal et al., 2015). Our finding shows that the amplifying and hair cell lineages are not predetermined, but rather that the location of cells within the neuromast and the signals they are exposed to determine their fate. 


\section{Neuromasts likely possess quiescent and active stem cells}

Based on cell behavior and gene expression studies we postulate that lateral line neuromasts possess active and quiescent stem cells. Because amplifying support cells in the poles self-renew continuously and only differentiate if displaced into the center, we postulate that amplifying cells represent active stem cells. In addition, neuromasts possibly possess two populations of quiescent stem cells. The first population are cells in the $A / P$ compartment that are relatively quiescent during homeostasis and regeneration (Fig. 2H, (Cruz et al., 2015; Romero-Carvajal et al., 2015). These cells start to proliferate after manipulations of the Fgf, Notch or Wnt pathways (Fig. 6D, (Romero-Carvajal et al., 2015)). Long term lineage tracing experiments have to be performed to assess if they indeed present stem cells. The second quiescent, long term stem cell population are the mantle cells that give rise to hair cells in long term lineage analyses but that do not respond to acute neomycin-induced hair cell death (Romero-Carvajal et al., 2015; Seleit et al., 2017; Viader-Llargues et al., 2018). Interestingly, mantle cells express tspan1, and even though not the exact homolog, planarian tspan1 marks a subset of stem cells (neoblasts; An 2018, (Steiner et al., 2014)). Support cells also give rise to mantle cells when mantle cells are ablated (Viader-Llargues et al., 2018) arguing that active and quiescent stem cells can convert back and forth as shown in other systems (Clevers and Watt, 2018). For example, in the intestine slow-cycling, label-retaining stem cells in the +4 position can give rise to stem cells at the bottom of the crypt, which conversely can also give rise to +4 stem cells (Takeda et al., 2011).

Quiescent stem cells in hematopoiesis, the brain, skeletal muscle, hair follicle and Drosophila germline stem cells are also distinguished by their low level of protein synthesis and transcription (Blanco et al., 2016; Llorens-Bobadilla et al., 2015; Sanchez et al., 2016; Signer et al., 2014; Zismanov et al., 2016). A characteristic of stem cell activation is consequently the upregulation of protein synthesis and associated factors, such as ribosomal proteins (Baser et al., 2017; Signer et al., 2014). A heatmap of $r p l$ genes and rps genes shows that in neuromasts these genes are lowly expressed in central support cells (clusters 7, 8, 9, 14), mantle cells (cluster 5,6) and A/P cells (cluster 13) but are upregulated in dividing cells (clusters 3 and 4 ) and in D-V cells (clusters 11 , 12; Fig. 3B', C', Fig. S3). Synthesis of these ribosomal proteins is completely shut down 
in mature hair cells (cluster 1; Fig. 3C'). Based on their low ribosomal protein synthesis central support cells and mantle cells resemble quiescent stem cells, whereas D/V cells and dividing cells resemble activated stem cells or progenitor cells.

\section{Support cells share gene expression profiles with stem cells in other organs}

The notion that some support cells constitute stem cells is also supported by the finding that their gene expression profiles share many genes with stem cells in the CNS, heart, intestine or hair follicles. For example, neural stem cells in the subventricular zone of the CNS and radial glial cells are characterized by glutamate aspartate transporter (GLAST) and Prominin-1 (also known as CD133) expression (Llorens-Bobadilla et al., 2015). In neuromasts, s/c1a3a/glasta and prominin1a are expressed strongly in central and A/P support cells and prominin $1 b$ is specifically enriched in A/P cells. Likewise, genes associated with intestinal, hair follicle and neural stem cells (NSCs), such hopx and alpl are strongly expressed in mantle, A/P, and amplifying cells adjacent to mantle cells, but are downregulated in central support cells, forming a ring of expression similarly to fndc7rs4 (Fig. 1O, 3G, (Li et al., 2015a; Liu et al., 2018). Genes specifically expressed in central support cells beneath the hair cells likewise express genes that label stem cells in other organs, such as fabp7/Blbp, which labels glioma stem cells, radial glia cells, NSCs, (Kim et al., 2016; Morihiro et al., 2013) and is/1 that is expressed in quiescent intestinal stem cells and stem cells in the heart (Makarev and Gorivodsky, 2014; Shin et al., 2015). However, in lateral line neuromasts central cells only give rise to hair cells and we therefore do not consider them to be stem cells.

A comparison of the transcriptional profiles of support cells in regenerating species, such as zebrafish and chicken with mouse support cells will be highly informative. Do mammalian support cells also still express many of the above-mentioned stem cell genes, or do mammalian support cells represent a more differentiated cell population? The results from such analyses will help us determine if mammalian support cells need to be reprogrammed for efficient induction of regeneration. 


\section{Signals that control multipotency versus differentiation}

It is still unknown what signals prevent amplifying support cells from differentiating in the D/V poles, as Notch signaling does not seem to be active in these regions based on Notch reporter expression ( $T g(T p 1 b g l o b: e G F P$, (Romero-Carvajal et al., 2015)). Likewise, loss of Fgf3 signaling does not lead to the loss of amplifying divisions in the D/V poles demonstrating that Fgf3 signaling is not involved in preventing amplifying support cells from differentiating. D/V polar gene expression, such as fsta, wnt2 and sost, correlates with the occurrence of amplifying support cells and these genes are downregulated as cells differentiate into hair cells. However, their expression extends further centrally beyond the row of cells immediately next to the mantle cells suggesting that they are not specifically regulating amplifying cells. We therefore hypothesize that, as immediate neighbors of amplifying support cells, mantle cells are involved in sending anti-differentiation signals. These signals still remain to be identified.

\section{Fgf3 inhibits Wnt signaling and proliferation possibly via Sost}

Wnt signaling induces and is required for support cell proliferation in neuromasts (Head et al., 2013; Jacques et al., 2013; Romero-Carvajal et al., 2015; Wada and Kawakami, 2015). In fgf3-- Wnt signaling is upregulated causing cells to proliferate (Fig. 8). We found that of the neuromast-expressed secreted Wnt inhibitors sfrp1a, dkk2, sost and sostdc1b, only sost is downregulated in fgf3--/ (Fig. 7D', data not shown, (RomeroCarvajal et al., 2015; Wada et al., 2013). Since sost is also downregulated after hair cell death (Fig. 7F') it may have an important role in inhibiting hair cell regeneration. As Wnt signaling also induces proliferation in mammalian hair cell progenitors (Chai et al., 2012; Jacques et al., 2012; Jan et al., 2013; Shi et al., 2012) a role for Sost in this system should be tested. Fgf signaling could also inhibit proliferation by regulating other receptor tyrosine kinase activities, e.g. via inhibition of EGFR by Sprouty2 (Balasooriya et al., 2016). sprouty 2 is also down regulated in $\mathrm{fgf3}^{- \text {- }}$ after hair cell death and could perform a similar inhibitory function in homeostatic neuromasts (Data file 14). Fgf signaling also inhibits proliferation in the regenerating utricle and the basilar papilla of chicken (Jiang et al., 2018; Ku et al., 2014). Likewise, addition of Fgf2 or Fgf20 to auditory or vestibular cultures 
inhibits support cell proliferation (Ku et al., 2014; Oesterle et al., 2000), suggesting that the inhibitory effect of Fgf signaling on progenitor proliferation is evolutionary conserved in species that can regenerate their sensory hair cells.

Experiments utilizing chemical inhibition of Fgfr have been less clear and in some studies had no effect on proliferation or even led to the inhibition of proliferation (Jacques et al., 2012, Ku et al., 2014, Lee et al., 2005). The differences in the effect of chemical inhibition can likely be attributed to differences in culture conditions, timing or doses of drug treatment, underscoring the importance of utilizing multiple methods of signaling pathway inhibition, particularly gene mutations.

\section{A role for Fgf is specification?}

While our data suggest that the main role of fgf3 in mature neuromasts is in regulating proliferation, it is also possible that fgf3 acts to maintain hair cell progenitors in an undifferentiated, non-sensory state as has been observed in the developing zebrafish ear (Maier and Whitfield, 2014). Likewise, in the mouse cochlea loss of Fgfr3 results in increased hair cells at the expense of support cells (Hayashi et al., 2007; Puligilla et al., 2007), while activating mutations in Fgfr3 or loss of function mutation in the Fgfr inhibitor Spry2 lead to transformation of one support cell type into another (Mansour et al., 2013; Mansour et al., 2009; Shim et al., 2005). However, a possible inhibitory effect of fgf3 on hair cell fate has to be rather subtle, as we only observe a limited increase in hair cell numbers, and our scRNA-Seq analyses did not reveal any obvious candidates that might regulate cell fate in a Fgf-dependent fashion.

\section{Interactions between the Fgf and Notch pathways}

Just like Fgf, Notch signaling is immediately downregulated after hair cell death causing cell proliferation. During homeostasis both pathways inhibit proliferation through negative regulation of Wnt activity (Ma et al., 2008; Romero-Carvajal et al., 2015). To test if Fgf and Notch act in the same pathway we performed epistasis experiments. In fgf $^{-/-}$ mutants expression of a Notch reporter and Notch target genes are not affected suggesting that Notch signaling is largely intact in fgf $^{-/-}$(Fig. 8G-K'). Also, while pharmacological inhibition of Notch activity during homeostasis decreases fgf3 
expression it has no effect on Fgf target genes (Fig. 8L-P'). Additionally, activating Notch signaling by over-expression of a Notch intracellular domain inhibits proliferation and differentiation during regeneration in both wildtype and $f g f 3^{-/-}$(Fig. 8R, T, V). This finding shows that Notch inhibits Wnt signaling even in the absence of Fgf3. These data argue that Fgf and Notch signaling are functioning largely in parallel. However, $h s: n i c d$ by itself is more effective in inhibiting proliferation than $h s$ :nicd in $f g \mathrm{f3}^{-/}$, arguing that Notch signaling likely inhibits a small fraction of proliferation via Fgf (Fig. 8V, Fig. S10). We therefore postulate that the transient down regulation of both of these pathways immediately after hair cell death is required to maximally activate Wnt signaling and induce proliferation. Nevertheless, the Fgf and Notch pathways are reactivated before hair cell regeneration is complete (Jiang et al., 2014) and play additional roles later in regeneration, such as ensuring that not too many support cells differentiate. As such, in mammals a short inhibition of one or both of these pathways is more likely to result in functional regeneration than prolonged treatments.

\section{Conclusion}

The scRNA-Seq analysis revealed previously unidentified support cell populations and combined with in situ validation of these cell groups identified lineages that either lead to stem cell self-renewal or hair cell differentiation. Importantly, we have identified the cascade of gene activation and repression that leads to hair cell differentiation. Our analyses led to the hypothesis that some of the support cell populations are involved in signaling to trigger regeneration, which we tested by scRNA-Seq analyses of fgf3 mutants that strikingly show increased proliferation and hair cell regeneration. These experiments identified fgf3 targets that we could not identify in bulk RNA-Seq analyses. Having characterized the support cell transcriptome of a regenerating species allows us to identify commonalities and differences with mouse support cells that do not trigger a meaningful regenerative response (Burns et al., 2015; Maass et al., 2016). Such a comparison will become even more powerful once adult mouse single cell transcriptomes of support cells are available. 


\section{Acknowledgments}

We are grateful to Drs. A. Sánchez Alvarado and J. Sandler for valuable comments on the manuscript, and C. Burns, S. McFarlane, E. Ober, J. Rawls, A. Nechiporuk, V. Korsh, G. Crump, K. Poss and B. Appel for strains and reagents. We are also thankful to members of the Piotrowski lab for insightful discussions. We thank the Stowers Institute Aquatics Facility for excellent fish care and M. Miller for help with scientific illustration. This work was funded by an NIH (NIDCD) award 1R01DC015488-01A1 to T.P, the Hearing Health Foundation, and by institutional support from the Stowers Institute for Medical Research.

\section{Author Contributions}

M.E.L., N.K. D.D., S.B. and T.P. designed the experiments. M.E.L., D.D., S.B. and T.P. analyzed and interpreted data and wrote the paper. N.K performed all pilot experiments. M.E.L., N.K., S.B., H.B., M.K.S., T.G.-E., and A.R.-C. performed all other experiments. K.H., A.P., A.P., J.S.H. designed experiments and provided technical assistance. E. M. B.-N. provided zebrafish lines. D.D. performed the bioinformatic analyses. 


\section{Figure Legends:}

Fig. 1. Single cell RNA-Seq reveals support cell heterogeneity.

(A) Et(Gw57a) labels support cells with GFP.

(B) Schematic of a cross section through a neuromast.

(C) Heatmap showing the expression levels of the top 50 marker genes (y-axis) for each cluster (x-axis), sorted by highest fold change.

(D) t-SNE plot showing the different cell clusters.

(E) Table of marker genes that distinguish the different cell clusters.

(F-Q) t-SNE plots of selected cluster markers and in situ hybridization with these genes. $(R, T$ and $U)$ Schematics of dorsal views of neuromasts with the different cell types colored.

(S) Schematic of a cross section through the center of a neuromast.

\section{Fig. 2. Cycling cells characterize the amplifying and differentiating lineages.}

(A) pcna labels all proliferating cells.

(B) $m c m 4$ labels cells that are replicating DNA early in the cell cycle.

(C) cdk1 labels cells in late stages of the cell cycle.

(D) Table of early and late cell cycle genes.

(E) Still image of a time lapse movie of a homeostatic neuromast in which all dividing cells were tracked. Red dots indicate the position of pre-division amplifying cells, green dots indicate differentiating cells (Romero-Carvajal et al., 2015).

(F) Schematic dorsal view of a neuromast showing that amplifying cells are next to mantle cells in the poles (red), whereas differentiating cells are centrally located (adapted from (Romero-Carvajal et al., 2015)).

(G) BrdU analysis of 18 homeostatic neuromasts that were labeled with $\mathrm{BrdU}$ for $24 \mathrm{~h}$ (Romero-Carvajal et al., 2015). The position of each dividing support cell was plotted. Cells that divided symmetrically and self-renewed are plotted in red; dividing cells that differentiated into hair cells are in green. Quiescent support cells are in grey and show that cells in the A/P poles are relatively quiescent and if they divide, they differentiate. Mantle cells are not shown. 
$(H, I)$ Rose diagrams show that the D/V poles possess slightly more cells than the A/P poles $(\mathrm{H})$, however a larger percentage of them proliferates $(\mathrm{I})$.

(J) $w n t 2$ is expressed in the domain of amplifying cells.

(K) the zona pellucida-like domain-containing protein 1gene si:ch73-261i21.5 is expressed in the quiescent region.

Fig. 3. Organizing clusters along a putative path of development reveals amplifying and differentiating lineages.

(A) Dendrogram of cell clusters. Each branch point (node) is labeled. Genes enriched in each branch are shown in Data file 7.

$(B, C)$ Genes selected from the node heatmaps show how some genes are shared between different clusters indicating the existence of two different lineages. Heat bar shows log2 fold expression changes.

(B) Amplifying lineage: Mantle cells (clusters 5,6) to proliferating, self-renewing support cells (cluster 3). Green arrow shows that some amplifying cells switch over to the differentiating lineage when displaced toward the center of the neuromast. The relationships with cluster 13 cells is unclear. This cluster is thus set aside.

(C) Differentiating lineage: Central support cells $(7,9,8)$ to differentiated hair cells (clusters 1,2).

(B', C') Heatmaps of ribosomal genes in the two lineages suggest increased transcription as support cells are activated. Mantle cells, central cells and differentiated hair cells show low levels of ribosome biogenesis (see Fig. S3).

(D-J) t-SNE plots of selected genes labeling the different lineages.

(D) sox2 labels all support cells.

(E-G) The amplifying lineage is labeled by tspan1, sost and hopx.

(H) atoh1a labels the differentiating/hair cell lineage.

(I) gata2b labels mostly the central cells.

(J) prox1a labels mostly central cells in cluster 7 .

(K) A gw57a; prox1a; pou4f3:GFP transgenic neuromast shows that red, prox1a-positive cells sit immediately beneath the green hair cells. 
(L) Each node in the PAGA graph represents a cluster and the weight of the lines represents the statistical measure of connectivity between clusters.

(M) A ForceAtlas2 plot shows connectivity between individual cells. The arrow points at connections between amplifying cells (cluster 3 ) and differentiating cells (cluster 4).

Figure 4. Dynamics of gene expression during hair cell differentiation.

$(\mathrm{A}-\mathrm{H}) \mathrm{t}$-SNE plots of selected genes at different stages along the hair cell trajectory. Genes that show similar expression patterns are listed below the respective t-SNE plots. (I) Expression heatmap of hair cell lineage genes with cells from clusters $14,4 \mathrm{a} / \mathrm{b}, 2$, and 1 ordered along pseudotime (see Fig. 4A). Each gene \# corresponds to the row index in Data file 11.

(J) Heatmap of genes that are downregulated as hair cells mature. Heat bar shows log2 fold expression changes.

(K) In situ of fndc7a. Genes that are expressed in support cells but are downregulated in the hair cell lineage form a ring of expression.

(L-N) A NF $F_{K} B 2: g f p$ reporter line shows expression in all support cells but not the hair cell lineage.

(O) Maturing hair cells downregulated a number of genes as they develop from young to mature hair cells (clusters 2 and 1). Heat bar shows log2 fold expression changes.

Figure 5. scRNA-seq reveals that fgf 3 is expressed in central support cells and its downregulation enhances regeneration.

(A-H) Fgf pathway genes are expressed in 5 dpf neuromasts. (A'-H') Fgf pathway genes are downregulated $1 \mathrm{hr}$ after hair cell death (post neo). (I and J) DASPEl staining of sibling (I) and fgf3-- larvae $(\mathrm{J}) 24$ hours (hrs) post neomycin showing hair cells.

(K) Quantification of ET4:GFP (+) hair cells $24 \mathrm{hrs}$ post neomycin in siblings and fgf3 $^{-{ }^{-}}$ neuromasts. fgf3 ${ }^{-/}$show increased hair cell and support cell numbers during regeneration. Error bars show the $95 \%$ confidence interval $(\mathrm{Cl}) .{ }^{* * *} p<0.0004$, unpaired t-test. 
(L) Quantification of total neuromast cell numbers at $5 \mathrm{dpf}$ in homeostatic sibling and fgf3 -- neuromasts. Even during homeostasis $\mathrm{fgf3}^{-/-}$neuromasts possess more cells. Error bars show $95 \% \mathrm{Cl} .{ }^{* *} \mathrm{p}<0.0084$, unpaired t-test.

(M) Homeostasis scRNA-Seq expression heatmap of Fgf pathway genes. Heat bar shows $\log 2$ fold expression changes.

(N-O) Double transgenic for pou4f3:gfp and fgf3:h2b-mturquoise2 at 5dpf.

Dorsal and lateral views, respectively. Hair cells are in green, fgf3-expressing nuclei of central cells are in cyan.

(P-Q) Double transgenic for prox1a:tag-rfp and fgf3:h2b-mturquoise2 at 5dpf. prox1a and fgf3 are co-expressed in central support cells.

Figure 6. Loss of $\mathrm{fgf3}^{-/-}$causes increased support cell proliferation during homeostasis and regeneration.

(A-B) Spatial analysis of amplifying (red squares), differentiation (green triangles) cell divisions and quiescent mantle cells (blue X's) in sibling and $\mathrm{fg}^{\mathrm{f}} \mathrm{3}^{-\mathrm{-}}$ neuromasts during homeostasis. Quiescent and BrdU-positive cells from 18 neuromasts are superimposed onto the same X-Y plane. N.S.= not significant.

( $\left.\mathrm{A}^{\prime}-\mathrm{B}^{\prime \prime}\right)$ Rose diagrams of the angular positions of $\mathrm{BrdU}(+)$ support cells (red) or hair cells (green) in sibling and $\mathrm{fgf}^{-/-}$during homeostasis. D/V clustering and directional bias to the posterior was analyzed with a Binomial distribution test, ${ }^{*} p<0.05,{ }^{* *} p<0.008$.

(C-D) Spatial analysis of amplifying and differentiation cell divisions or quiescent mantle cells in sibling and $\mathrm{fgf3}^{-/-} 24 \mathrm{hrs}$ post neomycin.

(C'-D") Rose diagrams of the angular positions of BrdU-positive support cells or hair cells in sibling or $\mathrm{fgf3}^{-/-} 24 \mathrm{hrs}$ post neomycin. D/V clustering and directional bias to the posterior was analyzed with a Binomial distribution test, ${ }^{* * *} p<0.00001,{ }^{* *} p<0.008$

(E) BrdU index of amplifying, differentiating and total cell divisions in sibling and fgf3 $^{-/-}$ during homeostasis. Error bars show $95 \% \mathrm{Cl}$. p-value determined by unpaired t-test, ${ }^{*} \mathrm{p}<0.03,{ }^{* *} \mathrm{p}<0.007$.

(F) BrdU index of amplifying, differentiating and total cell divisions in siblings and fgf3 $^{-/-}$ mutants during $24 \mathrm{hrs}$ post neomycin treatment. Error bars show $95 \% \mathrm{Cl}$. p-value determined by unpaired t-test, ${ }^{* * *} p<0.0005,{ }^{* * *} p<0.0001$. 
(G-H) Alkaline phosphatase staining of sibling or fgfr1a $\mathrm{a}^{-/ / f g f r} 2^{-/}$at $5 \mathrm{dpf}$.

(I) Quantification of total neuromast cell number at $5 \mathrm{dpf}$ in siblings, fgfr2 ${ }^{-/-}$, fgfr1 $\mathrm{a}^{-/-}$and fgfr1 $a^{-/-/ f g f r} 2^{-/-}$. Error bars show $95 \%$ Cl. p-value determined by unpaired t-test, ${ }^{* *} \mathrm{p}<0.007$, $* * * * p<0.0001$.

(J-K) Spatial analysis of all cell divisions (orange squares) or quiescent cells (grey $\mathrm{X}$ ) in sibling or fgfr1a/fgfr2--- during homeostasis.

(L) EdU index of total cell divisions in siblings and fgfr $1 \mathrm{a} / \mathrm{fg}_{\mathrm{fr}} \mathrm{2}^{-/}$mutants during homeostasis. Error bars show $95 \% \mathrm{Cl}$. p-value determined by unpaired t-test, ${ }^{*} \mathrm{p}=0.03$

Figure 7. scRNA-Seq analysis of fgf 3 mutants identifies $f g f 3$ targets.

(A) $t$-SNE plot depicting the integration of fgf3 mutant and sibling scRNA-Seq data sets. Sibling cells in blue, fgf3 $^{-/-}$cells in red.

(B) Graph-based clustering of both fgf3 mutant and sibling data sets. No major cluster is missing in $\mathrm{fgf3}^{-/-}$.

(C) Heatmap of genes downregulated in 5 dpf $\mathrm{fgf3}^{-/-}$neuromasts.

(D-F') sost expression is downregulated in $5 \mathrm{dpf} \mathrm{fgf3}^{-/-}$mutants; after expression of dnfgfr1a and after $1 \mathrm{hr}$ post neomycin treatment.

(G-G') The Wnt target gene, wnt10a, is upregulated in $5 \mathrm{dpf}$ fgf3 $^{-/-}$neuromasts.

Figure 8. Fgf and Notch signaling largely act in parallel to inhibit Wnt-induced proliferation during homeostasis.

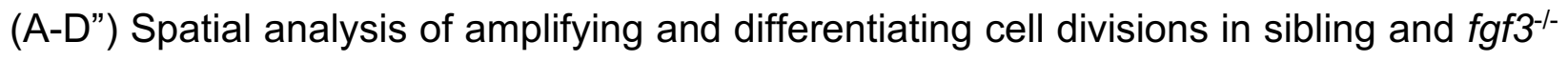
with or without $d k k 1$ expression $24 \mathrm{hrs}$ post neomycin. D/V clustering and directional bias to the posterior was analyzed with a Binomial distribution test, ${ }^{*} p=0.03,{ }^{* *} p<0.008$.

(E) Quantification of ET4:GFP-positive hair cells $24 \mathrm{hrs}$ post neomycin in sibling and fgf3/- with or without dkk1. Error bars show 95\% Cl. p-value determined by Anova and Tukey post-Hoc test, ${ }^{* * *} \mathrm{p}=0.001$.

(F) EdU index of amplifying, differentiating and total cell divisions in sibling and fgf3 $^{-/-}$with or without dkk1 24 hrs post neomycin. Error bars show 95\% Cl. p-value determined by Anova and Tukey post-Hoc test, ${ }^{*} p<0.02,{ }^{* *} p<0.004,{ }^{* * *} p<0.0001$. (G-K') Expression of Notch pathway genes. 
(G-G') the notch reporter, atoh1a (H-H'), cdkn1bb (I-I'), her4.1 (J-J') and hey1 (K-K') are unchanged in $5 \mathrm{dpf}$ fgf3 ${ }^{-/-}$.

(L-P') LY411575 inhibits her4.1 (L-L') and fgf3 (M-M'), but not etv4 (N-N'), fgf10a (O-O'), or fgfr1a (P-P') in 5dpf neuromasts.

(Q-T') Spatial analysis of amplifying and differentiating cell divisions in sibling and fgf3-/with or without notch1a-intracellular domain expression 24 hrs post neomycin. D/V clustering and directional bias to the posterior was analyzed with a Binomial distribution test, ${ }^{* *} p<0.001,{ }^{* * *} p<0.004$

(U) Quantification of ET4:GFP-positive hair cells $24 \mathrm{hrs}$ post neomycin in sibling and fgf3I- with or without notch1a-intracellular domain (nicd). Error bars show 95\% Cl. p-value determined by Anova and Tukey post-Hoc test, ${ }^{* * *} p<0.0001$.

(V) Quantification of amplifying, differentiating and total cell divisions in sibling and fgf3 $^{-/-}$ with or without nicd $24 \mathrm{hrs}$ post neomycin. Error bars show 95\% Cl. p-value determined by Anova and Tukey post-Hoc test, ${ }^{* * * *} \mathrm{p}<0.0001$.

\section{Supplemental Figures}

Figure S1. Related to Figure 2: t-SNE plot, cell cycle genes regressed out. Cluster 4 (differentiating divisions) and cluster 3 cells (amplifying support cells) now cluster with central and D/V support cells, respectively (dashed lines).

Figure S2. Related to Figure 2: Heatmap of human deafness genes that are expressed in homeostatic lateral line scRNA-Seq data.

Figure S3. Related to Figure 3: Heatmap of the expression of ribosomal protein genes in homeostatic lateral line cell scRNA-Seq data, reflecting transcriptional activity. Cluster 13 is set aside because the relationships with cluster 13 cells is unclear. Heat bar shows log2 fold expression changes.

Figure S4: Related to Figure 3. Still images of a movie of prox1a:tagRFP-positive cells differentiating into pou4f3:gfp-positive hair cells. 
Figure S5. Related to Figure 4: Cilia gene expression in young (cluster 2) and mature hair cell (cluster 1).

Figure S6. Related to Figure 4: GO terms of genes down regulated in Hair Cell clusters 1 and 2.

Figure S7. Related to Figure 4: Notch signaling plays an essential role in inhibiting proliferation and maintaining support cell fates.

(A, B) Heatmap and t-SNE plots of Notch receptors, ligands, modulators (Ifng, mfng, numb) and downstream targets (e.g. hey1, her4.1). hey1 is a good read out for Notch signal activation and is active in all support cells and downregulated in the hair cell lineage, whereas delta $a / b / c / d$ are expressed in hair cell progenitors.

(C, D) The notch reporter $\operatorname{Tg}(T p 1: e G F P)$ is expressed in a mosaic fashion in central support cells underlying hair cells but not in hair cells themselves or the amplifying support cells in the D/V poles. atoh1a, the Notch ligands dla and jag2b are already expressed in central support cells before they proliferate (cluster 14), whereas dld and dlc are only expressed in proliferating progenitors (cluster 4). On the other hand, jag2b and dll4 are also or only expressed in differentiated hair cells (clusters 1,2) suggesting that their loss could contribute or cause the downregulation of Notch signaling after hair cell death.

Figure S8. Expression of dnfgr1 also induces neuromast cell proliferation.

(A-B") Spatial analysis of amplifying and differentiation cell divisions in $h s$ sibling and hs:dnfgfr1 larvae during homeostasis. Clustering was analyzed with a Binomial distribution test, ${ }^{* * * *} p<0.0001$.

(C) EdU index of amplifying, differentiation and total cell divisions in homeostatic $h s$ sibling and hs:dnfgfr1 larvae. Error bars show 95\% Cl. p-value determined by unpaired ttest, ${ }^{*} \mathrm{p}<0.02,{ }^{* *} \mathrm{p}<0.008$.

Figure S9. Related to Figure 7: Selection of genes that are differentially expressed in fgf3 mutants. 
(A) RT-qPCR with candidate genes identified in the $f g 3^{-/}$scRNA-Seq analysis. Error bar:

SD, t-test, ${ }^{* *} p<0.01,{ }^{* * *} p<0.001$, and ${ }^{* * * *} p<0.0001$.

(B) Heatmap of genes upregulated in fgf3 mutant lateral line cells.

(C-D') In situ hybridization of is/1 that is slightly upregulated in $\mathrm{fgf3}^{-/-}$neuromasts.

Figure S10. Related to Figure 8: Schematic of signaling pathway interactions in a homeostatic neuromast (Modified after Romero-Carvajal et al., 2015). Notch and fgf3 inhibit Wnt signaling in parallel in homeostatic neuromasts. The downregulation of Notch and Fgf signaling after hair cell death leads to the upregulation of Wnt signaling and proliferation in central, differentiating and D/V, amplifying support cells.

Supplementary Movie 1. Related to Figures 3K, S4: Tg(prox1a:tagRFP;pou4f3:gfp) during regeneration. A dividing prox1a-positive cell downregulates prox1a:tagRFP and upregulates the hair cell marker pou4f3:gfp.

Supplementary Movie 2. Related to Figure 5N: 3D animation of a fgf3:H2Bmturquoise2 and pou4f3:gfp-expressing neuromast.

\section{Supplementary Material}

Data file 1. Related to Figure 1: excel file of genes that are expressed in at least three cells.

Data file 2. Related to Figure 1E: excel file of cluster marker genes.

Data file 3. Related to Figure 1E: t-SNE plots of all cluster marker genes.

Data file 4. Related to Figure 2D: excel file of cell cycle genes.

Data file 5. Related to Figure 2D: t-SNE plots of cell cycle genes.

Data file 6. Related to Figure S2: excel file of zebrafish orthologs of human deafness genes.

Data file 7. Related to Figure 3A: excel files of differentially expressed genes between nodes (dendrogram).

Data file 8. Related to Figure 3A: heatmaps of dendrogram node genes. 
Data file 9. Related to Figure 4A-H: excel file of hair cell lineage genes.

Data file 10. Related to Figure 4A-H: t-SNE plots of hair cell lineage genes.

Data file 11. Related to Figure 4I: excel file of hair cell genes ordered along pseudotime.

Data file 12. Related to Figure S5: excel file of cilia genes.

Data file 13. Related to Figure 7: excel file of cluster markers in $\mathrm{fgf3}^{-\mathrm{f}^{-}}$scRNA-Seq.

Data file 14. Related to Figure 7C, S9B: differentially expressed genes in the fgf3 ${ }^{-/}$.

Data file 15. Related to Figure S9A: Primer table for RT-qPCR.

Data file 16. Related to Figures 1, 2, 5, 7 and 8: primers used for in situ probes.

\section{Materials and Methods:}

Fish lines and husbandry

ET(krt4:EGFP)SqGw57a (Kondrychyn et al., 2011), Tg(pou4f3:GAP-GFP)s356t (Xiao et al., 2005), fgf3t26212 (Herzog et al., 2004), Tg(hsp70l:dkk11b-GFP)w32tg (StoickCooper et al., 2007), Tg(hsp70l:MYC-notch1a,cryaa:Cerulean) ${ }^{f b 12 T g}$ (Zhao et al., 2014), Tg(hsp70l:dnfgfr1a-EGFP)pd1tg (Lee et al., 2005), TgBAC(prox1a:KALTA4,4xUAS-

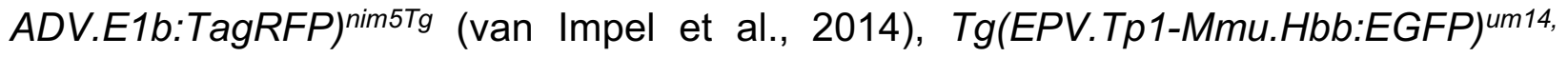
Et(krt4:EGFP)sqet4ET and Et(krt4:EGFP)sqet20ET (Parinov et al., 2004). $\operatorname{Tg}(6 \times N F k B: E G F P)^{n c 1}$ (Kanther et al., 2011). fgfr1a ${ }^{\text {sa38715 }}$ and fgfr2 ${ }^{\text {sa30975 }}$ are from the Sanger Institute Zebrafish Mutation project.

\section{Generation of Tg(fgf3:H2B-mturquoise2) $)^{\text {psi60Tg }}$}

H2B-mturquoise2 was placed near the 5' region of fgf3 using non-homologous repair with Crisper/Cas9 (Auer et al., 2014; Kimura et al., 2014). A Crisper recognition site (GGCCATGGAAACTAAATCTGCGG) was chosen 584bp in front of the fgf3 transcription start site. The same recognition site was cloned by PCR onto both ends of a construct containing a 56bp -actin minimal promoter driving human-H2B fused at the c-terminus with mturquoise2 followed by the SV40 polyA from the Tol2 kit (Kwan et al., 2007). This plasmid was mixed with the crRNA (GGCCATGGAAACTAAATCTG, IDT), tracrRna (IDT) and Cas9 protein (PNA Bio) and complexed for 10 minutes at room temperature then placed on ice. The complex was then injected into the cell of a one cell stage zebrafish embryo. Integrated DNA will just contain the minimal -actin promoter, 
H2B-mturquoise2 and the polyA sequence without any plasmid DNA. In a few larvae, fluorescence could be seen by $24 \mathrm{hrs}$ and onward. Fluorescent embryos were sorted and raised to identify founders that showed H2B-mturquoise expression similar to fgf3 expression. All experiments were performed according to guidelines established by the Stowers Institute IACUC review board.

\section{Sensory hair cell ablation}

For hair cell ablation experiments 5 days post fertilization (dpf) fish were exposed to $300 \mathrm{mM}$ Neomycin (Sigma-Aldrich) for 30 minutes at room temperature. Neomycin was then washed out and larvae were allowed to recover at $28^{\circ} \mathrm{C}$ for as long as the experiment lasted.

\section{Proliferation analysis}

BrdU (Sigma-Aldrich) was added at $10 \mathrm{mM}$ with $1 \%$ DMSO in E2. Larvae were treated for $24 \mathrm{hrs}$ then fixed in $4 \%$ paraformaldehyde overnight at $4{ }^{\circ} \mathrm{C}$. Mouse anti-BrdU (Sigma-Aldrich) and rabbit anti-GFP (Invitrogen) immunohistochemistry with DAPI (Invitrogen) counterstain was performed as described (Lush and Piotrowski, 2014b). EdU (Carbosynth) was added at 3.3mM with 1\% DMSO in E2. Larvae were treated for 24hrs then fixed in $4 \%$ paraformaldehyde overnight at $4^{\circ} \mathrm{C}$. For staining, larvae were washed 3 times 10 minutes each in PBS/0.8\% Trition-X (PBSTX), blocked for $1 \mathrm{hr}$ in 3\%BSA/PBSTX, washed 3 times 5 minutes each in PBS then put in fresh staining solution for 30 minutes. Staining solution contains $1 \mathrm{xT}$ Tris buffered saline, $0.1 \%$ Tween-20, 2mM $\mathrm{CuSO}_{4}, 2.5 \mathrm{mM}$ Alexa-594-Azide (Invitrogen) and 50mM ascorbic acid. After staining, larvae were washed extensively in PBSTX. Larvae were then processed for anti-GFP immunohistochemistry and DAPI staining as described above. Stained larvae were imaged on a Zeiss LSM780 confocal microscope at 40X. Three posterior lateral line neuromasts (L1, L2 and L3) were imaged per fish. Cell numbers were manually counted in Imaris software. Spatial positioning was performed as described (Romero-Carvajal et al., 2015; Venero Galanternik et al., 2016). 


\section{In situ hybridization and alkaline phosphatase staining}

In situ hybridization was performed as described with modifications (Kopinke et al., 2006). Incubation time in proteinase $\mathrm{K}$ (Roche) depended on the batch, and varied from 2-5 minutes at room temperature. Pre-hybridization was performed for at least $2 \mathrm{hrs}$ at $65^{\circ} \mathrm{C}$. Probes used were fgfr1a, fgf3, fgf10a, and etv4 (Aman and Piotrowski, 2009), fgfr2 (Rohs et al., 2013), dld (Jiang et al., 2014), wnt2 (Poulain and Ober, 2011), wnt10a (Lush and Piotrowski, 2014b), wnt11r (Duncan et al., 2015), gfp (Dorsky et al., 2002), atoh1a and notch3 (Itoh and Chitnis, 2001) and sfrp1a (Tendeng and Houart, 2006) Additional probes were generated by PCR from zebrafish cDNA and cloned into the topo-pCRII vector (Invitrogen). See Data file 16 for list or primers used. Alkaline phosphatase staining was performed as described (Lush and Piotrowski, 2014a).

\section{Heat shock paradigm}

Heat shock induction of transgene expression varied depending on the transgenic line used. Initially $5 \mathrm{dpf}$ larvae were heat shocked for $1 \mathrm{hr}$ at $37^{\circ} \mathrm{C}$ then put back at $28^{\circ} \mathrm{C}$ for $1 \mathrm{hr}$. Larvae were then heat shocked for $1 \mathrm{hr}$ at a higher temperature $\left(39^{\circ} \mathrm{C}\right.$ for notch $1 \mathrm{a}-$ intraceullar and $40^{\circ} \mathrm{C}$ for $d k k 1 \mathrm{a}$ and dnfgfr $1 \mathrm{a}$ ), put at $28^{\circ} \mathrm{C}$ for $1 \mathrm{hr}$, followed by another higher temperature heat shock $\left(39^{\circ} \mathrm{C}\right.$ or $40{ }^{\circ} \mathrm{C}$ ) for $1 \mathrm{hr}$. Larvae were then allowed to recover for $1 \mathrm{hr}$ at $28^{\circ} \mathrm{C}$ then fixed in $4 \%$ paraformaldehyde for in situ hybridization or continued with neomycin and proliferation analysis. For neomycin experiments, larvae were treated for 30 minutes in $300 \mu \mathrm{M}$, then extensively washed and immediately placed in EdU as described above. Larvae were then heat shock at the higher temperature followed by $2 \mathrm{hrs}$ recovery at $28^{\circ} \mathrm{C}$. The $1 \mathrm{hr}$ heat shock followed by $2 \mathrm{hrs}$ recovery was repeated for a total of $24 \mathrm{hrs}$ post neomycin treatment. Larvae were then fixed in $4 \%$ paraformaldehyde overnight at $4^{\circ} \mathrm{C}$.

\section{Time-lapse imaging and Confocal imaging}

TgBAC(prox1a:KALTA4,4xUAS-ADV.E1b:TagRFP)

were crossed to $T g$ (pou4f3:GAP-GFP)s356t and larvae were raised to $5 \mathrm{dpf}$. Time-lapse imaging after neomycin treatment was carried out on a Zeiss LSM780 confocal microscope as described (Venero Galanternik et al., 2016). Tg(fgf3:H2B- 
mturquoise2) $)^{\text {psi60Tg } / T g(p o u 4 f 3: G A P-G F P) s 356 t ~ o r ~ T g(f g f 3: H 2 B-m t u r q u o i s e 2) ~}{ }^{\text {psi60Tg/ }}$

TgBAC(prox1a:KALTA4,4xUAS-ADV.E1b:TagRFP) double transgenic larvae were imaged live as above. Three-dimensional rendering and image analysis were done using Imaris (Bitplane).

\section{Sample preparation for scRNA-seq}

Embryo dissociation and FACS

5 dpf Tgs(pou4f3:GAP-GFP/GW57a:GFP) zebrafish embryos were dissociated by adding $1.5 \mathrm{ml}$ (per 100 embryos) of $0.25 \%$ Trypsin-EDTA (Thermo Fisher Scientific, Waltham, MA. USA) and triturated with $1 \mathrm{ml}$ pipette tip for $3 \mathrm{~min}$ on ice. To collect dissociated cells, cells were filtered with 70- $\mu \mathrm{m}$ Cup Filcons (BD Biosciences, San Jose, CA. USA) and washed with ice-cold DPBS (centrifugation at $2000 \mathrm{rpm}$ for 6 mins at $4^{\circ} \mathrm{C}$ ). Cells were stained with Hoechst 33342 (final concentration: $0.005 \mu \mathrm{g} / \mu \mathrm{l}$ ) or Draq5 (1:2000) (biostatus, UK) and 7-AAD (final concentration: $0.5 \mu \mathrm{g} / \mathrm{ml}$ ) or DAPI (5 $\mu \mathrm{g}$ per ml) to gate out dead cell populations. FACS was performed at the Cytometry Core facility (Stowers Institute for Medical Research) using BD Influx Cell Sorter (BD Biosciences, San Jose, CA. USA).

\section{X Chromium scRNA-seq library construction}

scRNA-seq was carried out with 10X Chromium single cell platform (10X Genomics, Pleasanton, CA. USA). FAC-sorted live or $\mathrm{MeOH}$-fixed cells were used as the input source for the scRNA-seq. MeOH-fixed cells were rehydrated with rehydration buffer (0.5\% BSA and $0.5 \mathrm{U} / \mu \mathrm{l}$ RNase-inhibitor in ice-cold DPBS) following manufacturer's instructions (10X Genomics). The maximum recommended volume of single cell suspension (34 ul) was loaded on a Chromium Single Cell Controller (10x Genomics) targeting 1500-2000 cells per sample. Chromium Single Cell 3' Library \& Gel Bead Kit v2 (10X Genomics) was used for libraries preparation according to manufacturer's instructions. Resulting short fragment libraries were checked for quality and quantity using an Agilent 2100 Bioanalyzer and Invitrogen Qubit Fluorometer. Libraries were sequenced to a depth of $\sim 160-330 \mathrm{M}$ reads each on an Illumina HiSeq 2500 instrument using Rapid 
SBS v2 chemistry with the following paired read lengths: 26 bp Read1, 8 bp I7 Index and 98 bp Read2.

\section{scRNA-Seq read alignment and quantification}

Raw reads were demultiplexed and aligned to version 10 of the zebrafish genome (GRCz10) using the Cell Ranger pipeline from 10X Genomics (version 1.3.1 for wildtype and version 2.1 .1 for ggf $^{--}$data sets). 1,666 cell barcodes were obtained for wildtype embryos, 1,932 for fgf3 siblings and 1,459 for fgf3 mutants. These quantities were estimated using Cell Ranger's barcode ranking algorithm, which estimates cell counts by obtaining barcodes that vary within one order of magnitude of the top 1 percent of barcodes by top UMI counts. The resulting barcodes (henceforth referred to as cells) were used to generate a UMI count matrix for downstream analyses. Data deposition: the BAM files and count matrices produced by Cell Ranger have been deposited in the Gene Expression Omnibus (GEO) database, www.ncbi.nlm.nih.gov/geo (accession no. GSE123241).

\section{Quality control, dimensional reduction, and cell classification}

Subsequent analyses on UMI count matrix for all three data sets were performed using the R package Seurat (version 2.3.4, (Butler et al., 2018)) following the standard workflow outlined in the pbmc3k example on the Satija lab webpage (https://satijalab.org). Both fgf3 sibling and mutant data sets were analyzed independently using the same parameters and arguments, and then each data set was merged using the Seurat function MergeSeurat(). Initial gene quality control was performed by filtering out genes expressed in less than 3 cells for the WT data set, and 5 for the fgf 3 sibling/mutant data sets. The remaining UMI counts were then log normalized. Gene selection for dimensional reduction was accomplished using the Seurat function FindVariableGenes() with the following arguments for the WT data set: x.low.cutoff $=0.001$, x.high.cutoff $=3.0$, and $y$.cutoff $=0.5$; and for the fgf 3 sibling/mutant data sets: $x$.low.cutoff $=0.20$ and $y$.cutoff $=$ -0.20 . Following gene selection, all log-normalized expression values were then scaled and centered using ScaleData(). For dimensional reduction, we chose to use the first 6 principal components (PCs) for wildtype and the first 19 for the fgf3 sibling/mutant data 
sets. PCs were chosen according to the PCA elbow plot, which orders PCs from highest to lowest based on the percentage of variance explained by each PC. Thus, each set of PCs chosen showed the highest percentage of variance explained on the elbow plot. Next, we performed clustering on each set of principal components, and for twodimensional visualization, we performed a second round of dimensional reduction using t-SNE. Cells for all data sets were classified according to their marker gene expression. Markers for each cell type were identified based on their differential gene expression using the Seurat function FindAllMarkers(). Genes with an adjusted p-value less than 0.001 were retained. For the pairwise comparison between fgf3 mutant and sibling data sets, we used the function FindMarkers() and retained genes with a fold change greater than 0.10 , or less than -0.10 . Genes differentially expressed between dendrogram nodes were calculated using the function FindAllMarkersNode(), and we kept the top 100 genes with the highest $p$-values for each node comparison. All three data sets contained nonspecific cell types that contained markers for skin and blood cells which were removed from the final analysis.

\section{Pseudotime Analysis}

All data contained within our processed Seurat object for the wildtype data set was converted to the AnnaData format for pseudotime analysis in Scanpy (version 1.2.2, (Wolf et al., 2018)), using the Seurat function convert. We recalculated $k$-nearest neighbors at $\mathrm{k}=15$ and chose cluster 14 as our putative "stem cell" population. Pseudotime was calculated using Scanpy's partitioned-based graph abstraction function, paga. To visualize gene expression in pseudotime, cells from clusters $14,4,2$, and 1 were subsetted into a separate matrix and ordered according to their pseudotime values from least to greatest. Next, we chose genes differentially expressed between clusters, and differentially expressed between selected nodes in our cluster dendrogram. The resulting genes were ordered according to our understanding of neuromast biology and pseudotime expression patterns. The final count matrix was then log normalized and rendered as a heatmap using the python package Seaborn (version 0.8.1).

\section{GO term analysis}


The GO term analysis was performed in DAVID (Database for Annotation, Visualization and Integrated Discovery, Huang da et al., 2009).

\section{Shiny Apps and Data repository}

The Shiny app web interface generates t-SNE plots, violin plots, co-expression tSNE plots and heatmaps from the homeostasis scRNA-Seq data. The user can choose the genes to plot and the results can be saved as pdfs. Instructions are provided in the welcome page of the Shiny app. We are also in the process of uploading the data into gene Expression Analysis Resource (gEAR), a website for visualization and comparative analysis of multi-omic data, with an emphasis on hearing research (https://umgear.org).

\section{RT-qPCR}

RNA extraction and cDNA synthesis

Total RNA was extracted from FAC-sorted cells using Trizol (Thermo Fisher Scientific, Waltham, MA. USA), chloroform and isopropanol. During isopropanol precipitation, to enhance the pellet visibility, GlycoBlue coprecipitant (Thermo Fisher Scientific, Waltham, MA. USA) was used. Following that, total RNA was washed with $80 \%$ ice-cold Ethanol and resuspended in RNase-free water. The first-strand cDNA synthesis and cDNA amplification were done using SMART-Seq v4 Ultra Low Input RNA kit (Takara Bio USA, Mountain View, CA. USA) following manufacturer's instructions.

\section{Quantitative PCR}

Q-PCR was carried out using ABI SYBR Green master mix (Applied Biosystems, Foster City, USA) in the QuantStudio 7 Real-Time PCR System with a 384-Well Block (Applied Biosystems, Foster City, USA). The reaction program consisted of four steps: UDG treatment $\left(50^{\circ} \mathrm{C}\right.$ for 10 minutes), quantitation $\left(40\right.$ cycles of $95^{\circ} \mathrm{C}$ for $15 \mathrm{~s}, 60^{\circ} \mathrm{C}$ for $60 \mathrm{~s})$ and melting curve analysis $\left(95^{\circ} \mathrm{C}\right.$ for $15 \mathrm{~s}, 60^{\circ} \mathrm{C}$ for $60 \mathrm{~s}, 95^{\circ} \mathrm{C}$ for $\left.15 \mathrm{~s}\right)$. The experiment was performed in triplicate. All the signals were normalised to the ef1 $\alpha$ expression level. All primer sequences are provided in Data file 15. 


\section{Bibliography}

Aman, A., and Piotrowski, T. (2009). Multiple signaling interactions coordinate collective cell migration of the posterior lateral line primordium. Cell Adh Migr 3, 365-368.

Auer, T.O., Duroure, K., De Cian, A., Concordet, J.P., and Del Bene, F. (2014). Highly efficient CRISPR/Cas9-mediated knock-in in zebrafish by homology-independent DNA repair. Genome Res 24, 142-153.

Balak, K.J., Corwin, J.T., and Jones, J.E. (1990). Regenerated hair cells can originate from supporting cell progeny: evidence from phototoxicity and laser ablation experiments in the lateral line system. J Neurosci 10, 2502-2512.

Balasooriya, G.I., Johnson, J.A., Basson, M.A., and Rawlins, E.L. (2016). An FGFR1-SPRY2 Signaling Axis Limits Basal Cell Proliferation in the Steady-State Airway Epithelium. Dev Cell 37, 85-97.

Baser, A., Skabkin, M., and Martin-Villalba, A. (2017). Neural Stem Cell Activation and the Role of Protein Synthesis. Brain Plast 3, 27-41.

Bermingham-McDonogh, O., Oesterle, E.C., Stone, J.S., Hume, C.R., Huynh, H.M., and Hayashi, T. (2006). Expression of Prox1 during mouse cochlear development. J Comp Neurol 496, 172186.

Bermingham-McDonogh, O., and Rubel, E.W. (2003). Hair cell regeneration: winging our way towards a sound future. Curr Opin Neurobiol 13, 119-126.

Blanco, S., Bandiera, R., Popis, M., Hussain, S., Lombard, P., Aleksic, J., Sajini, A., Tanna, H., Cortes-Garrido, R., Gkatza, N., et al. (2016). Stem cell function and stress response are controlled by protein synthesis. Nature 534, 335-340.

Brignull, H.R., Raible, D.W., and Stone, J.S. (2009). Feathers and fins: non-mammalian models for hair cell regeneration. Brain Res 1277, 12-23.

Burns, J.C., Kelly, M.C., Hoa, M., Morell, R.J., and Kelley, M.W. (2015). Single-cell RNA-Seq resolves cellular complexity in sensory organs from the neonatal inner ear. Nat Commun 6, 8557.

Butler, A., Hoffman, P., Smibert, P., Papalexi, E., and Satija, R. (2018). Integrating single-cell transcriptomic data across different conditions, technologies, and species. Nat Biotechnol 36, 411-420.

Cai, T., and Groves, A.K. (2015). The Role of Atonal Factors in Mechanosensory Cell Specification and Function. Mol Neurobiol 52, 1315-1329.

Chai, R., Kuo, B., Wang, T., Liaw, E.J., Xia, A., Jan, T.A., Liu, Z., Taketo, M.M., Oghalai, J.S., Nusse, R., et al. (2012). Wnt signaling induces proliferation of sensory precursors in the postnatal mouse cochlea. Proceedings of the National Academy of Sciences of the United States of America 109, 8167-8172.

Clevers, H., and Watt, F.M. (2018). Defining Adult Stem Cells by Function, not by Phenotype. Annu Rev Biochem 87, 1015-1027. 
Corwin, J.T., and Cotanche, D.A. (1988). Regeneration of sensory hair cells after acoustic trauma. Science $240,1772-1774$.

Cruz, I.A., Kappedal, R., Mackenzie, S.M., Hailey, D.W., Hoffman, T.L., Schilling, T.F., and Raible, D.W. (2015). Robust regeneration of adult zebrafish lateral line hair cells reflects continued precursor pool maintenance. Dev Biol.

Dabdoub, A., Puligilla, C., Jones, J.M., Fritzsch, B., Cheah, K.S., Pevny, L.H., and Kelley, M.W. (2008). Sox2 signaling in prosensory domain specification and subsequent hair cell differentiation in the developing cochlea. Proceedings of the National Academy of Sciences of the United States of America 105, 18396-18401.

Dorsky, R.I., Sheldahl, L.C., and Moon, R.T. (2002). A transgenic Lef1/beta-catenin-dependent reporter is expressed in spatially restricted domains throughout zebrafish development. Dev Biol $241,229-237$.

Dufourcq, P., Roussigné, M., Blader, P., Rosa, F., Peyrieras, N., and Vriz, S. (2006). Mechanosensory organ regeneration in adults: the zebrafish lateral line as a model. Molecular and cellular neurosciences $33,180-187$.

Duncan, J.S., and Fritzsch, B. (2012). Evolution of sound and balance perception: innovations that aggregate single hair cells into the ear and transform a gravistatic sensor into the organ of corti. Anatomical record 295, 1760-1774.

Duncan, R.N., Panahi, S., Piotrowski, T., and Dorsky, R.I. (2015). Identification of Wnt Genes Expressed in Neural Progenitor Zones during Zebrafish Brain Development. PloS one 10, e0145810.

Fuchs, E. (2009). The tortoise and the hair: slow-cycling cells in the stem cell race. Cell 137, 811819.

Ghysen, A., and Dambly-Chaudière, C. (2007). The lateral line microcosmos. Genes Dev 21, 2118-2130.

Harris, J.A., Cheng, A.G., Cunningham, L.L., MacDonald, G., Raible, D.W., and Rubel, E.W. (2003). Neomycin-induced hair cell death and rapid regeneration in the lateral line of zebrafish (Danio rerio). In J Assoc Res Otolaryngol, pp. 219-234.

Hayashi, T., Cunningham, D., and Bermingham-McDonogh, O. (2007). Loss of Fgfr3 leads to excess hair cell development in the mouse organ of Corti. Dev Dyn 236, 525-533.

Head, J.R., Gacioch, L., Pennisi, M., and Meyers, J.R. (2013). Activation of canonical Wnt/betacatenin signaling stimulates proliferation in neuromasts in the zebrafish posterior lateral line. Dev Dyn 242, 832-846.

Herzog, W., Sonntag, C., von der Hardt, S., Roehl, H.H., Varga, Z.M., and Hammerschmidt, M. (2004). Fgf3 signaling from the ventral diencephalon is required for early specification and subsequent survival of the zebrafish adenohypophysis. Development 131, 3681-3692. 
Hewitt, K.J., Johnson, K.D., Gao, X., Keles, S., and Bresnick, E.H. (2016). The Hematopoietic Stem and Progenitor Cell Cistrome: GATA Factor-Dependent cis-Regulatory Mechanisms. Curr Top Dev Biol 118, 45-76.

Huang da, W., Sherman, B.T., and Lempicki, R.A. (2009). Systematic and integrative analysis of large gene lists using DAVID bioinformatics resources. Nat Protoc 4, 44-57.

Itoh, M., and Chitnis, A.B. (2001). Expression of proneural and neurogenic genes in the zebrafish lateral line primordium correlates with selection of hair cell fate in neuromasts. Mechanisms of development 102, 263-266.

Jacques, B.E., Montgomery, W.H.t., Uribe, P.M., Yatteau, A., Asuncion, J.D., Resendiz, G., Matsui, J.I., and Dabdoub, A. (2013). The role of Wnt/beta-catenin signaling in proliferation and regeneration of the developing basilar papilla and lateral line. Developmental neurobiology.

Jacques, B.E., Puligilla, C., Weichert, R.M., Ferrer-Vaquer, A., Hadjantonakis, A.-K., Kelley, M.W., and Dabdoub, A. (2012). A dual function for canonical Wnt/ $\beta$-catenin signaling in the developing mammalian cochlea. Development (Cambridge, England) 139, 4395-4404.

Jan, T.A., Chai, R., Sayyid, Z.N., van Amerongen, R., Xia, A., Wang, T., Sinkkonen, S.T., Zeng, Y.A., Levin, J.R., Heller, S., et al. (2013). Tympanic border cells are Wnt-responsive and can act as progenitors for postnatal mouse cochlear cells. Development 140, 1196-1206.

Jiang, L., Romero-Carvajal, A., Haug, J.S., Seidel, C.W., and Piotrowski, T. (2014). Geneexpression analysis of hair cell regeneration in the zebrafish lateral line. Proceedings of the National Academy of Sciences of the United States of America 111, E1383-1392.

Jiang, L., Xu, J., Jin, R., Bai, H., Zhang, M., Yang, S., Zhang, X., Zhang, X., Han, Z., and Zeng, S. (2018). Transcriptomic analysis of chicken cochleae after gentamicin damage and the involvement of four signaling pathways (Notch, FGF, Wnt and BMP) in hair cell regeneration. Hear Res 361, 66-79.

Jones, J.E., and Corwin, J.T. (1993). Replacement of lateral line sensory organs during tail regeneration in salamanders: identification of progenitor cells and analysis of leukocyte activity. The Journal of neuroscience : the official journal of the Society for Neuroscience 13, 1022-1034.

Jones, J.E., and Corwin, J.T. (1996). Regeneration of sensory cells after laser ablation in the lateral line system: hair cell lineage and macrophage behavior revealed by time-lapse video microscopy. The Journal of neuroscience : the official journal of the Society for Neuroscience 16, 649-662.

Kanther, M., Sun, X., Muhlbauer, M., Mackey, L.C., Flynn, E.J., 3rd, Bagnat, M., Jobin, C., and Rawls, J.F. (2011). Microbial colonization induces dynamic temporal and spatial patterns of NFkappaB activation in the zebrafish digestive tract. Gastroenterology 141, 197-207.

Kim, B., Feng, S., Yun, S.W., Leong, C., Satapathy, R., Wan, S.Y., and Chang, Y.T. (2016). A Fluorescent Probe for Neural Stem/Progenitor Cells with High Differentiation Capability into Neurons. ChemBioChem 17, 2118-2122. 
Kimura, Y., Hisano, Y., Kawahara, A., and Higashijima, S. (2014). Efficient generation of knockin transgenic zebrafish carrying reporter/driver genes by CRISPR/Cas9-mediated genome engineering. Sci Rep 4, 6545.

Kniss, J.S., Jiang, L., and Piotrowski, T. (2016). Insights into sensory hair cell regeneration from the zebrafish lateral line. Curr Opin Genet Dev 40, 32-40.

Kondrychyn, I., Teh, C., Garcia-Lecea, M., Guan, Y., Kang, A., and Korzh, V. (2011). Zebrafish Enhancer TRAP transgenic line database ZETRAP 2.0. Zebrafish 8, 181-182.

Kopinke, D., Sasine, J., Swift, J., Stephens, W.Z., and Piotrowski, T. (2006). Retinoic acid is required for endodermal pouch morphogenesis and not for pharyngeal endoderm specification. Dev Dyn 235, 2695-2709.

Ku, Y.C., Renaud, N.A., Veile, R.A., Helms, C., Voelker, C.C., Warchol, M.E., and Lovett, M. (2014). The transcriptome of utricle hair cell regeneration in the avian inner ear. The Journal of neuroscience : the official journal of the Society for Neuroscience 34, 3523-3535.

Kuzmichev, A.N., Kim, S.K., D'Alessio, A.C., Chenoweth, J.G., Wittko, I.M., Campanati, L., and McKay, R.D. (2012). Sox2 acts through Sox21 to regulate transcription in pluripotent and differentiated cells. Curr Biol 22, 1705-1710.

Kwan, K.M., Fujimoto, E., Grabher, C., Mangum, B.D., Hardy, M.E., Campbell, D.S., Parant, J.M., Yost, H.J., Kanki, J.P., and Chien, C.B. (2007). The Tol2kit: a multisite gateway-based construction kit for Tol2 transposon transgenesis constructs. Dev Dyn 236, 3088-3099.

Ledent, V. (2002). Postembryonic development of the posterior lateral line in zebrafish. Development 129, 597-604.

Lee, Y., Grill, S., Sanchez, A., Murphy-Ryan, M., and Poss, K.D. (2005). Fgf signaling instructs position-dependent growth rate during zebrafish fin regeneration. Development 132, 5173-5183.

Li, D., Takeda, N., Jain, R., Manderfield, L.J., Liu, F., Li, L., Anderson, S.A., and Epstein, J.A. (2015a). Hopx distinguishes hippocampal from lateral ventricle neural stem cells. Stem Cell Res $15,522-529$.

Li, W., Wu, J., Yang, J., Sun, S., Chai, R., Chen, Z.Y., and Li, H. (2015b). Notch inhibition induces mitotically generated hair cells in mammalian cochleae via activating the Wnt pathway. Proceedings of the National Academy of Sciences of the United States of America 112, 166-171.

Liu, W., Zhang, L., Xuan, K., Hu, C., Liu, S., Liao, L., Li, B., Jin, F., Shi, S., and Jin, Y. (2018). Alpl prevents bone ageing sensitivity by specifically regulating senescence and differentiation in mesenchymal stem cells. Bone Res 6, 27.

Llorens-Bobadilla, E., Zhao, S., Baser, A., Saiz-Castro, G., Zwadlo, K., and Martin-Villalba, A. (2015). Single-Cell Transcriptomics Reveals a Population of Dormant Neural Stem Cells that Become Activated upon Brain Injury. Cell stem cell 17, 329-340.

López-Schier, H., Starr, C.J., Kappler, J.A., Kollmar, R., and Hudspeth, A.J. (2004). Directional cell migration establishes the axes of planar polarity in the posterior lateral-line organ of the zebrafish. Dev Cell 7, 401-412. 
Lush, M.E., and Piotrowski, T. (2014a). ErbB expressing Schwann cells control lateral line progenitor cells via non-cell-autonomous regulation of $\mathrm{Wnt} / \beta$-catenin. eLife 3, e01832.

Lush, M.E., and Piotrowski, T. (2014b). Sensory hair cell regeneration in the zebrafish lateral line. Dev Dyn 243, 1187-1202.

Ma, E.Y., and Raible, D.W. (2009). Signaling pathways regulating zebrafish lateral line development. Curr Biol 19, R381-386.

Ma, E.Y., Rubel, E.W., and Raible, D.W. (2008). Notch signaling regulates the extent of hair cell regeneration in the zebrafish lateral line. J Neurosci 28, 2261-2273.

Maass, J.C., Gu, R., Cai, T., Wan, Y.W., Cantellano, S.C., Asprer, J.S., Zhang, H., Jen, H.I., Edlund, R.K., Liu, Z., et al. (2016). Transcriptomic Analysis of Mouse Cochlear Supporting Cell Maturation Reveals Large-Scale Changes in Notch Responsiveness Prior to the Onset of Hearing. PloS one 11, e0167286.

Maier, E.C., and Whitfield, T.T. (2014). RA and FGF signalling are required in the zebrafish otic vesicle to pattern and maintain ventral otic identities. PLoS Genet 10, e1004858.

Makarev, E., and Gorivodsky, M. (2014). Islet1 and its co-factor Ldb1 are expressed in quiescent cells of mouse intestinal epithelium. PloS one 9, e95256.

Mansour, S.L., Li, C., and Urness, L.D. (2013). Genetic rescue of Muenke syndrome model hearing loss reveals prolonged FGF-dependent plasticity in cochlear supporting cell fates. Genes Dev 27, 2320-2331.

Mansour, S.L., Twigg, S.R., Freeland, R.M., Wall, S.A., Li, C., and Wilkie, A.O. (2009). Hearing loss in a mouse model of Muenke syndrome. Hum Mol Genet 18, 43-50.

Matern, M.S., Beirl, A., Ogawa, Y., Song, Y., Paladugu, N., Kindt, K.S., and Hertzano, R. (2018). Transcriptomic Profiling of Zebrafish Hair Cells Using RiboTag. Front Cell Dev Biol 6, 47.

Morihiro, Y., Yasumoto, Y., Vaidyan, L.K., Sadahiro, H., Uchida, T., Inamura, A., Sharifi, K., Ideguchi, M., Nomura, S., Tokuda, N., et al. (2013). Fatty acid binding protein 7 as a marker of glioma stem cells. Pathol Int 63, 546-553.

Nicolson, T. (2005). The genetics of hearing and balance in zebrafish. Annu Rev Genet 39, 9-22.

Oesterle, E.C., Bhave, S.A., and Coltrera, M.D. (2000). Basic fibroblast growth factor inhibits cell proliferation in cultured avian inner ear sensory epithelia. J Comp Neurol 424, 307-326.

Parinov, S., Kondrichin, I., Korzh, V., and Emelyanov, A. (2004). Tol2 transposon-mediated enhancer trap to identify developmentally regulated zebrafish genes in vivo. Dev Dyn 231, 449459.

Poulain, M., and Ober, E.A. (2011). Interplay between Wnt2 and Wnt2bb controls multiple steps of early foregut-derived organ development. Development (Cambridge, England) 138, 3557-3568. 
Puligilla, C., Feng, F., Ishikawa, K., Bertuzzi, S., Dabdoub, A., Griffith, A.J., Fritzsch, B., and Kelley, M.W. (2007). Disruption of fibroblast growth factor receptor 3 signaling results in defects in cellular differentiation, neuronal patterning, and hearing impairment. Dev Dyn 236, 1905-1917.

Rinkenbaugh, A.L., and Baldwin, A.S. (2016). The NF-kappaB Pathway and Cancer Stem Cells. Cells 5.

Rohs, P., Ebert, A.M., Zuba, A., and McFarlane, S. (2013). Neuronal expression of fibroblast growth factor receptors in zebrafish. Gene expression patterns : GEP 13, 354-361.

Romero-Carvajal, A., Navajas Acedo, J., Jiang, L., Kozlovskaja-Gumbriene, A., Alexander, R., Li, H., and Piotrowski, T. (2015). Regeneration of Sensory Hair Cells Requires Localized Interactions between the Notch and Wnt Pathways. Dev Cell 34, 267-282.

Rubin, C.I., and Atweh, G.F. (2004). The role of stathmin in the regulation of the cell cycle. J Cell Biochem 93, 242-250.

Ryals, B.M., and Rubel, E.W. (1988). Hair cell regeneration after acoustic trauma in adult Coturnix quail. Science 240, 1774-1776.

Sanchez, C.G., Teixeira, F.K., Czech, B., Preall, J.B., Zamparini, A.L., Seifert, J.R., Malone, C.D., Hannon, G.J., and Lehmann, R. (2016). Regulation of Ribosome Biogenesis and Protein Synthesis Controls Germline Stem Cell Differentiation. Cell stem cell 18, 276-290.

Seleit, A., Kramer, I., Riebesehl, B.F., Ambrosio, E.M., Stolper, J.S., Lischik, C.Q., Dross, N., and Centanin, L. (2017). Neural stem cells induce the formation of their physical niche during organogenesis. Elife 6.

Shi, F., Kempfle, J.S., and Edge, A.S. (2012). Wnt-responsive Lgr5-expressing stem cells are hair cell progenitors in the cochlea. J Neurosci 32, 9639-9648.

Shim, K., Minowada, G., Coling, D.E., and Martin, G.R. (2005). Sprouty2, a mouse deafness gene, regulates cell fate decisions in the auditory sensory epithelium by antagonizing FGF signaling. Dev Cell 8, 553-564.

Shin, J., Berg, D.A., Zhu, Y., Shin, J.Y., Song, J., Bonaguidi, M.A., Enikolopov, G., Nauen, D.W., Christian, K.M., Ming, G.L., et al. (2015). Single-Cell RNA-Seq with Waterfall Reveals Molecular Cascades underlying Adult Neurogenesis. Cell stem cell 17, 360-372.

Shin, J., Poling, J., Park, H.C., and Appel, B. (2007). Notch signaling regulates neural precursor allocation and binary neuronal fate decisions in zebrafish. Development 134, 1911-1920.

Signer, R.A., Magee, J.A., Salic, A., and Morrison, S.J. (2014). Haematopoietic stem cells require a highly regulated protein synthesis rate. Nature 509, 49-54.

Steiner, A.B., Kim, T., Cabot, V., and Hudspeth, A.J. (2014). Dynamic gene expression by putative hair-cell progenitors during regeneration in the zebrafish lateral line. Proceedings of the National Academy of Sciences of the United States of America 111, E1393-1401. 
Stoick-Cooper, C.L., Weidinger, G., Riehle, K.J., Hubbert, C., Major, M.B., Fausto, N., and Moon, R.T. (2007). Distinct Wnt signaling pathways have opposing roles in appendage regeneration. Development 134, 479-489.

Takeda, N., Jain, R., LeBoeuf, M.R., Wang, Q., Lu, M.M., and Epstein, J.A. (2011). Interconversion between intestinal stem cell populations in distinct niches. Science 334, 14201424.

Tendeng, C., and Houart, C. (2006). Cloning and embryonic expression of five distinct sfrp genes in the zebrafish Danio rerio. Gene expression patterns : GEP 6, 761-771.

van Impel, A., Zhao, Z., Hermkens, D.M., Roukens, M.G., Fischer, J.C., Peterson-Maduro, J., Duckers, H., Ober, E.A., Ingham, P.W., and Schulte-Merker, S. (2014). Divergence of zebrafish and mouse lymphatic cell fate specification pathways. Development 141, 1228-1238.

Venero Galanternik, M., Navajas Acedo, J., Romero-Carvajal, A., and Piotrowski, T. (2016). Imaging collective cell migration and hair cell regeneration in the sensory lateral line. In The Zebrafish: Cellular and Developmental Biology, Part B Developmental Biology, H.W.I. Detrich, M. Westerfield, and L.I. Zon, eds. (Elsevier), pp. 211-256.

Viader-Llargues, O., Lupperger, V., Pola-Morell, L., Marr, C., and Lopez-Schier, H. (2018). Live cell-lineage tracing and machine learning reveal patterns of organ regeneration. Elife 7.

Wada, H., Ghysen, A., Asakawa, K., Abe, G., Ishitani, T., and Kawakami, K. (2013). Wnt/Dkk negative feedback regulates sensory organ size in zebrafish. Curr Biol 23, 1559-1565.

Wada, H., Ghysen, A., Satou, C., Higashijima, S.-I., Kawakami, K., Hamaguchi, S., and Sakaizumi, M. (2010). Dermal morphogenesis controls lateral line patterning during postembryonic development of teleost fish. Dev Biol 340, 583-594.

Wada, H., and Kawakami, K. (2015). Size control during organogenesis: Development of the lateral line organs in zebrafish. Dev Growth Differ 57, 169-178.

Whitfield, T.T. (2002). Zebrafish as a model for hearing and deafness. J Neurobiol 53, 157-171.

Wibowo, I., Pinto-Teixeira, F., Satou, C., Higashijima, S.-i., and López-Schier, H. (2011a). Compartmentalized Notch signaling sustains epithelial mirror symmetry. Development (Cambridge, England) 138, 1143-1152.

Wibowo, I., Pinto-Teixeira, F., Satou, C., Higashijima, S.-I., and López-Schier, H. (2011b). Compartmentalized Notch signaling sustains epithelial mirror symmetry. In Development, pp. 1143-1152.

Williams, J.A., and Holder, N. (2000). Cell turnover in neuromasts of zebrafish larvae. In Hear Res, pp. 171-181.

Wolf, F.A., Angerer, P., and Theis, F.J. (2018). SCANPY: large-scale single-cell gene expression data analysis. Genome Biol 19, 15. 
Xiao, T., Roeser, T., Staub, W., and Baier, H. (2005). A GFP-based genetic screen reveals mutations that disrupt the architecture of the zebrafish retinotectal projection. Development 132, 2955-2967.

Zakaria, N., Mohd Yusoff, N., Zakaria, Z., Widera, D., and Yahaya, B.H. (2018). Inhibition of NFkappaB Signaling Reduces the Stemness Characteristics of Lung Cancer Stem Cells. Front Oncol 8, 166.

Zhao, L., Borikova, A.L., Ben-Yair, R., Guner-Ataman, B., MacRae, C.A., Lee, R.T., Burns, C.G., and Burns, C.E. (2014). Notch signaling regulates cardiomyocyte proliferation during zebrafish heart regeneration. Proceedings of the National Academy of Sciences of the United States of America 111, 1403-1408.

Zismanov, V., Chichkov, V., Colangelo, V., Jamet, S., Wang, S., Syme, A., Koromilas, A.E., and Crist, C. (2016). Phosphorylation of elF2alpha Is a Translational Control Mechanism Regulating Muscle Stem Cell Quiescence and Self-Renewal. Cell stem cell 18, 79-90. 
bioRxiv preprint doi: https://doi.org/10.1101/496612; this version posted December 14,2018 . The copyright holder for this preprint (which was not certified by peer review) is the author/funder, who has granted bioRxiv a license to display the preprint in perpetuity. It is made available

\section{Figure 1}
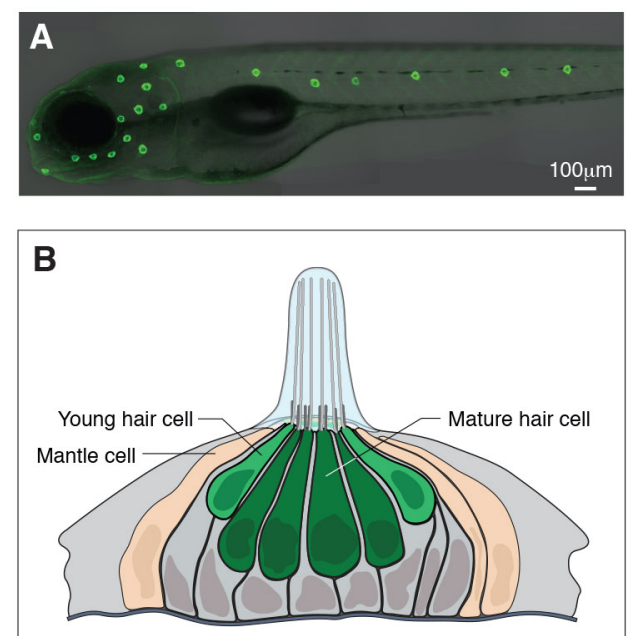

\section{E}

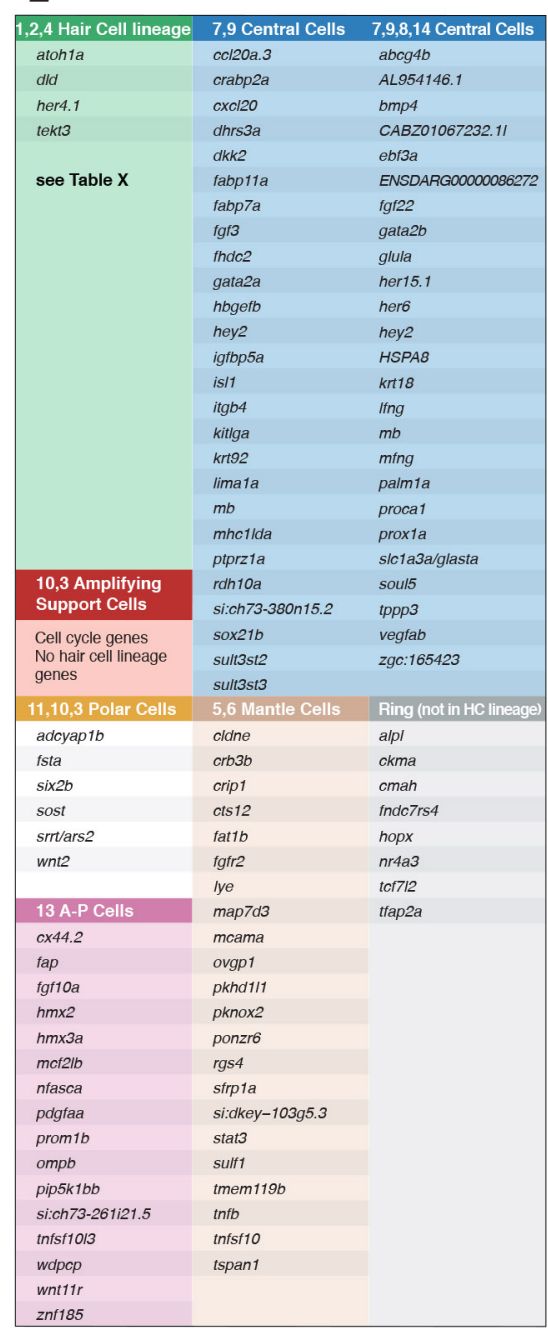

R
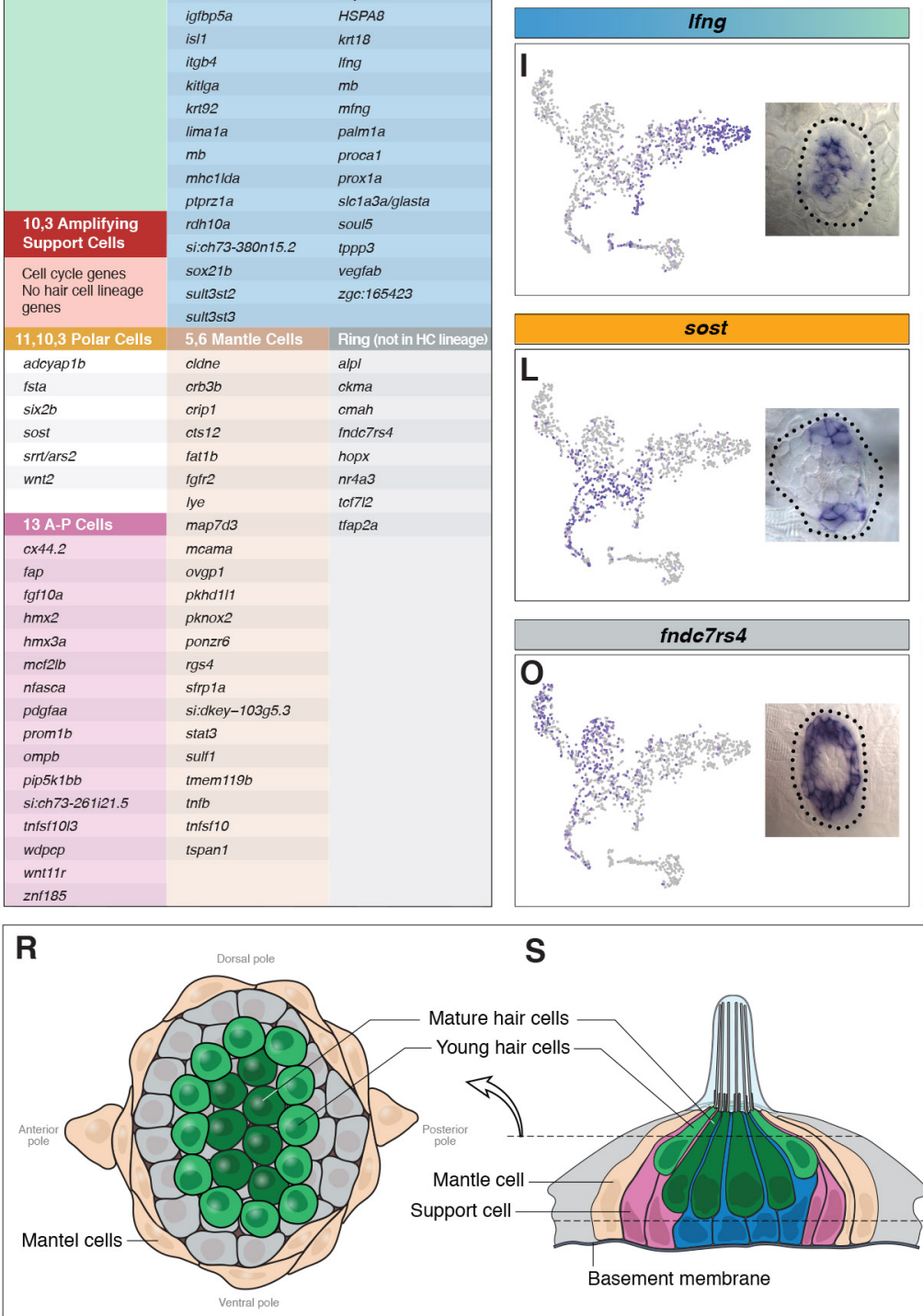
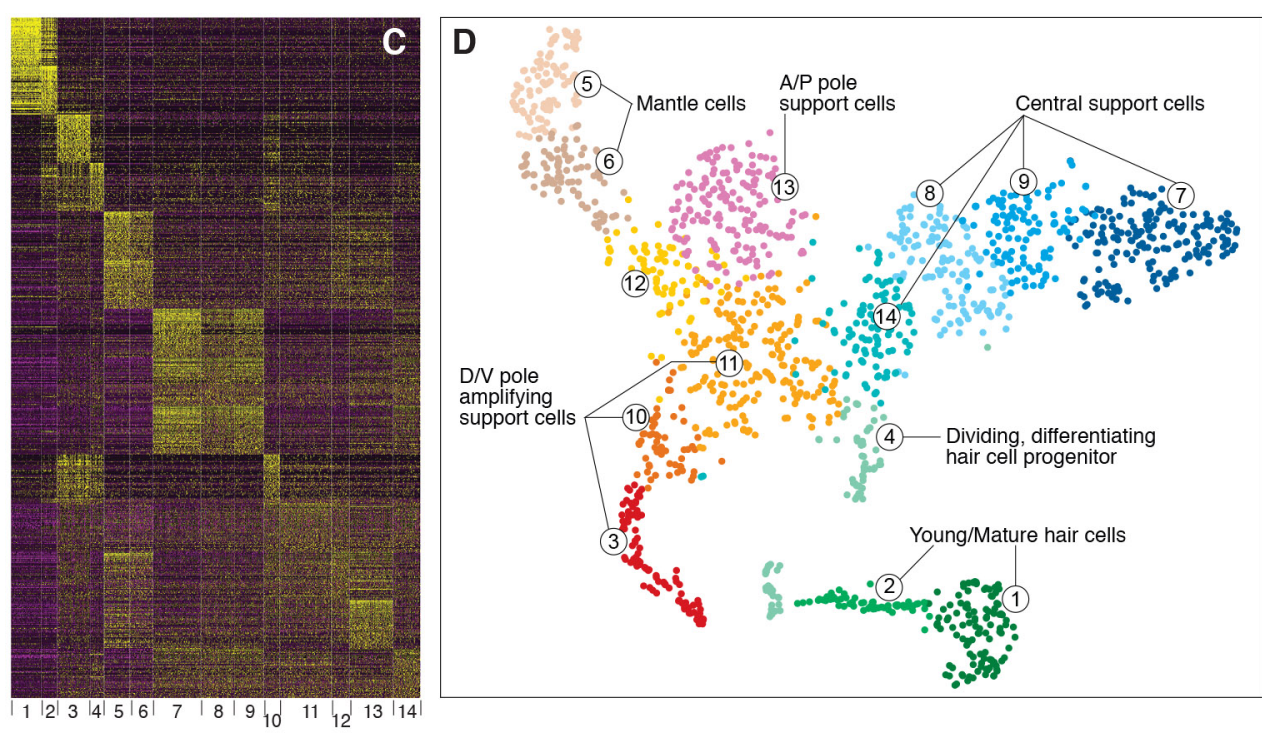
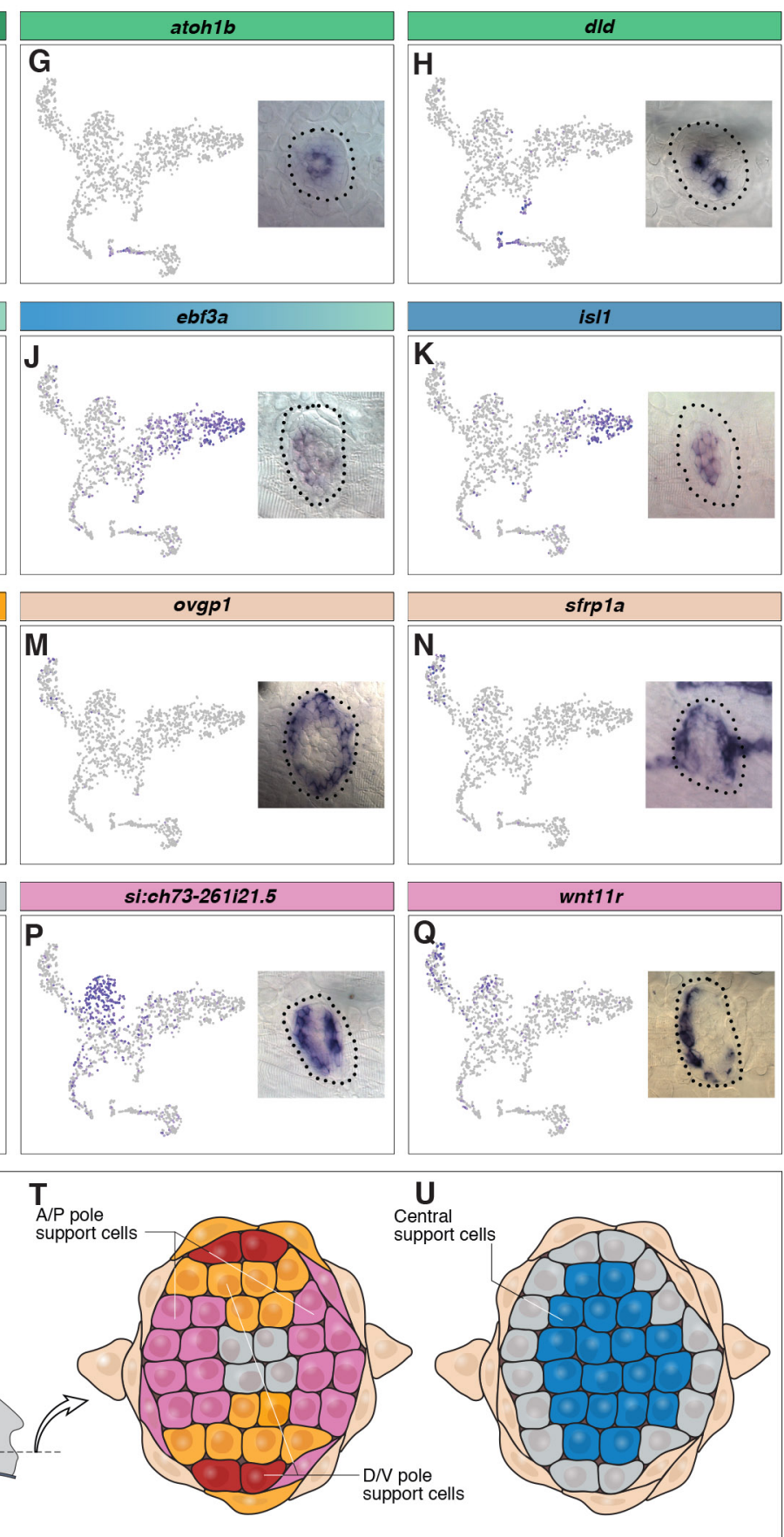

support cells

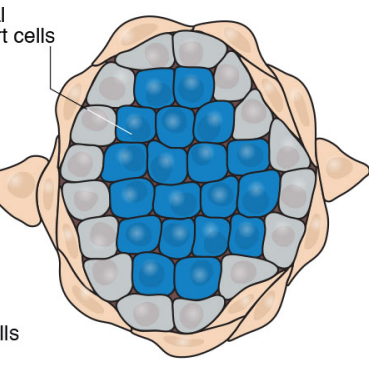


bioRxiv preprint doi: https://doi.org/10.1101/496612; this version posted December 14,2018 . The copyright holder for this preprint (which was not certified by peer review) is the author/funder, who has granted bioRxiv a license to display the preprint in perpetuity. It is made available under aCC-BY 4.0 International license.

\section{Figure 2}

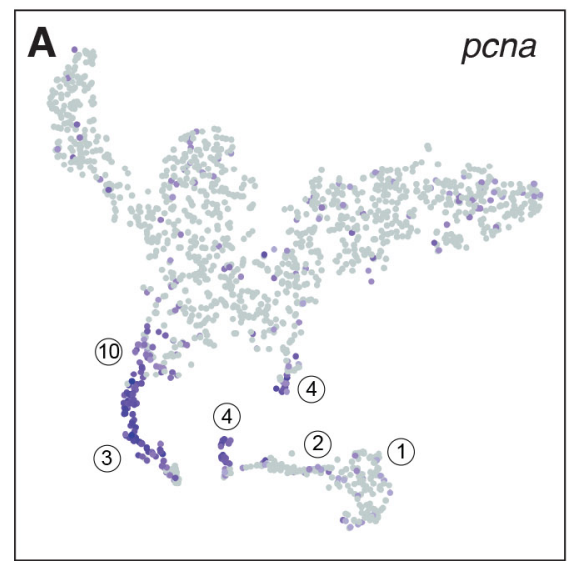

D

\begin{tabular}{|llllllll|}
\hline General Cell Cycle: & pcna & stmn1a & & & & & \\
Early Cell Cycle: & chaf1a & cdca7a & hells & gmnn & pold1 & msh2 & DNA replication \\
& mcm4 & mcm5 & mcm6 & fen1 & mcm3 & & DNA repair \\
Late Cell Cycle: & arhgef39 & asf1ba & atad2 & aurkb & birc5a & ccna2 & Chromosome Segregation \\
& ccnb1 & ccnb2 & ccnb3 & cdca8 & cdk1 & cks1b & Mitotic Nuclear Division \\
& $c k s 2$ & $d c k$ & dlgap5 & foxm1 & g2e3 & h2afx & \\
& hmmr & INCENP & kiaa0101 & kif11 & knstrn & kpna2 & \\
& lbr & mad211 & mibp & mki67 & neil3 & ncapd2 \\
& nuf2 & nusap1 & plk1 & rpa3 & rrm2 & rrm2.1 & \\
& slc29a1 & smc4 & spc25 & top2a & tpx2 & ube2c & \\
& ube2t & zgc:110540 & prc1b & & & & \\
\end{tabular}

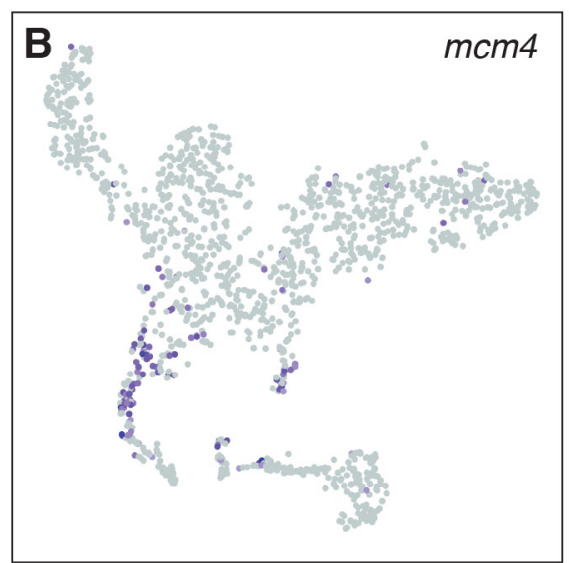

\section{GO terms}

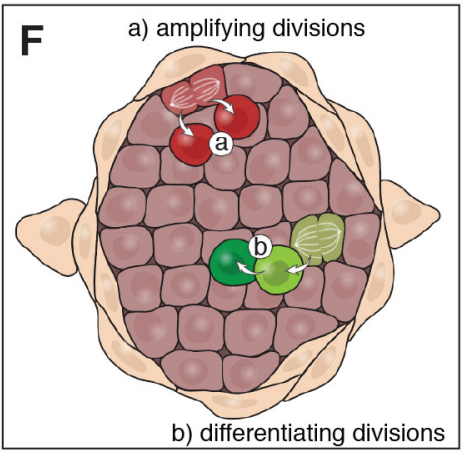

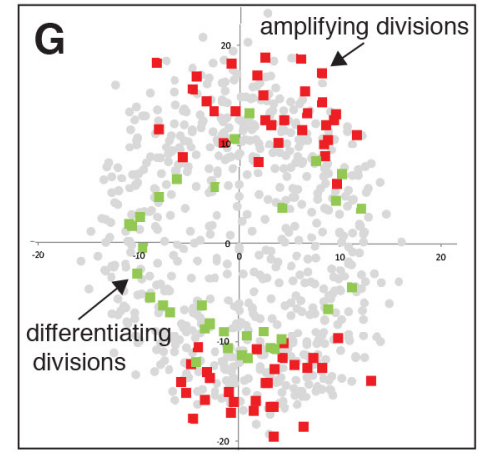
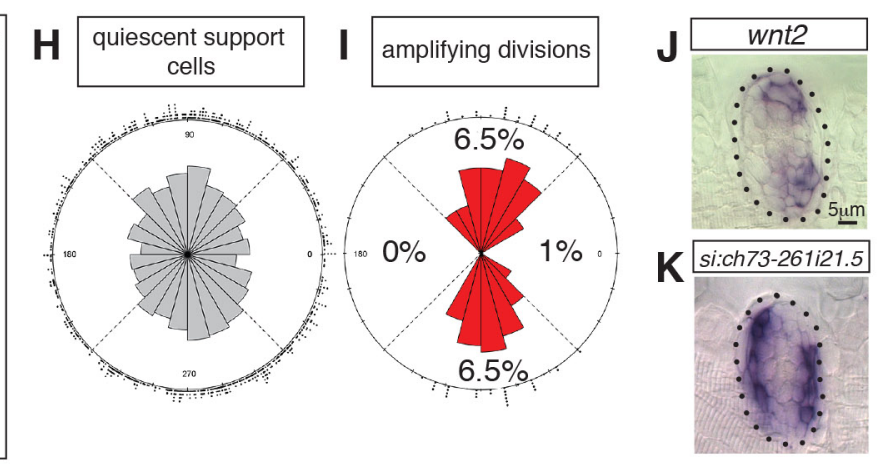
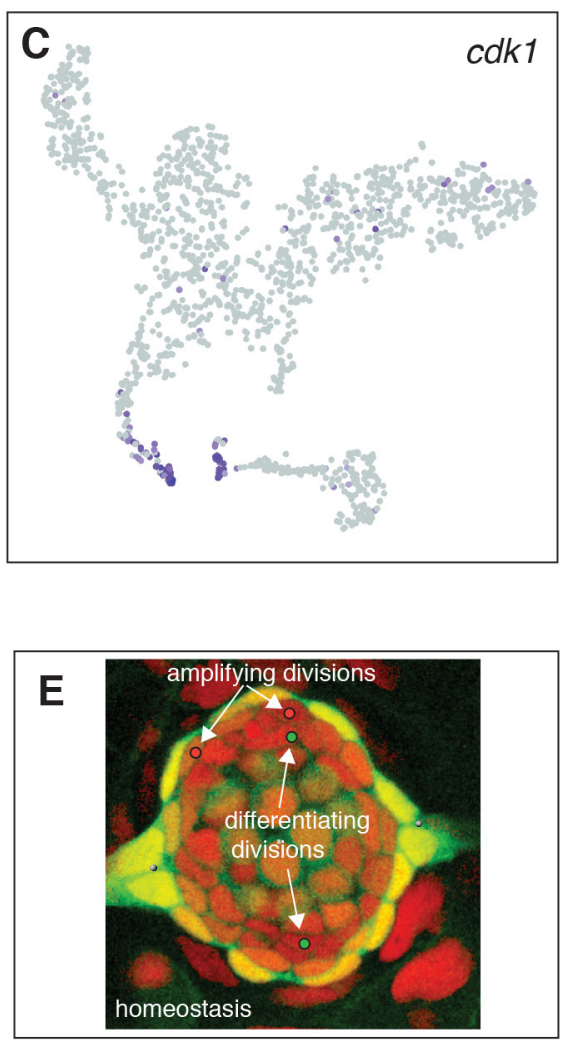
bioRxiv preprint doi: https://doi.org/10.1101/496612; this version posted December 14, 2018. The copyright holder for this preprint (which was not certified by peer review) is the author/funder, who has granted bioRxiv a license to display the preprint in perpetuity. It is made available

Figure 3 under ACC-BY 4.0 International license.

A

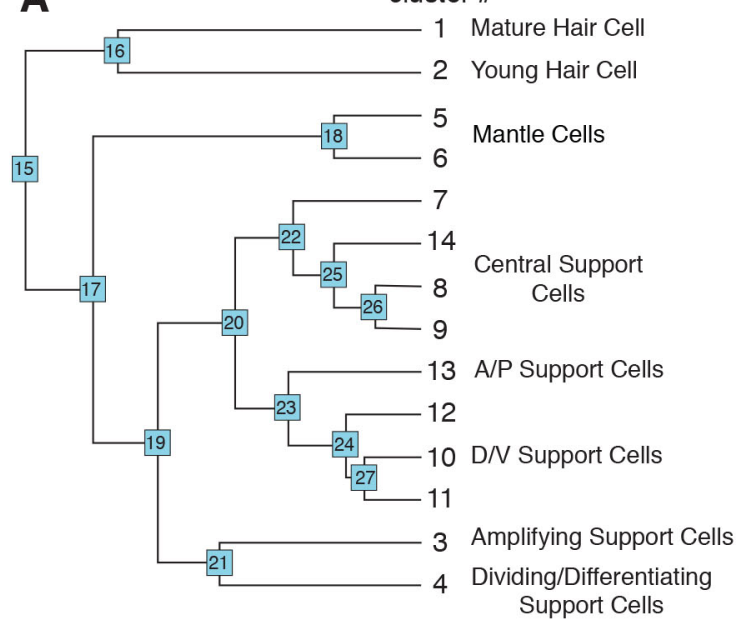

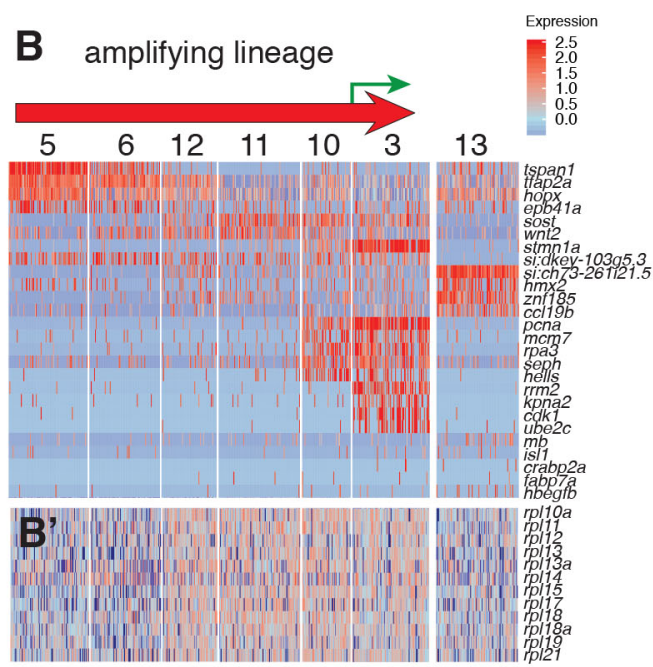

C differentiating lineage

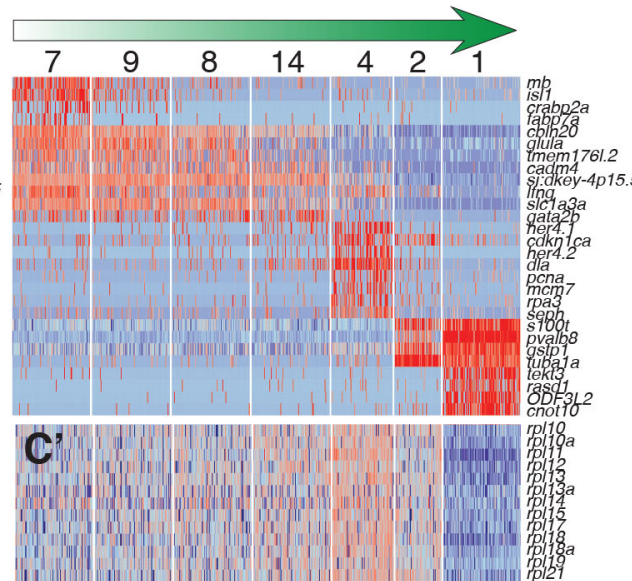

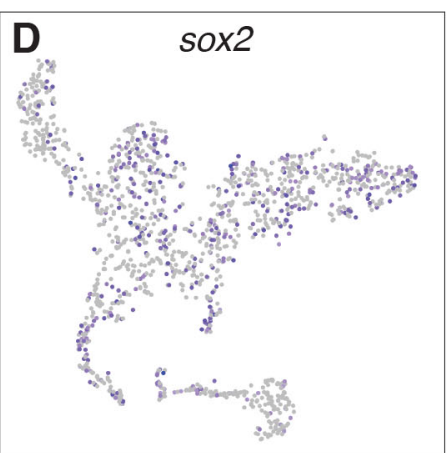

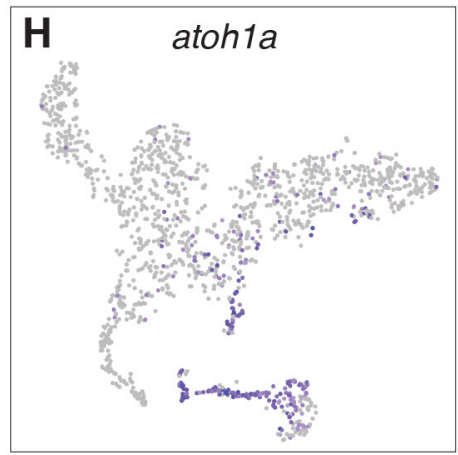

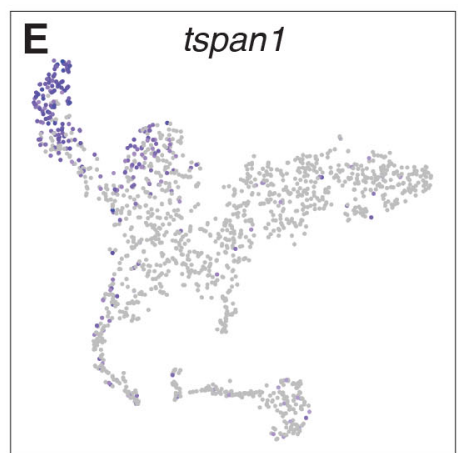

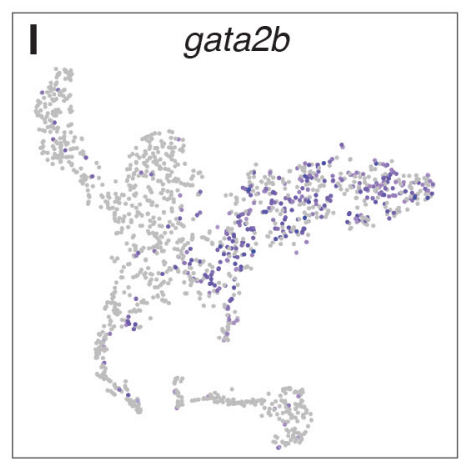

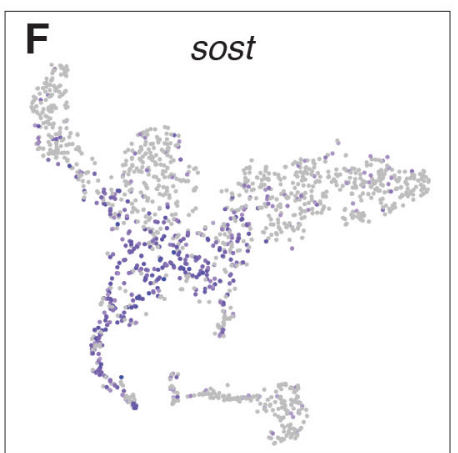

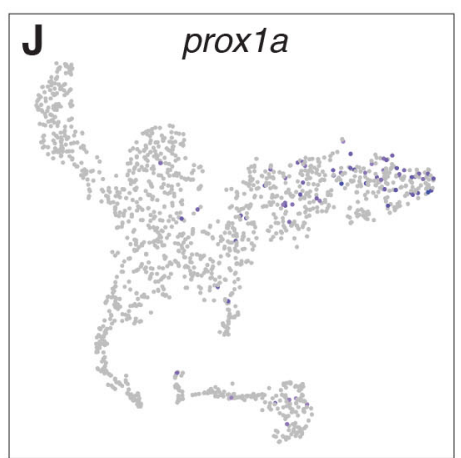

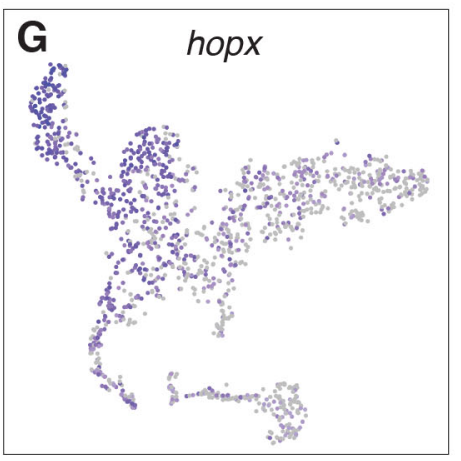

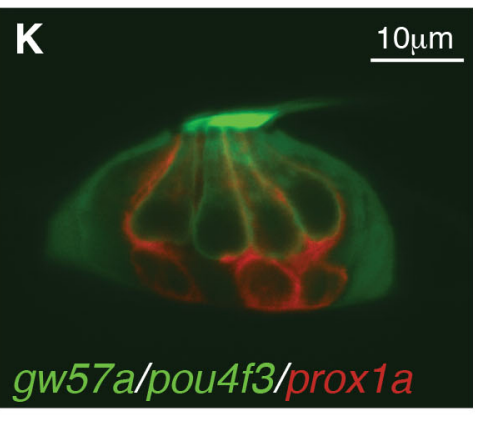

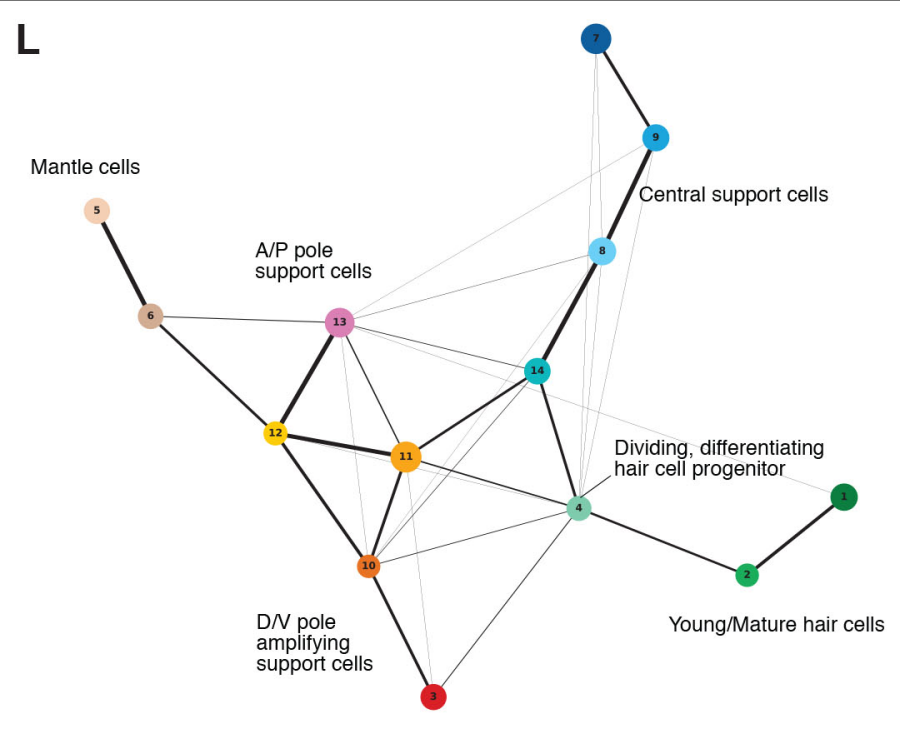

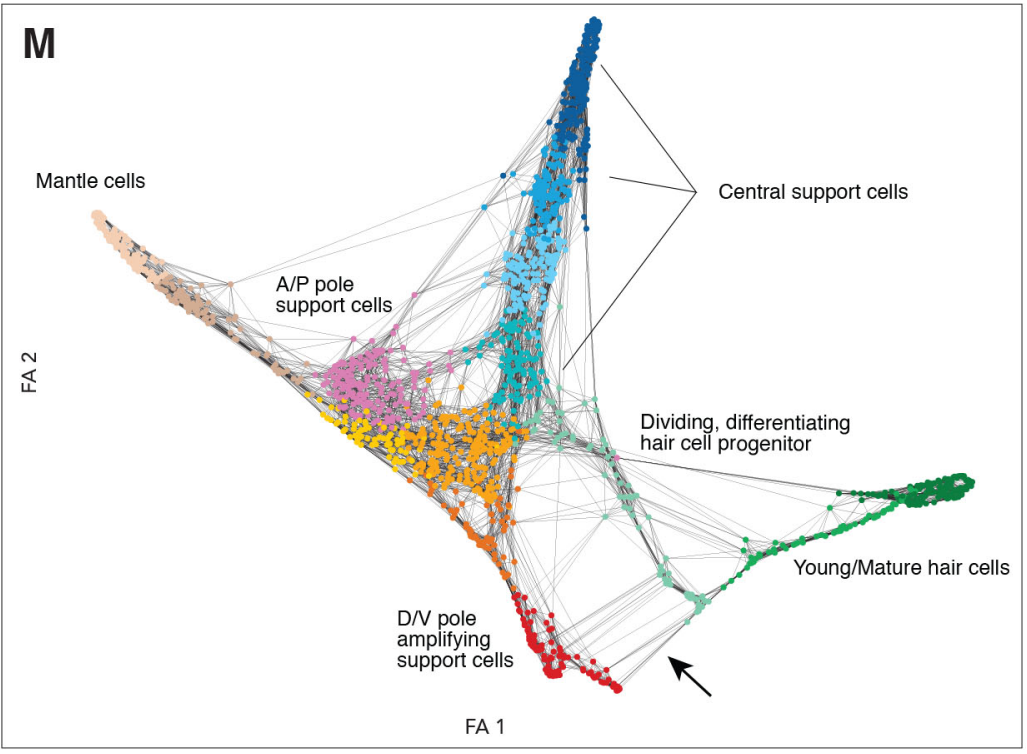


bioRxiv preprint doi: https://doi.org/10.1101/496612; this version posted December 14,2018 . The copyright holder for this preprint (which was

not certified by peer review) is the author/funder, who has granted bioRxiv a license to display the preprint in perpetuity. It is made available under aCC-BY 4.0 International license.

Figure 4
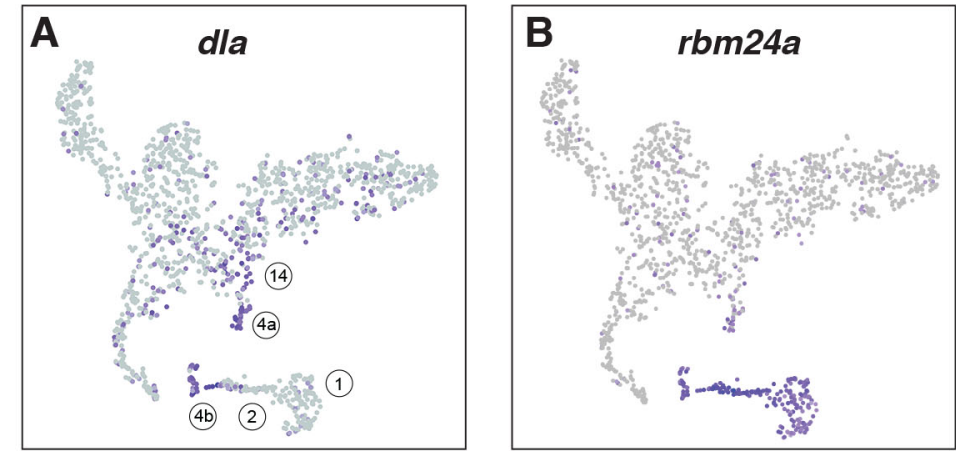

barhl1a, capsla1, dla, hsp90aa1.1, ift27, kitb, myo6b, nrxn3b, pllp, pou4f1, RASSF5, sall1a, smad7, tspan13b, tuba1a, zgc:158291

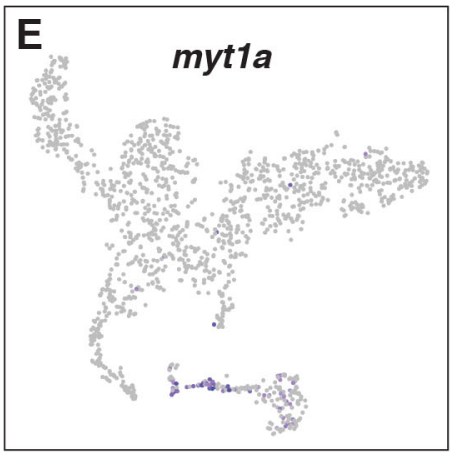

atoh1b, bc/2/10, drgx,

$k d m 6 b b$, myclb, shisa2,

srrm4, tnc, tox, zgc:171699

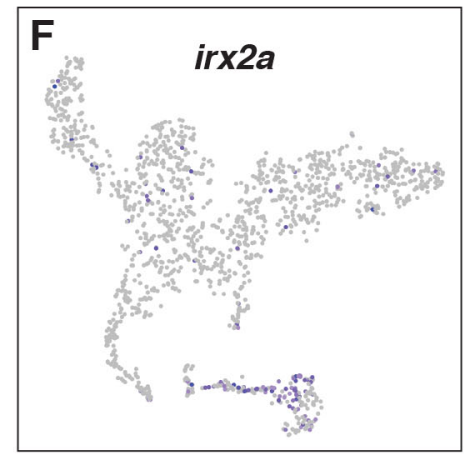

pax2a, pax $2 b$
I
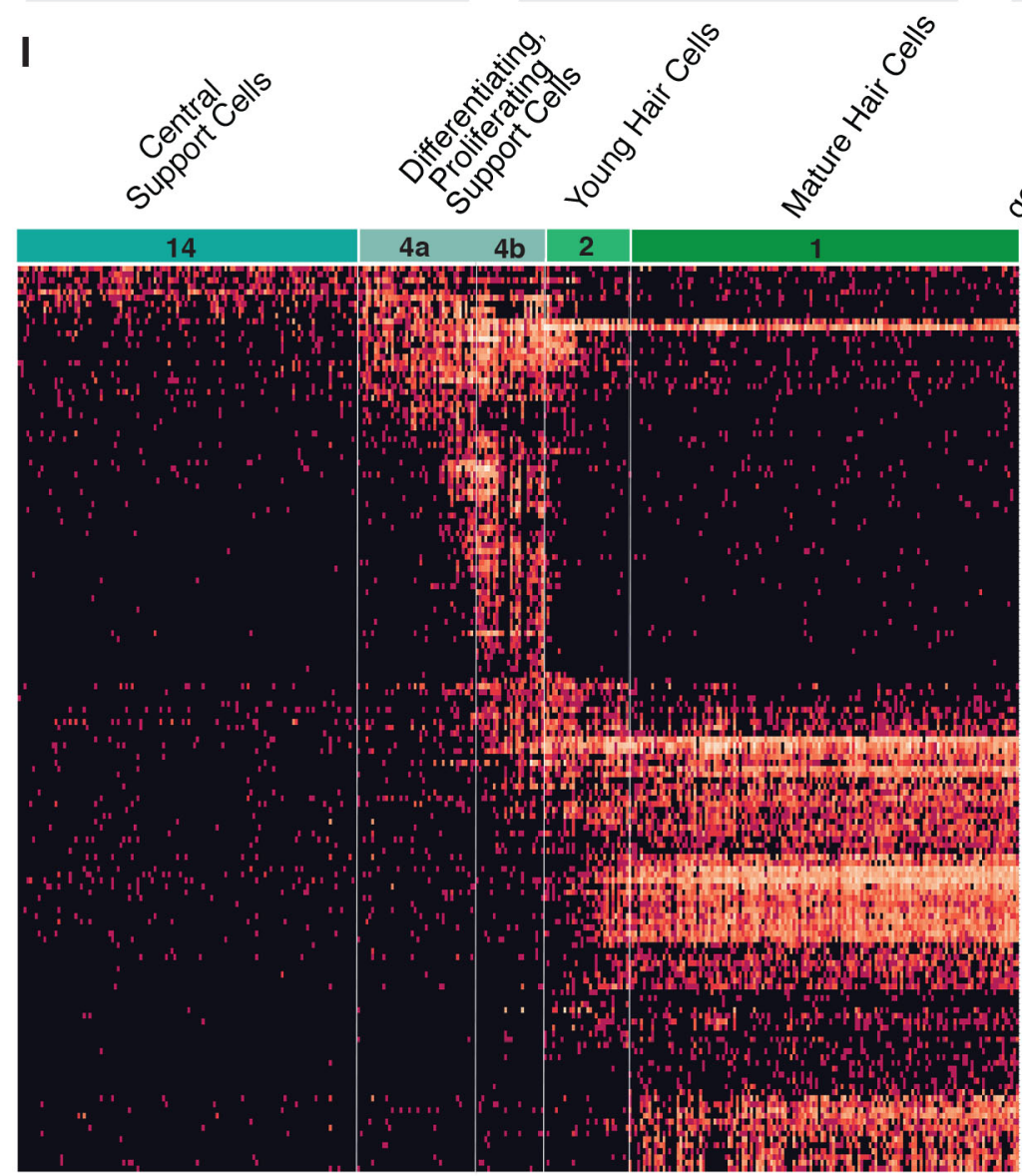

pseudotime

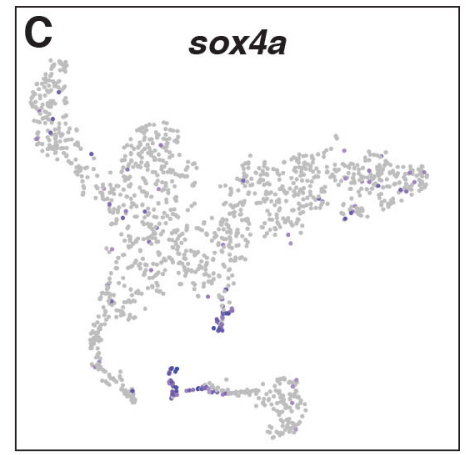

dlb, dlc, dld, her4.1,

gadd45gb. 1, insm1b, pcdh18b

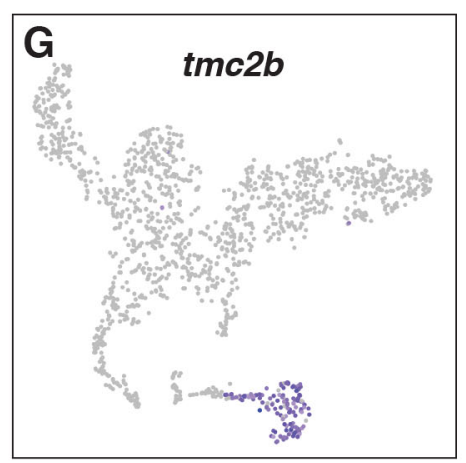

atp 1a3b, bdnf, camk2n1a, dll4 dnajc5b,emx2, gfi1aa, grxr1, Ihx4, otofb, pcdh7a, prdm1a, skor1a, tmc2b...

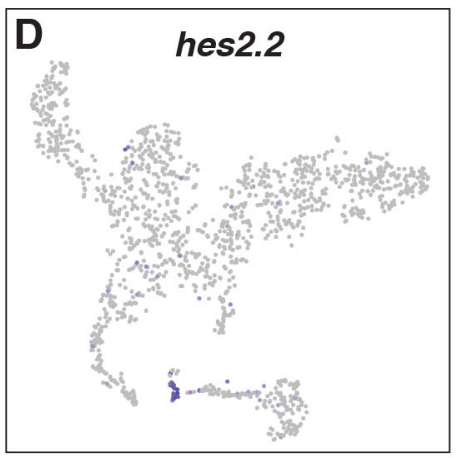

foxn4, im:7152348, pcah10b

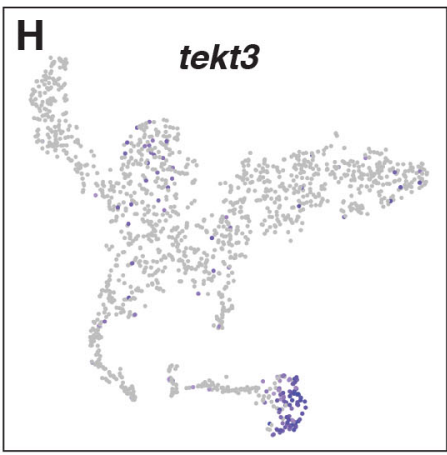

bcl2b, C11orf1, cnot10, cpn1.2, dnah9l, hif1aa, loxhd1b, Irrc53, myo3a, ODF3L2, rasd1, rprma, rtn4rl2b, zgc:113691...
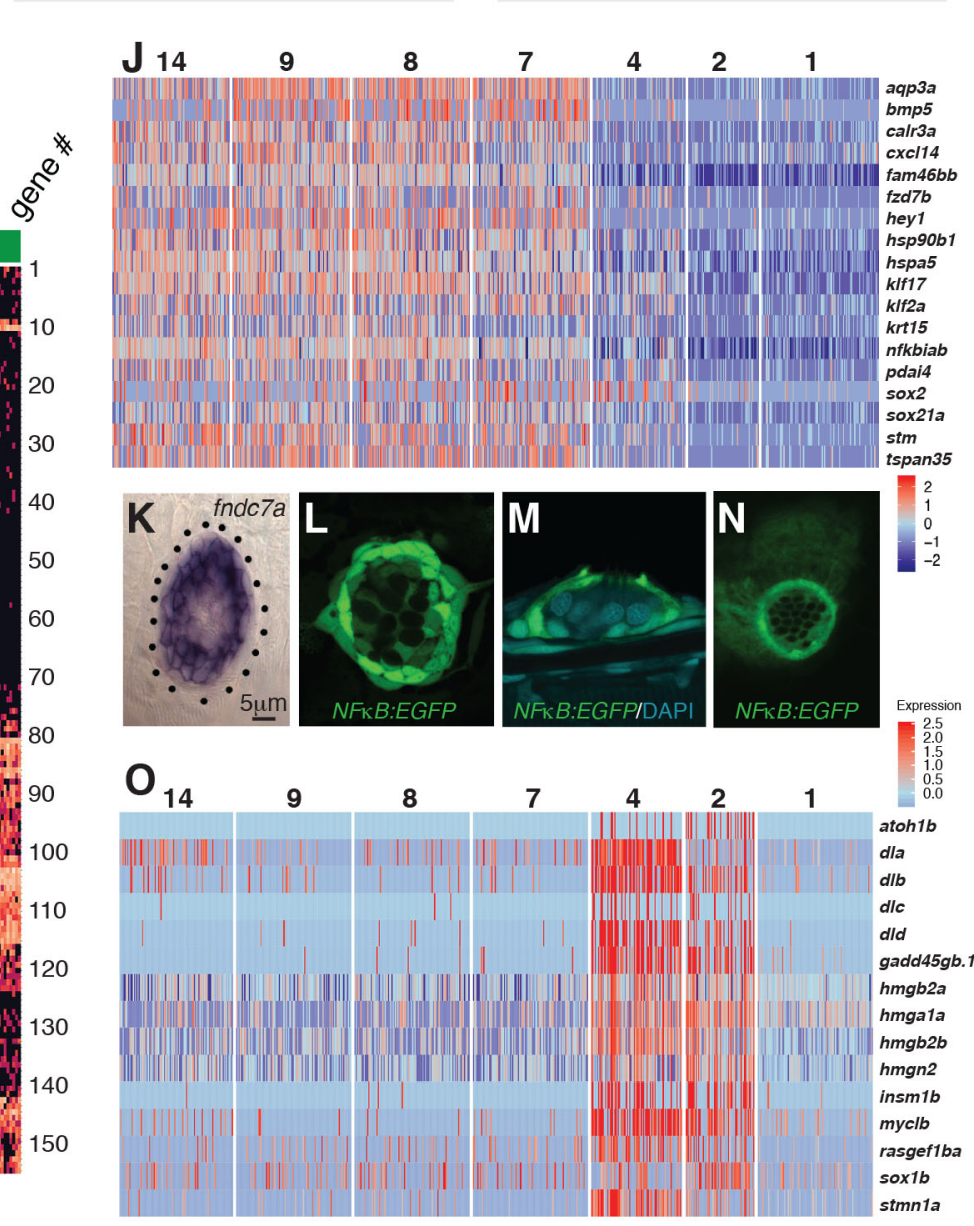
Figure 5 under aCC-BY 4.0 International license.
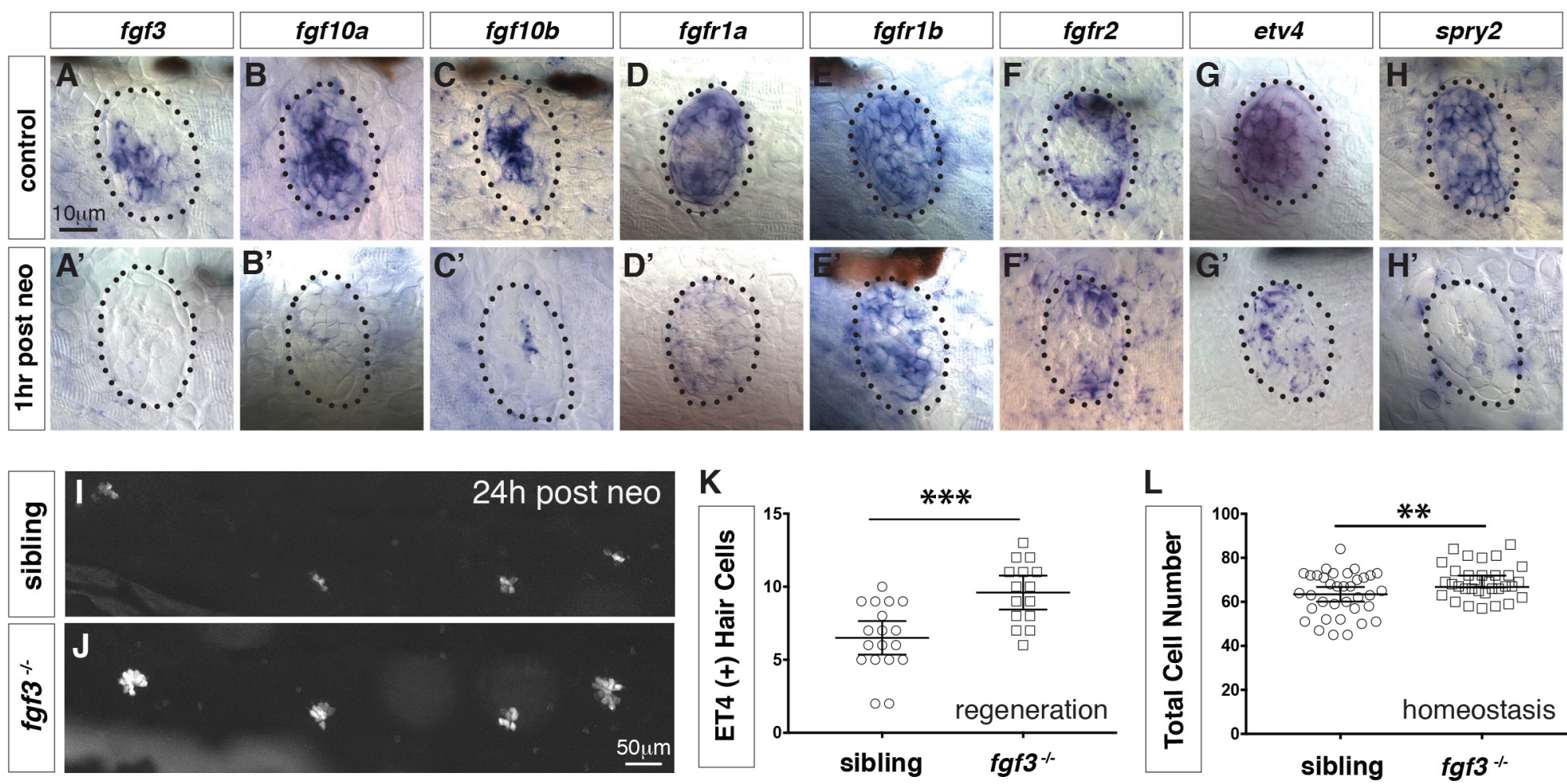

M
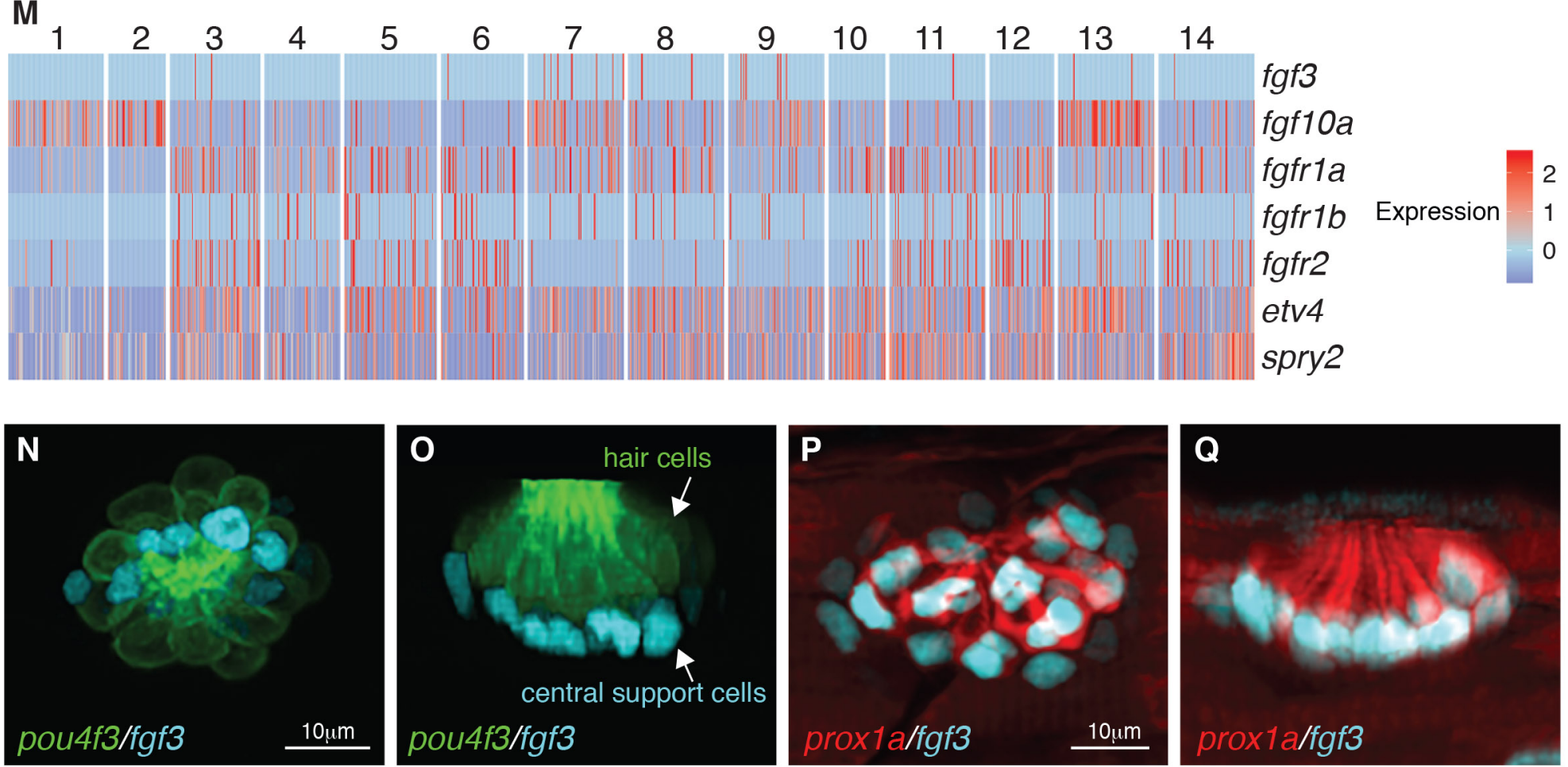
bioRxiv preprint doi: https://doi.org/10.1101/496612; this version posted December 14, 2018. The copyright holder for this preprint (which was not certified by peer review) is the author/funder, who has granted bioRxiv a license to display the preprint in perpetuity. It is made available Figure 6 under aCC-BY 4.0 International license.

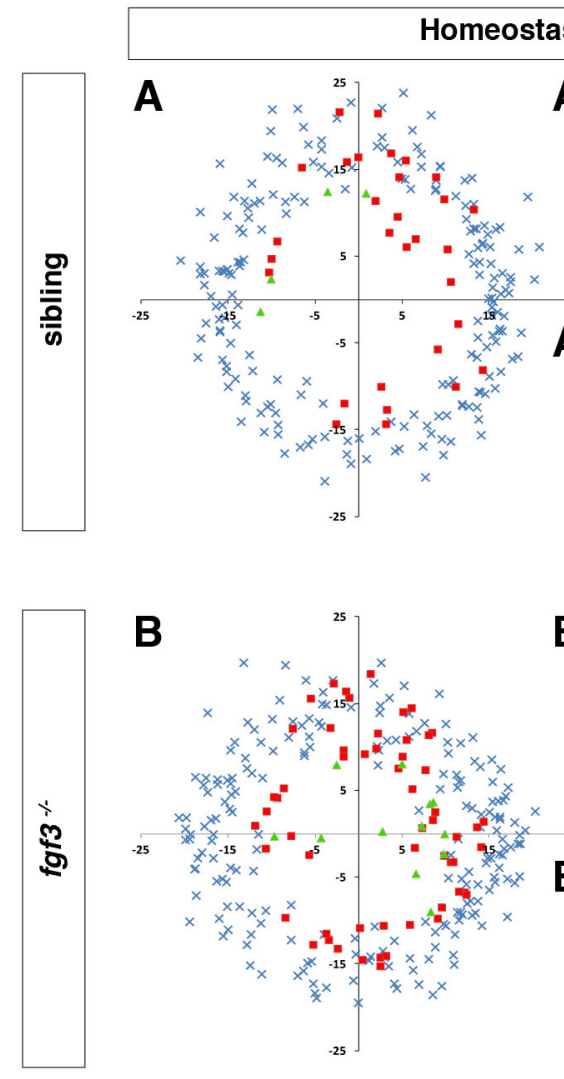

Amplifying Divisions

E
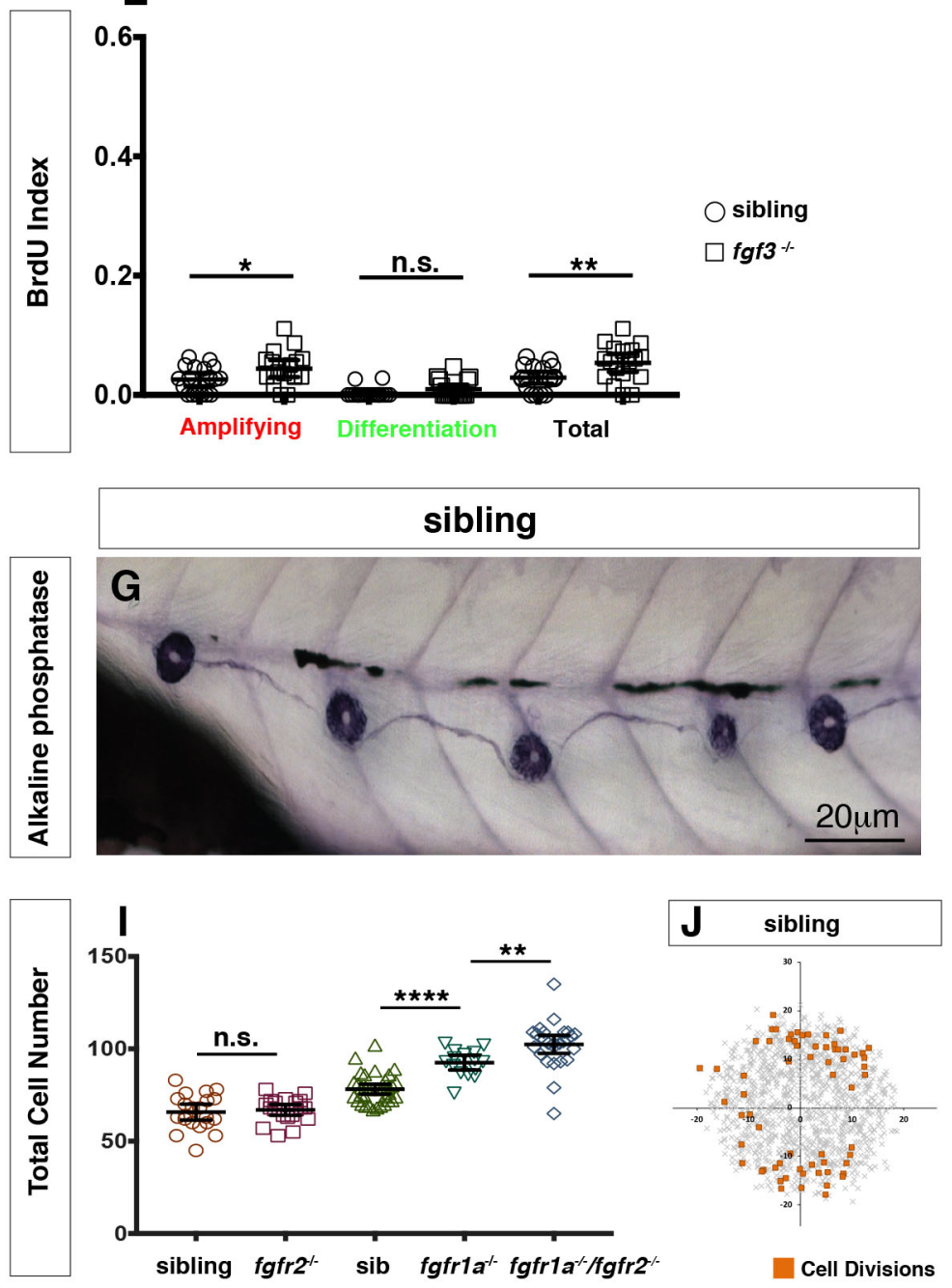

Cell Divisions

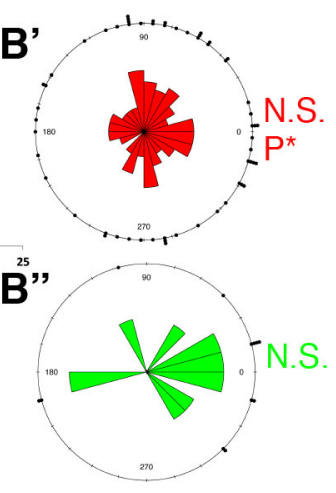

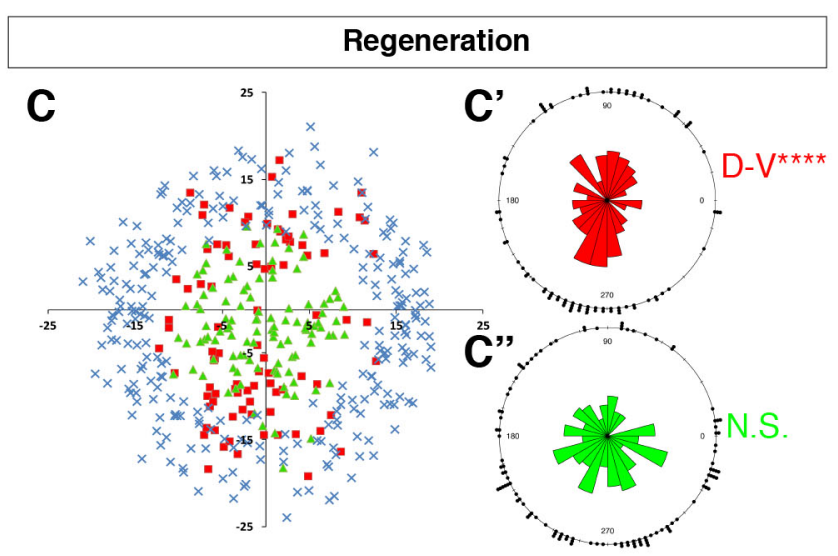
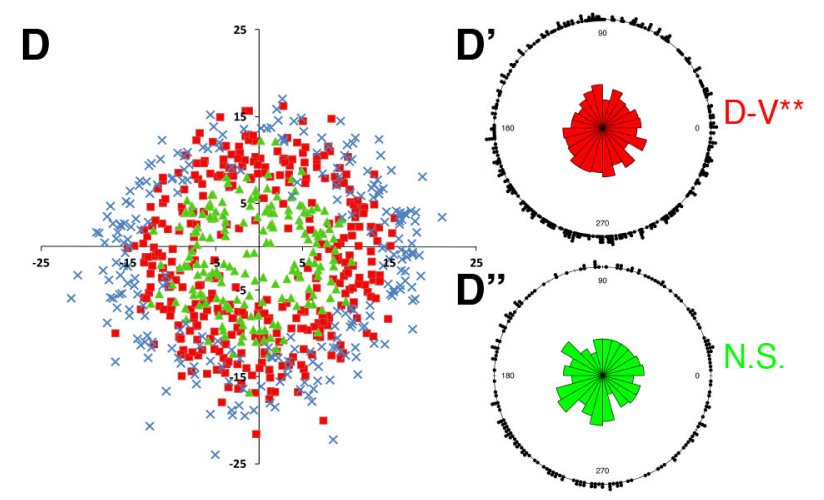

$\triangle$ Differentiation Divisions

X Quiescent Mantle Cells
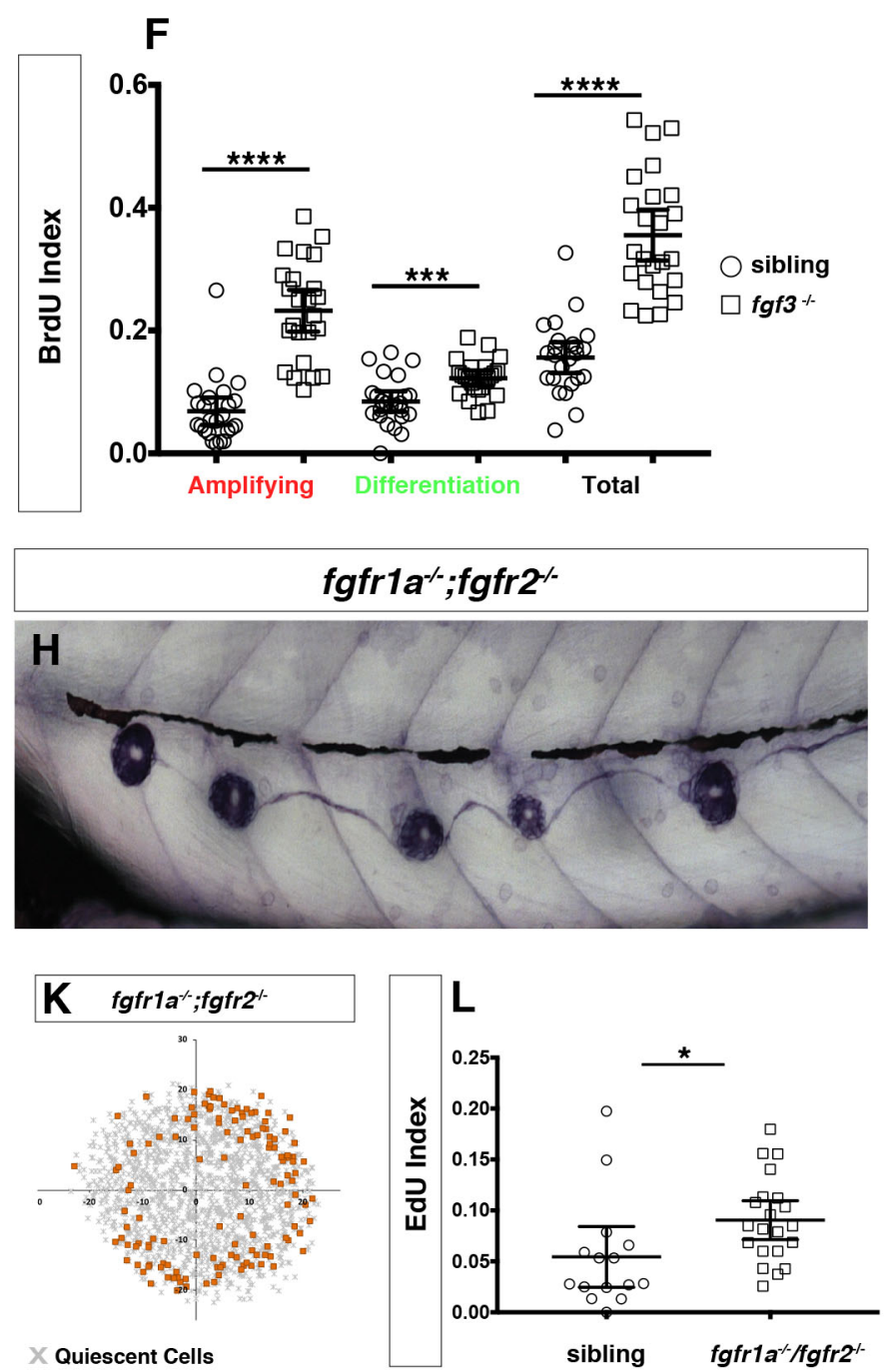
bioRxiv preprint doi: https://doi.org/10.1101/496612; this version posted December 14,2018 . The copyright holder for this preprint (which was not certified by peer review) is the author/funder, who has granted bioRxiv a license to display the preprint in perpetuity. It is made available under aCC-BY 4.0 International license.

\section{Figure 7}
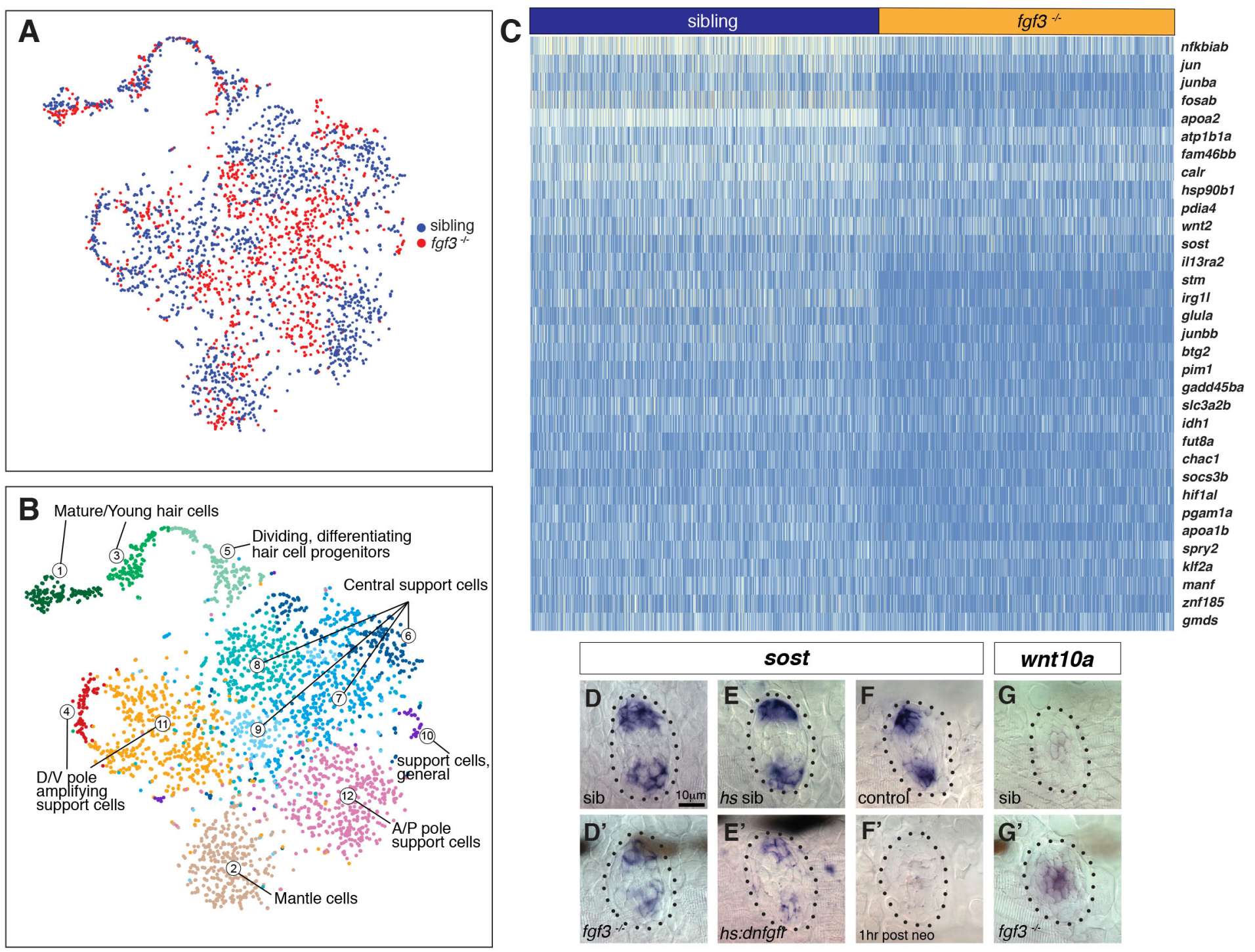
bioRxiv preprint doi: https://doi.org/10.1101/496612; this version posted December 14, 2018. The copyright holder for this preprint (which was not certified by peer review) is the author/funder, who has granted bioRxiv a license to display the preprint in perpetuity. It is made available

\section{Figure 8}
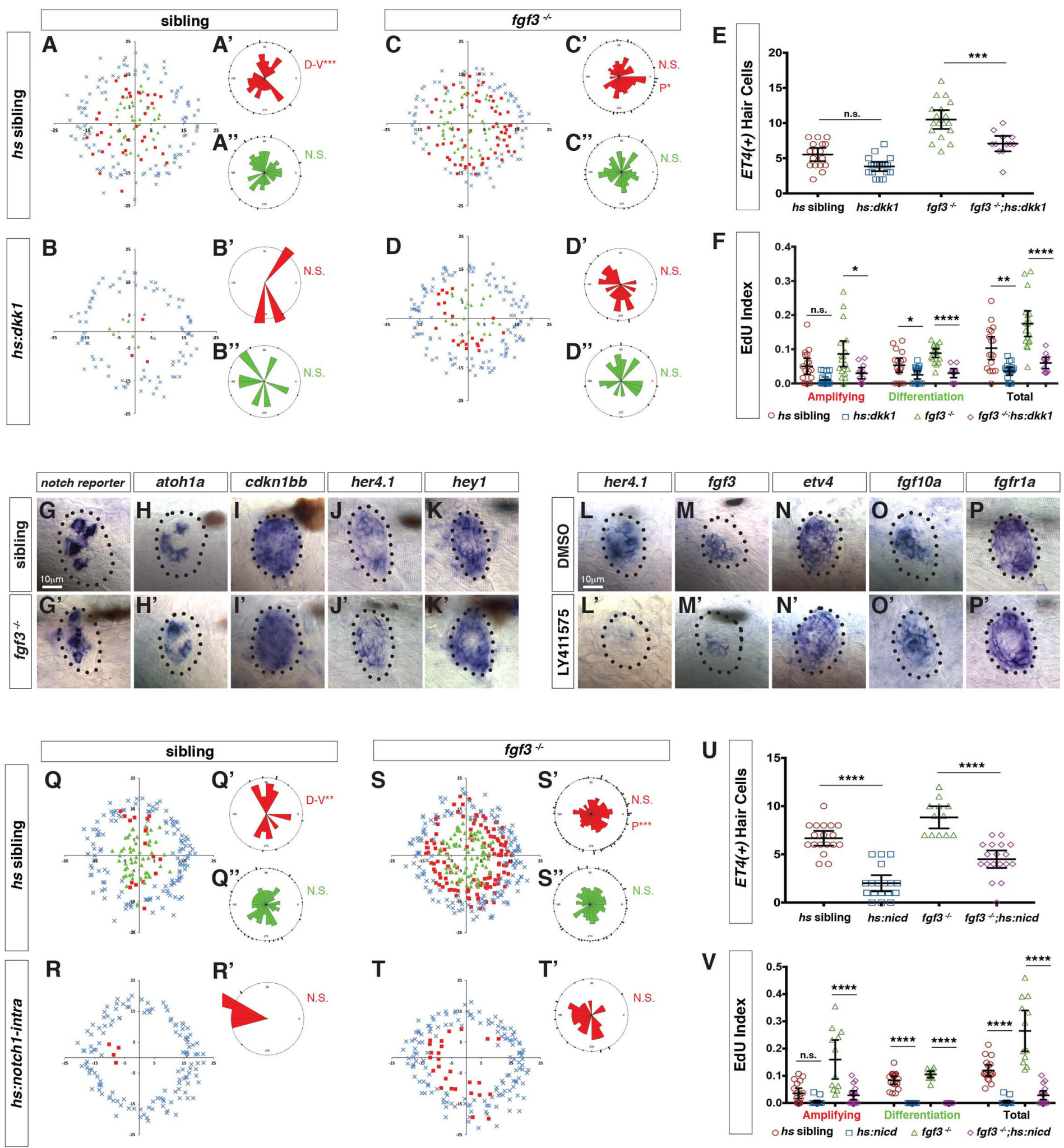
bioRxiv preprint doi: https://doi.org/10.1101/496612; this version posted December 14,2018 . The copyright holder for this preprint (which was not certified by peer review) is the author/funder, who has granted bioRxiv a license to display the preprint in perpetuity. It is made available under aCC-BY 4.0 International license.

\section{Figure S1}

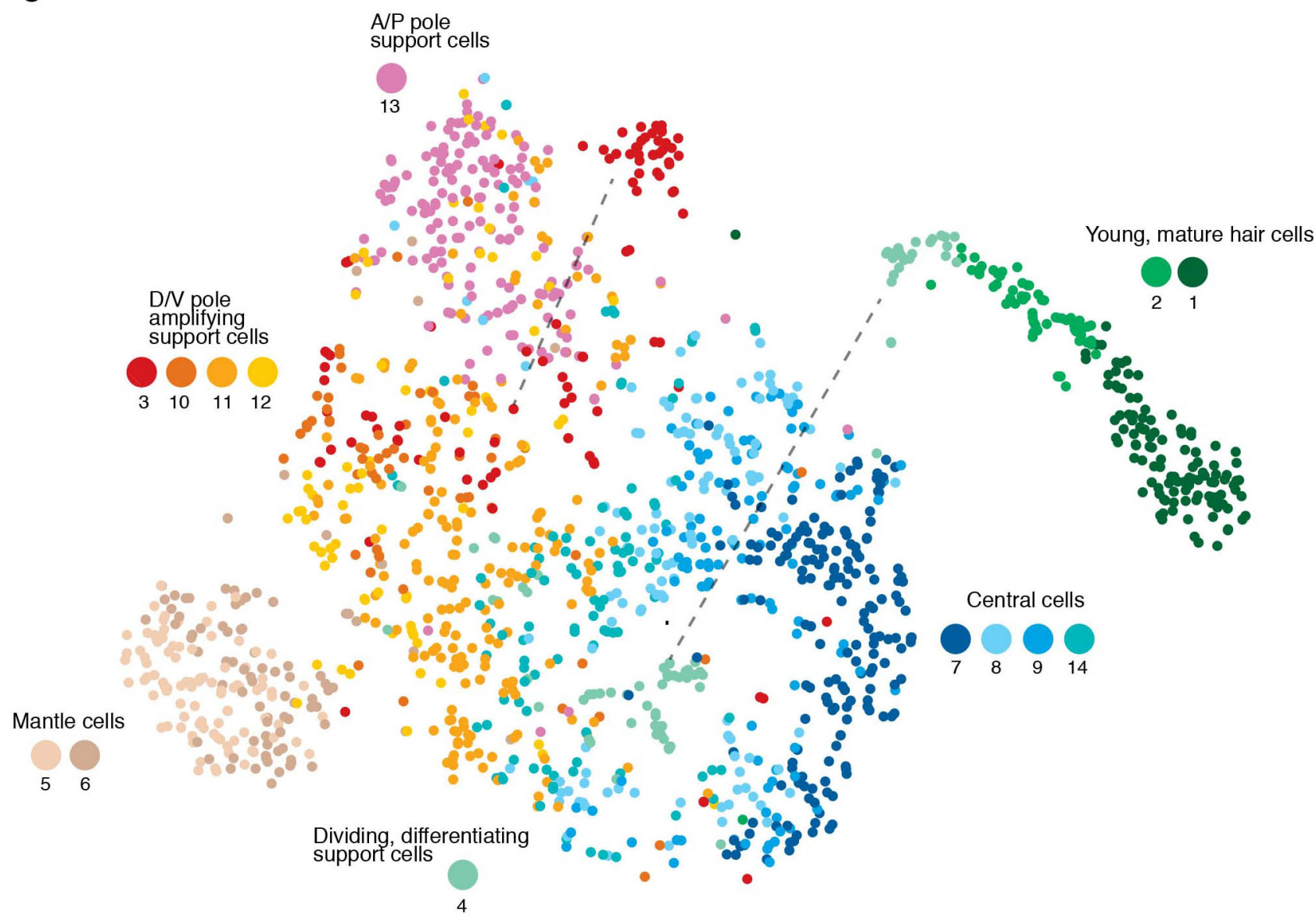


bioRxiv preprint doi: https://doi.org/10.1101/496612; this version posted December 14,2018 . The copyright holder for this preprint (which was not certified by peer review) is the author/funder, who has granted bioRxiv a license to display the preprint in perpetuity. It is made available under aCC-BY 4.0 International license.

\section{Figure S2 Human deafness genes}

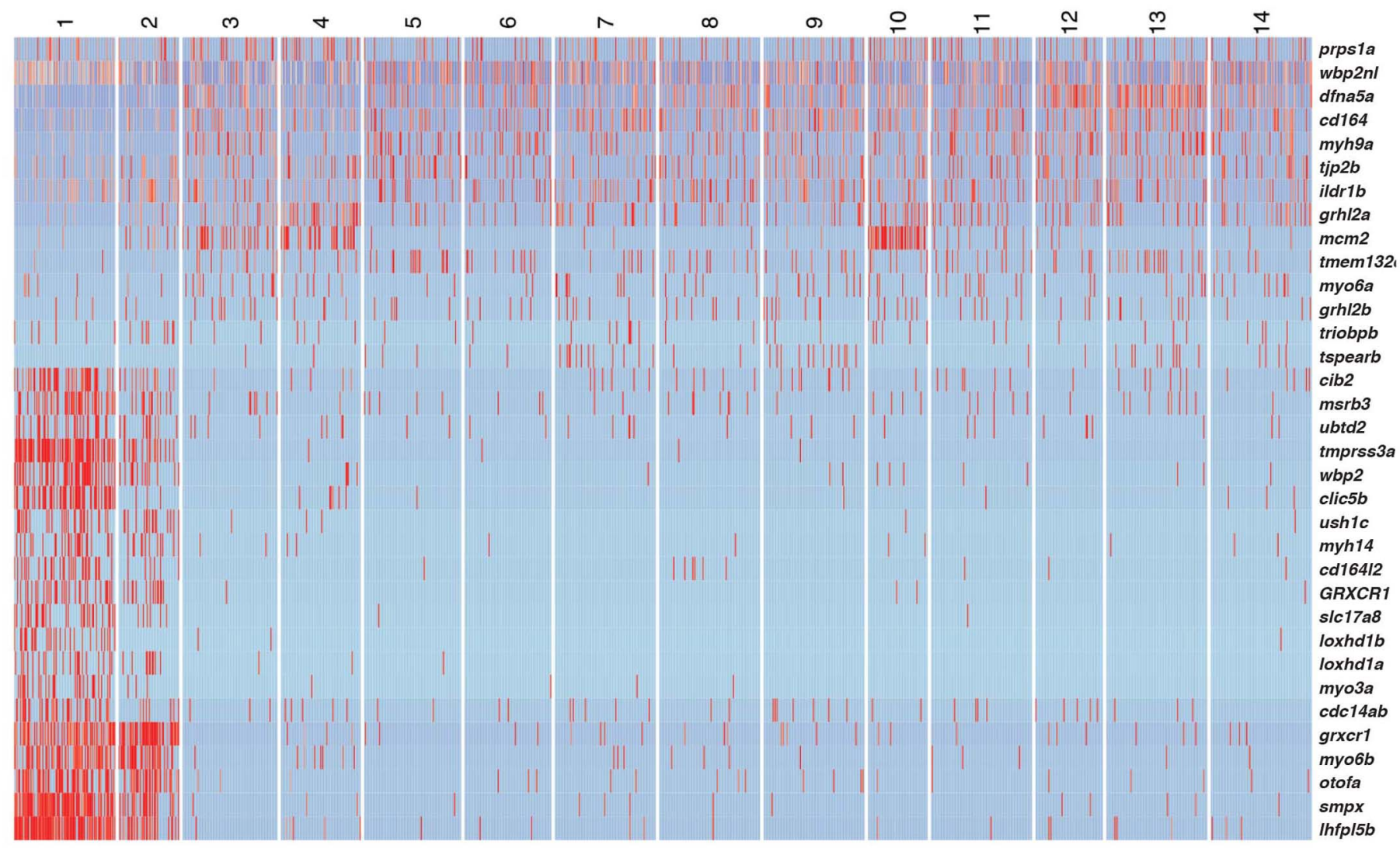


bioRxiv preprint doi: https://doi.org/10.1101/496612; this version posted December 14, 2018. The copyright holder for this preprint (which was not certified by peer review) is the author/funder, who has granted bioRxiv a license to display the preprint in perpetuity. It is made available under aCC-BY 4.0 International license.

Figure S3 Ribosomal protein genes reflect transcriptional activity
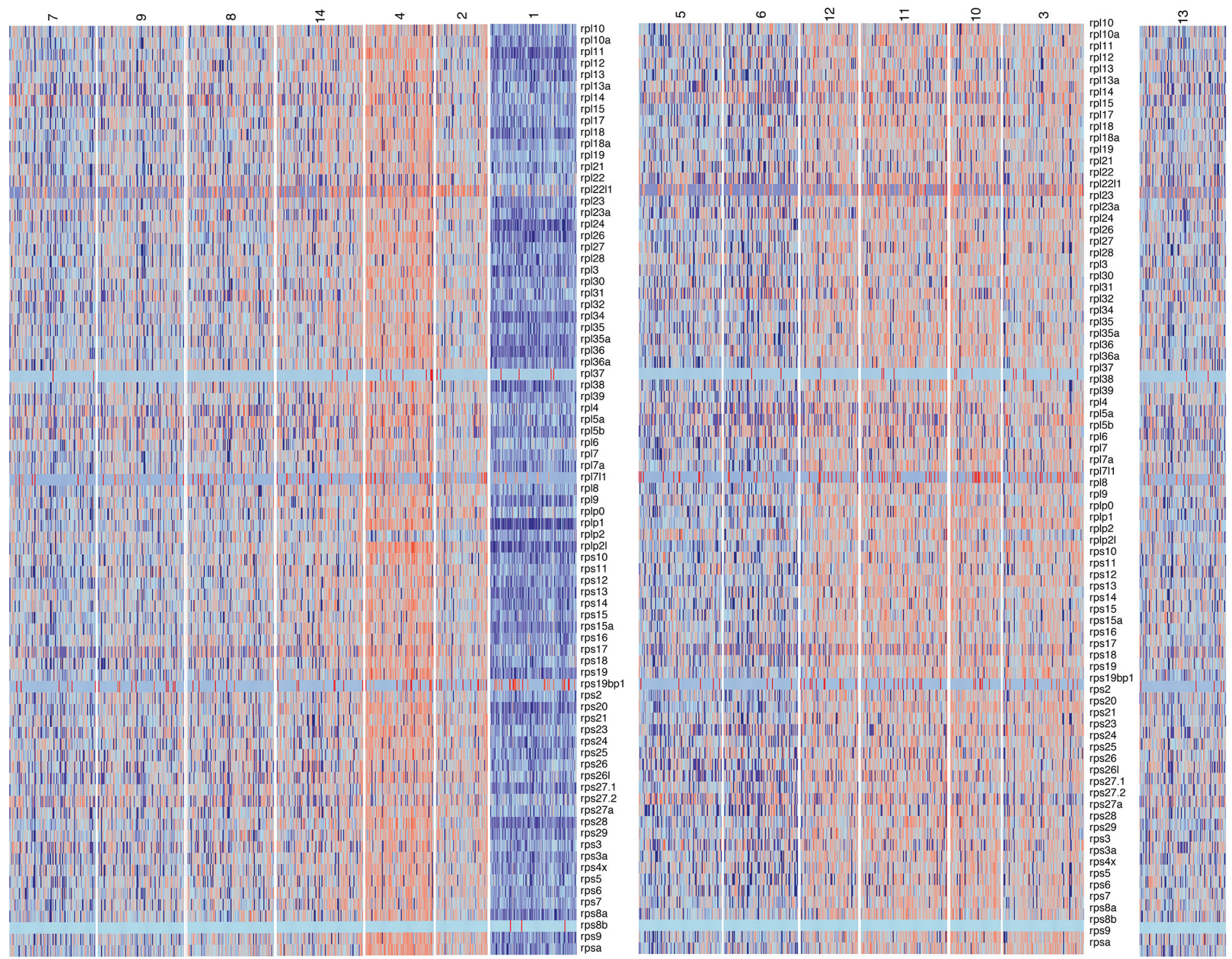

$\begin{array}{cc} & 2 \\ \text { Expression } & 1 \\ 0 \\ -1 \\ -2\end{array}$ 
bioRxiv preprint doi: https://doi.org/10.1101/496612; this version posted December 14, 2018. The copyright holder for this preprint (which was not certified by peer review) is the author/funder, who has granted bioRxiv a license to display the preprint in perpetuity. It is made available under aCC-BY 4.0 International license.

Figure S4 Still images of a time lapse movie of red prox1a-positive cells differentiating into green pou4f3-positive hair cells.
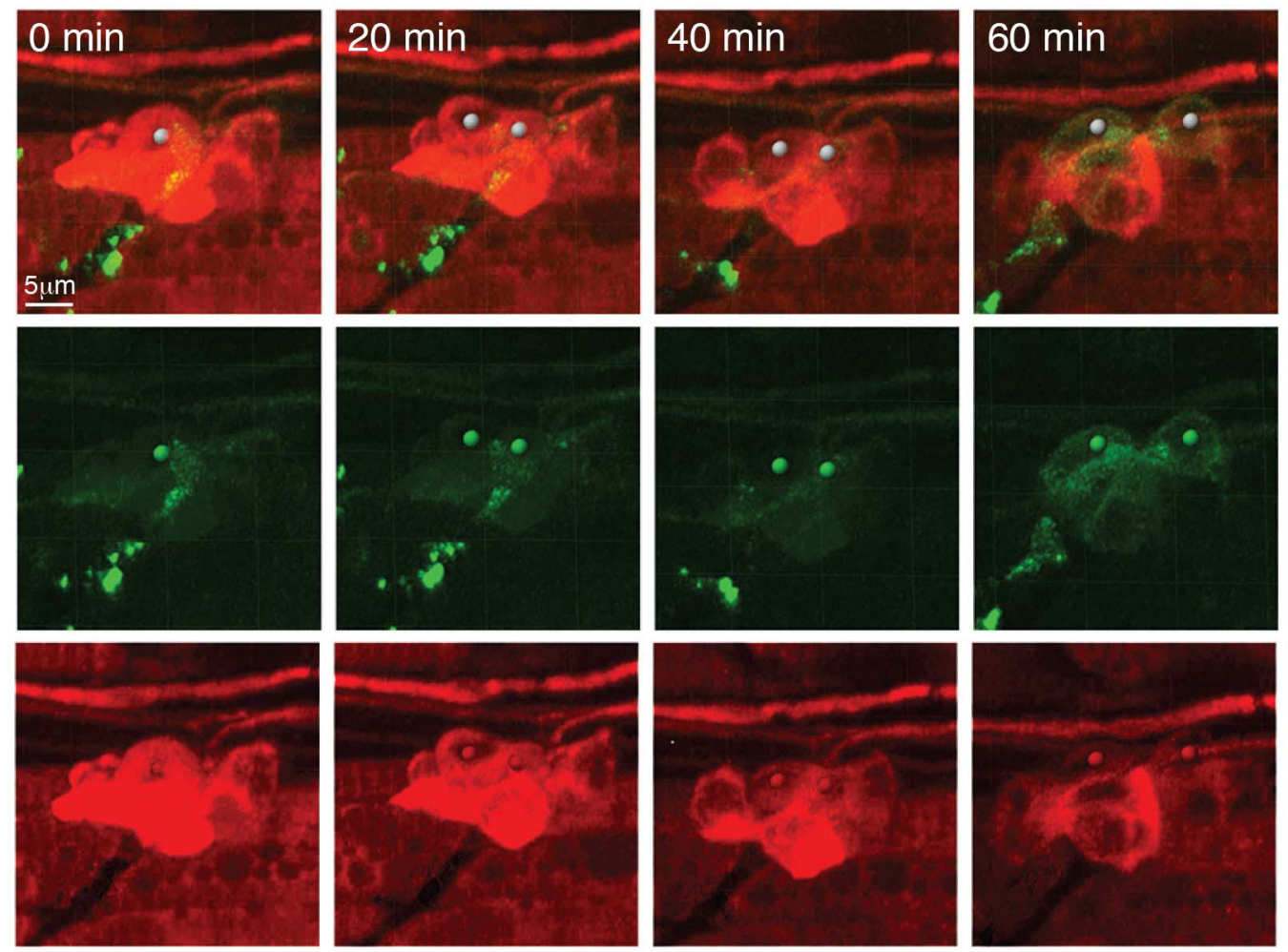
bioRxiv preprint doi: https://doi.org/10.1101/496612; this version posted December 14, 2018. The copyright holder for this preprint (which was not certified by peer review) is the author/funder, who has granted bioRxiv a license to display the preprint in perpetuity. It is made available under aCC-BY 4.0 International license.

Figure S5 Cilia and hair cell genes in cycling hair cell progenitors (cluster 4), young (cluster 2) and mature hair cells (cluster 1 )

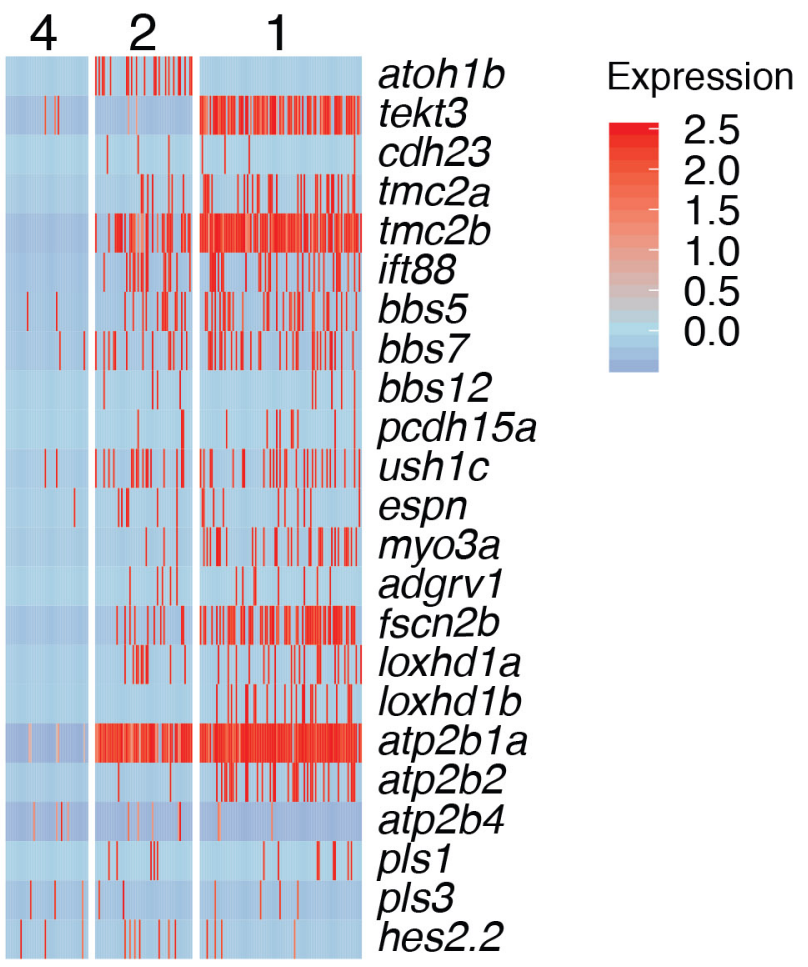


bioRxiv preprint doi: https://doi.org/10.1101/496612; this version posted December 14,2018 . The copyright holder for this preprint (which was not certified by peer review) is the author/funder, who has granted bioRxiv a license to display the preprint in perpetuity. It is made available under aCC-BY 4.0 International license.

Figure $\mathbf{S 6}$ (down in HCs)
ENSEMBL_GENE_ID

ENSDARG000000077982

ENSDARG00000015355

ENSDARG00000009094

ENSDARG00000089368

ENSDARG00000004023

ENSDARG00000020133

ENSDARG00000031664

ENSDARG00000012656

ENSDARG00000069196

ENSDARG00000100244

ENSDARG000000018303

ENSDARG000000030896

ENSDARG00000056438

ENSDARG00000070538

ENSDARG00000100826

ENSDARG00000074378

ENSDARG00000104773

ENSDARG00000043531

ENSDARG00000103483

ENSDARG00000099184

ENSDARG00000003820

ENSDARG000000053291

ENSDARG00000059279

ENSDARG00000031683

ENSEMBL_GENE_ID

ENSDARG00000077982

ENSDARG00000015355

ENSDARG00000089368

ENSDARG00000020133

ENSDARG00000018303

ENSDARG000000074378

ENSDARG00000104773

ENSDARG00000031683

ENSEMBL GENE ID

ENSDARG00000020850

ENSDARG00000102291

ENSDARG00000099104

ENSDARG00000005791

ENSDARG00000018334

ENSDARG00000088030

ENSDARG00000036298

ENSDARG00000013763

ENSDARG00000043154

ENSDARG00000098458

ENSEMBL_GENE_ID

ENSDARG00000015088

ENSDARG00000028396

ENSDARG00000037488

ENSDARG00000103979

ENSDARG00000102808

ENSDARG00000076290

ENSDARG00000003570

ENSDARG00000018491

ENSEMBL_GENE_ID

ENSDARG00000097691

ENSDARG00000074378

ENSDARG00000104773

ENSDARG00000043531

ENSDARG00000035810

ENSDARG00000018334

ENSEMBL_GENE_ID

ENSDARG00000011170

ENSDARG00000027589

ENSDARG00000045444

ENSDARG00000094673

ENSDARG00000041117

ENSDARG00000009534

ENSEMBL_GENE_ID

ENSDARG00000012656

ENSDARG00000103846

ENSDARG00000003570

ENSDARG00000100826

ENSDARG00000099351

ENSDARG00000031952
E74-like factor 3 (ets domain transcription factor, epithelial-specific )(elf3)

FOS-like antigen $1 \mathrm{a}(\mathrm{fos} \mid 1 \mathrm{a})$

GATA binding protein $2 \mathrm{~b}$ (gata2b).

HOP homeobox (hopx)

ISL LIM homeobox 1(is|1).

Jun dimerization protein $2 \mathrm{~b}$ (jdp2b).

SRY (sex determining region Y)-box 21a(sox21a)

activating transcription factor 6 (atf6).

early $B$-cell factor $1 \mathrm{~b}$ (ebf $1 \mathrm{~b}$ ).

early B-cell factor $3 a(e b f 3 a)$.

ets variant 4 (etv4)

forkhead box Q1a(foxq1a)

hairy-related 9 (her9).

hes-related family bHLH transcription factor with YRPW motif 1(hey1)

hypoxia-inducible factor 1 , alpha subunit, like(hif1al).

jun B proto-oncogene a(junba)

jun $B$ proto-oncogene $b$ (junbb)

jun proto-oncogene(jun)

lipopolysaccharide-induced TNF factor(litaf)

mitogen-activated protein kinase kinase 6(map2k6)

nuclear receptor subfamily 1 , group $\mathrm{D}$, member $2 \mathrm{a}(\mathrm{nr} 1 \mathrm{~d} 2 \mathrm{a})$.

proline-rich nuclear receptor coactivator 2(pnrc2).

transcription factor AP-2 alpha(tfap2a).

$\underline{v}$-fos $F B]$ murine osteosarcoma viral oncogene homolog $A b$ (fosab)

\section{E74-like factor 3 (ets domain transcription factor, epithelial-specific)(elf3).}

FOS-like antigen 1a(fosl1a)

HOP homeobox(hopx)

Jun dimerization protein $2 \mathrm{~b}(\mathrm{jdp} 2 \mathrm{~b})$

ets variant 4 (etv4).

jun B proto-oncogene a(junba)

jun $B$ proto-oncogene $b$ (junbb)

v-fos FBJ murine osteosarcoma viral oncogene homolog $A b$ (fosab)

\section{eukaryotic translation elongation factor 1 alpha 1 , like 1(eef1a1l1)}

eukaryotic translation elongation factor 1 delta a (guanine nucleotide exchange protein)(eef1da).

ribosomal protein $L 24(r p / 24)$

ribosomal protein $\mathrm{L} 28(\mathrm{rp} / 28)$

ribosomal protein L35(rpl35).

ribosomal protein L35a(rpl35a)

ribosomal protein $\mathrm{S} 13$ (rps13)

ribosome binding_protein $1 \mathrm{a}(\mathrm{rrbp} 1 \mathrm{a})$.

uncoupling protein 2(ucp2)

zgc: 171772 (zgc: 171772 ).

GENENAME

DnaJ (Hsp40) homolog, subfamily B, member 11(dnajb11)

FK506 binding_protein 5(fkbp5).

calnexin(canx).

calreticulin $3 a$ (calr3a)

calreticulin $3 \mathrm{~b}$ (calr $3 \mathrm{~b}$ )

calreticulin(calr).

heat shock protein 90, beta (grp94), member 1(hsp90b1).

protein disulfide isomerase family $\mathrm{A}$, member 4 (pdia4)

\section{KIAA0101(kiaa0101)}

jun $B$ proto-oncogene a(junba).

jun $B$ proto-oncogene $b$ (junbb).

jun proto-oncogene(jun).

regulator of cell cycle(rgcc)

ribosomal protein L35(rpl35).

\section{GENE NAME}

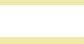

NDRG family member 2 (ndrg2).

frizzled class receptor $7 b(f z d 7 b)$.

frizzled class receptor $8 a(f z d 8 a)$

ras homolog_gene family, member $A b$ (rhoab)

wingless-type MMTV integration site family member 2(wnt2).

wntless Wnt ligand secretion mediator(w/s)

\section{GENE NAME}

activating transcription factor 6 (atf6)

heat shock protein 5 (hspa5).

heat shock protein 90 , beta (grp94), member 1(hsp90b1).

hypoxia-inducible factor 1 , alpha subunit, like(hif1al).

insulin-like growth factor binding protein 1a(igfbp1a).

myoglobin(mb)
Biological Process Direct

\author{
Regulation of Transcription \\ -DNA templated \\ (p-value: 4.2E-3)
}

Transcription from

polymerasell promoter

(p-value: 1.6E-2)

Translation

(p-value: 3.8E-3)

Protein folding

(p-value: 1.6E-4)

Regulation of Cell Cycle

(p-value: $4.0 \mathrm{E}-4$ )

Wnt signaling

(p-value: 8.2E-3)

Hypoxia

(p-value: 1.7E-4) 
bioRxiv preprint doi: https://doi.org/10.1101/496612; this version posted December 14, 2018. The copyright holder for this preprint (which was not certified by peer review) is the author/funder, who has granted bioRxiv a license to display the preprint in perpetuity. It is made available

Fig. S7 Notch pathway components under aCC-BY 4.0 International license.

A

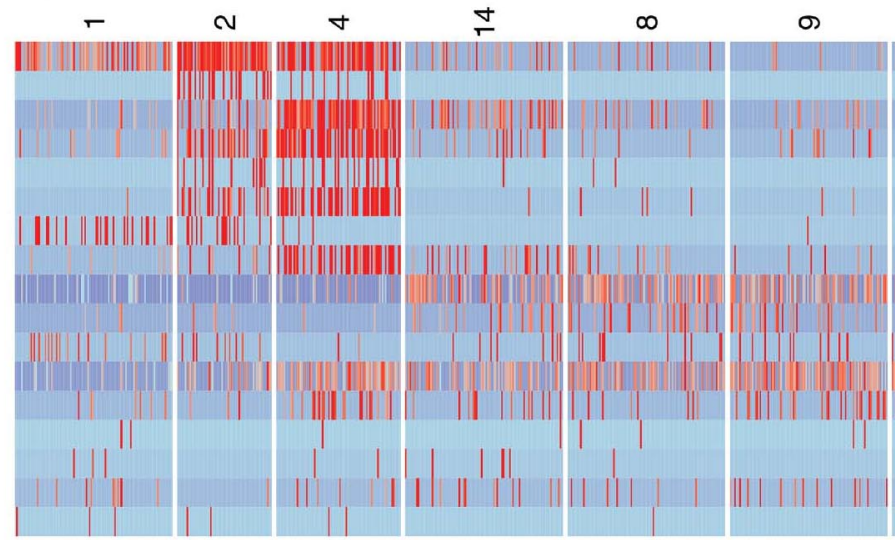

r

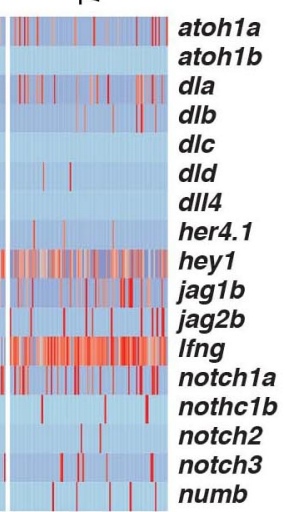

C

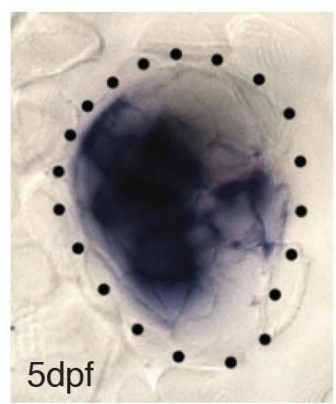

Notch domain

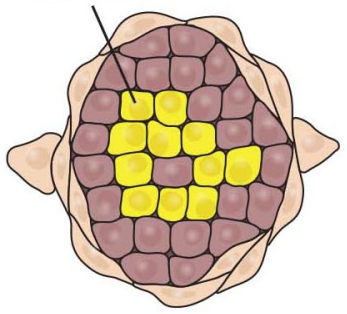

Notch reporter

B
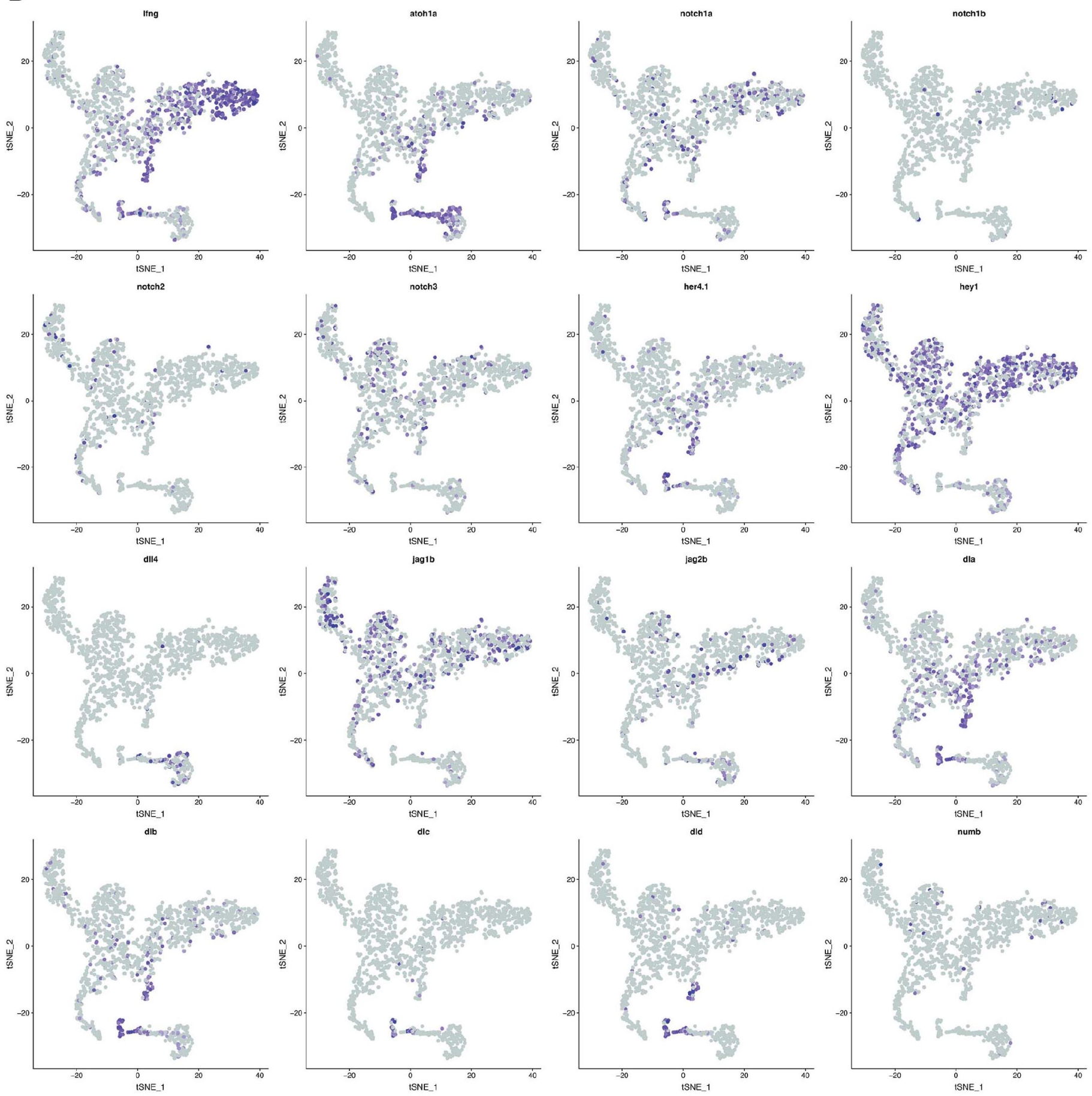
bioRxiv preprint doi: https://doi.org/10.1101/496612; this version posted December 14, 2018. The copyright holder for this preprint (which was not certified by peer review) is the author/funder, who has granted bioRxiv a license to display the preprint in perpetuity. It is made available under aCC-BY 4.0 International license.

Figure S8 Expression of $d n: f g f r 1$ also induces proliferation

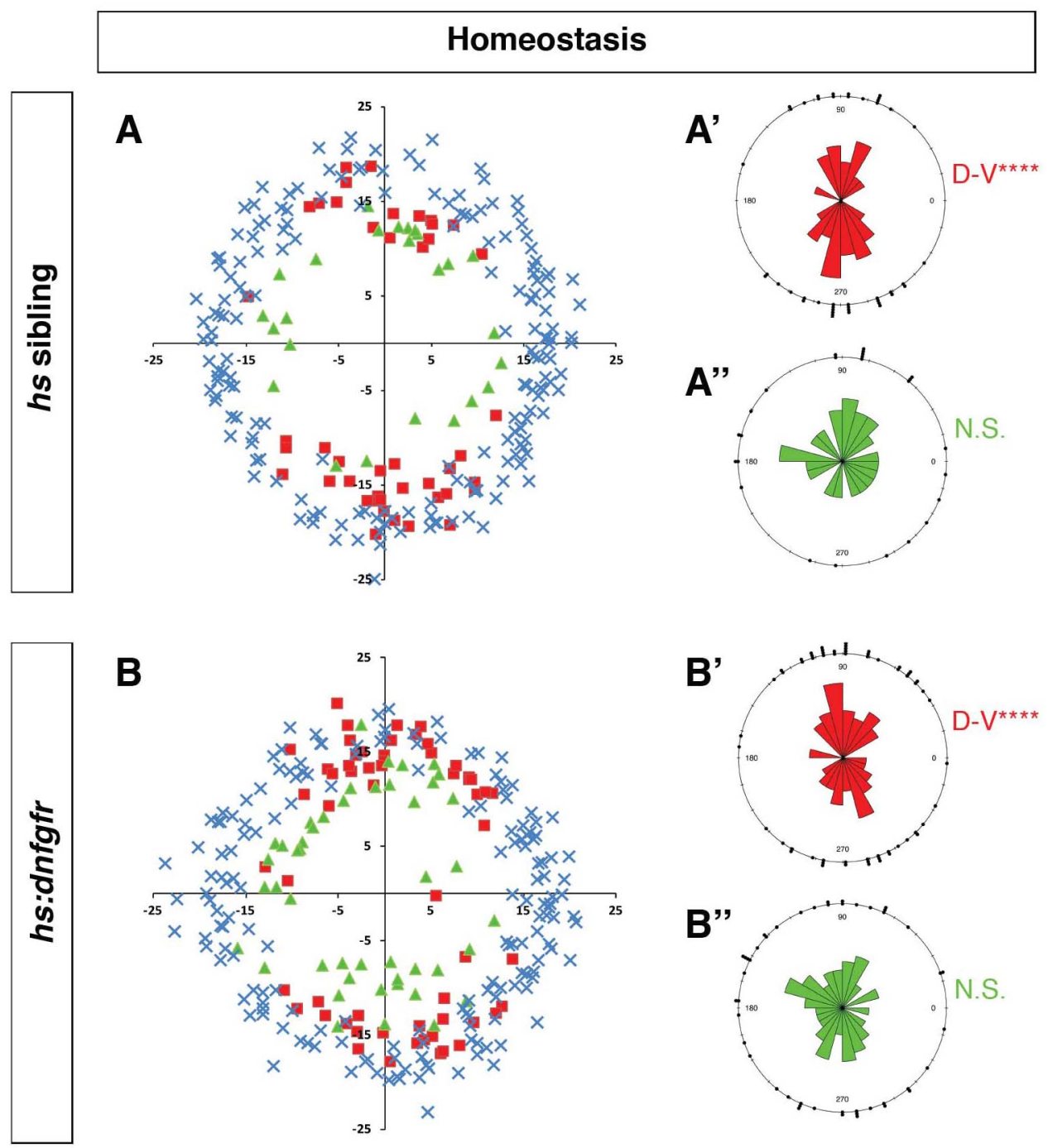

Amplifying Divisions

$\triangle$ Differentiation Divisions

X Quiescent Mantle Cells

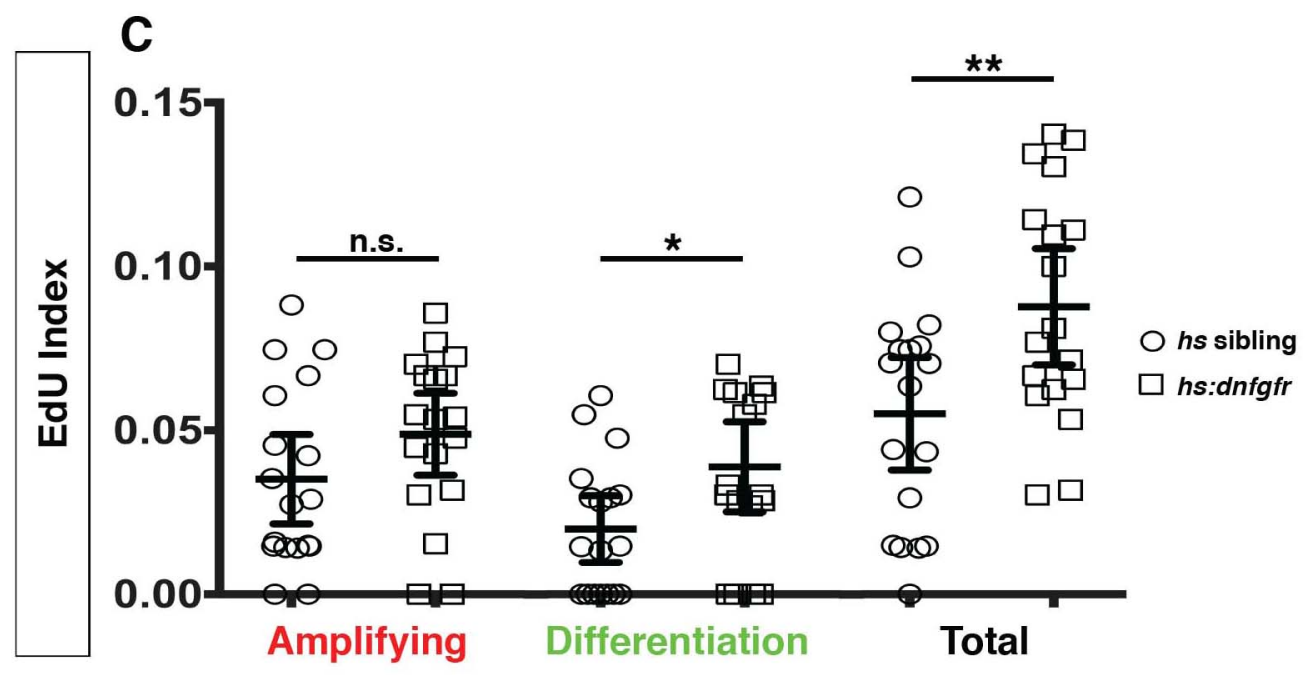


bioRxiv preprint doi: https://doi.org/10.1101/496612; this version posted December 14,2018 . The copyright holder for this preprint (which was not certified by peer review) is the author/funder, who has granted bioRxiv a license to display the preprint in perpetuity. It is made available under aCC-BY 4.0 International license.

Figure S9 Genes that are differentially expressed in $\mathrm{fg}^{-} \mathrm{3}^{-}$

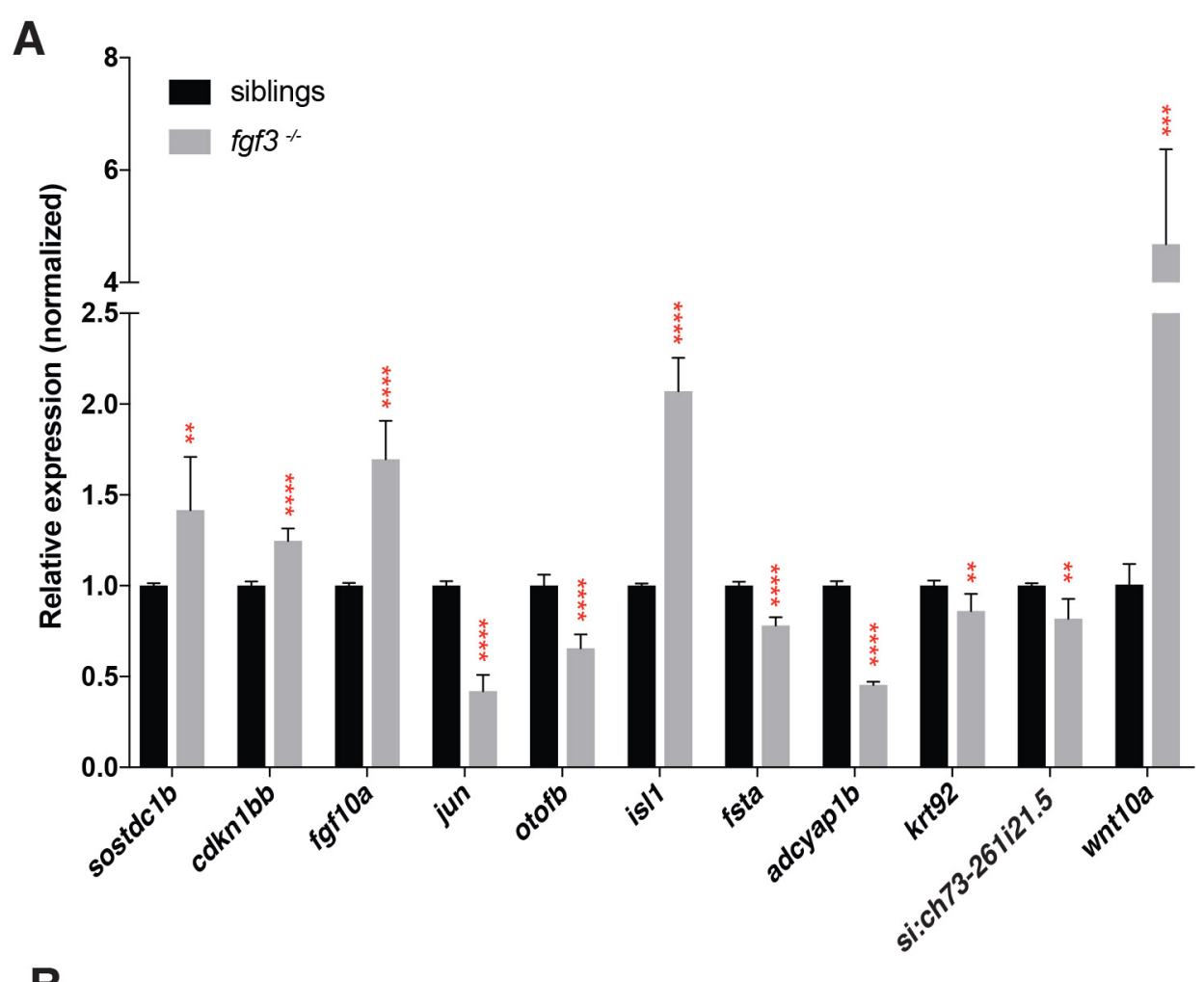

B

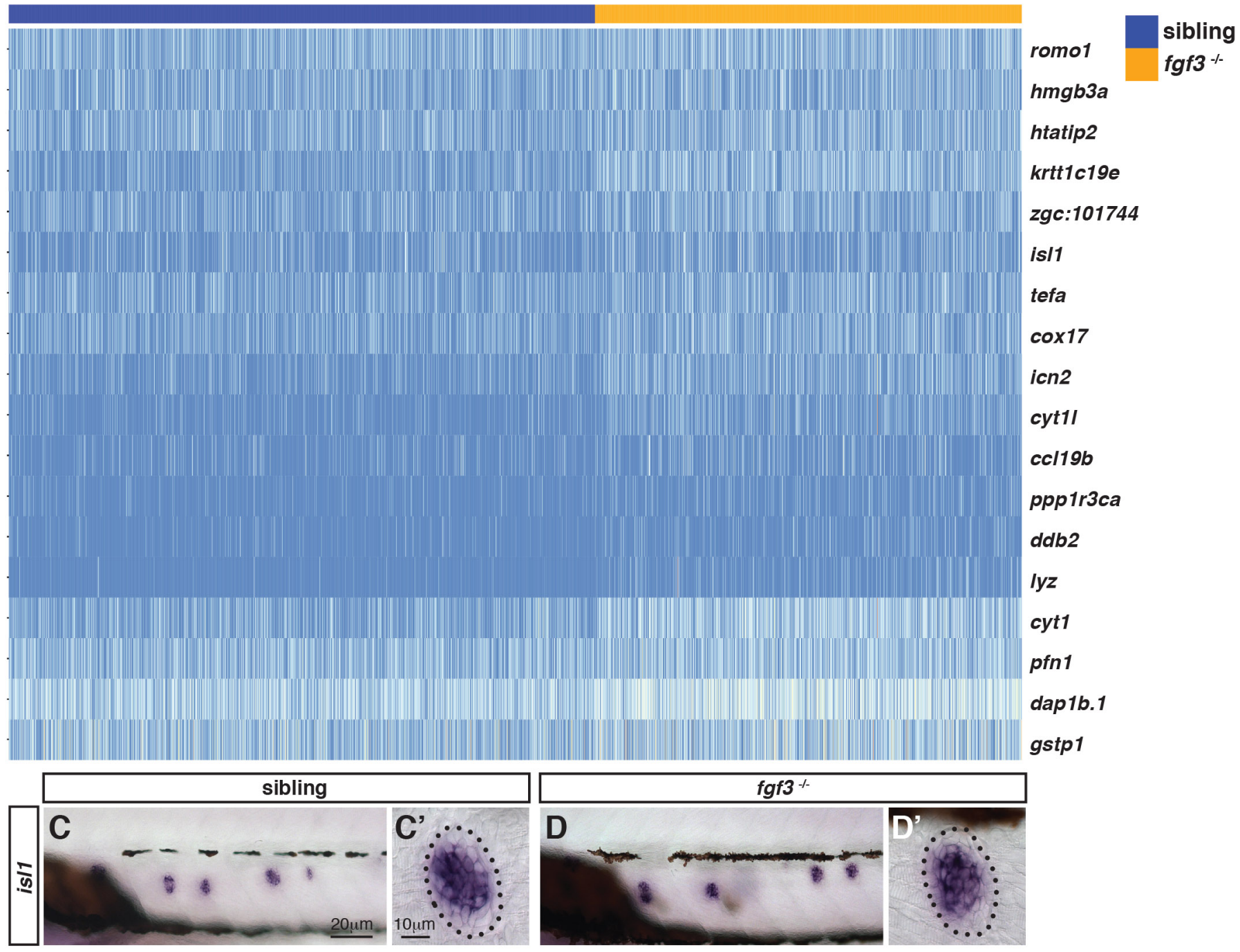


bioRxiv preprint doi: https://doi.org/10.1101/496612; this version posted December 14,2018 . The copyright holder for this preprint (which was not certified by peer review) is the author/funder, who has granted bioRxiv a license to display the preprint in perpetuity. It is made available under aCC-BY 4.0 International license.

\section{Figure S10}

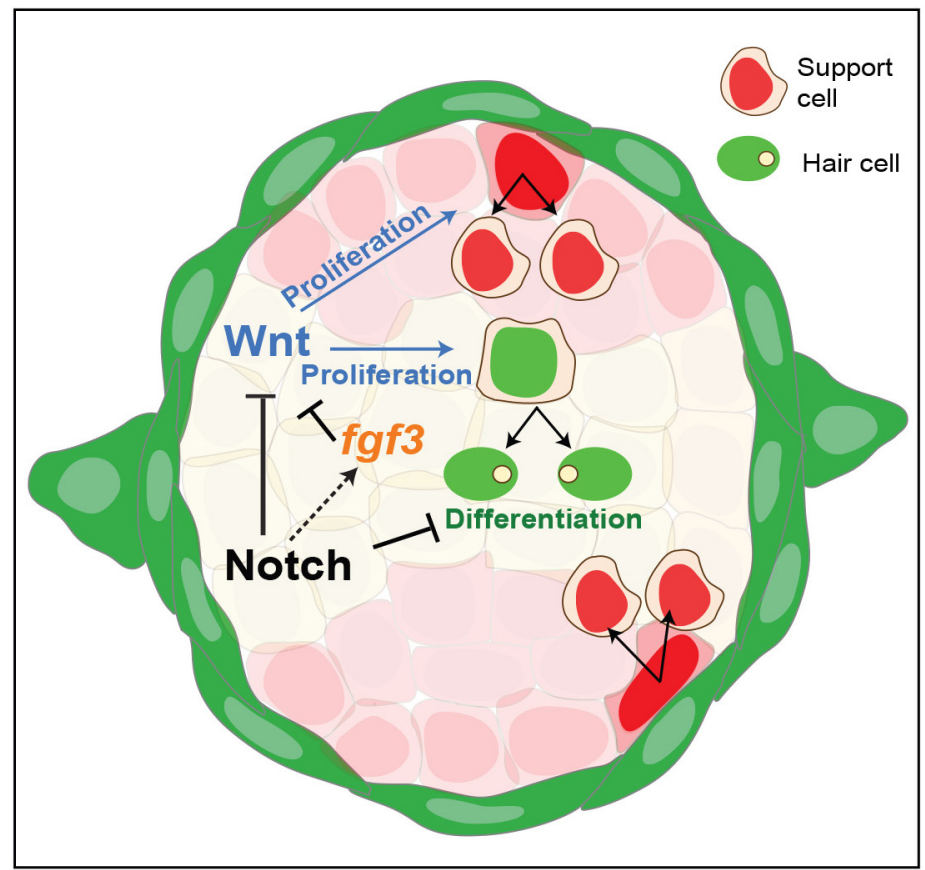

